\title{
Estimating the impact of parking on car ownership and commute mode choices
}

by

Omid Khazaeian

A thesis submitted to Victoria University of Wellington in fulfilment of the requirements for the degree of Doctor of Philosophy

Victoria University of Wellington

2021 


\begin{abstract}
Researchers in commuting studies predominantly focus on movements. However, every trip starts and terminates in a place. For drivers, commuting is a journey between parking locations. They start their journey from home parking, park near work, and eventually return to home parking. Cars spend most of the day parked, with associated externalities. Drivers waste time and fuel cruising for parking in city centres and waste other drivers' time and fuel by slowing traffic. More fuel consumption implies more carbon emissions and local air pollution. Providing off-street home parking increases house prices and reduces house affordability. Nonetheless, parking is a small part of the transportation literature and further research is needed to support a comprehensive understanding of parking and its impacts on travel behavior.
\end{abstract}

This thesis is centreed around three questions; "How does the quantity of home parking affect car ownership and commute mode?", "How do home parking type and quantity affect car ownership?", "How does walking time from parking location to work impact parking type choice?". Each question is answered in a separate chapter using a discrete choice model and a sample of commuters surveyed in the New Zealand Household Travel Survey (NZHTS) in the Greater Wellington Region (GWR), New Zealand.

$\mathrm{We}^{1}$ find that home parking quantity strongly and positively affects car ownership and proclivity for driving. Residential parking is the most important factor in encouraging carless households to acquire a car. High home parking supply motivates households to drive more often. More car trips from suburbs means higher demand for parking downtown and highlights the relationship between home parking and work parking. More garage spaces at home noticeably motivates households to have multiple cars. The number of driveway spaces positively influences owning more than two cars. An inverse relationship exists between onstreet parking demand and car ownership.

For work parking, we find that walking time from public off-street parking to work significantly discourages commuters from choosing public off-street parking. Walking time

\footnotetext{
${ }^{1}$ I use the writing convention of 'we'/'our' in preference over 'I'/'my' and I am the sole author of this research.
} 
from an on-street parking to work is also a significant disincentive for choosing On-street parking. The cost of on-street parking is important, followed by the number of on-street parking spaces. Elasticities show that the motivation of drivers to change parking type is close to their willingness to choose non-driving modes, if any parking features change. This similar willingness indicates a potential for achieving lower car use through parking restriction and improving non-driving modes.

This research contributes to the home parking literature by considering residential location as a choice that is interrelated with car ownership and mode choice. We study commuters who could live and work anywhere in a region (GWR) with a diverse range of socioeconomic characteristics, parking features, and traffic conditions, in order to give results that are more realistic and comprehensive. We mitigate the endogeneity between car ownership and home parking using novel instrumental variables for home parking. Our measure for on-street parking carefully considers parking competition and quantity. Commute length is measured as commute time to better represent commuters' perception of commute length. For work parking, we consider mode choices and parking alternatives simultaneously, and use novel demandbased measures for parking features.

We expect the findings of this research will contribute to a better understanding of how parking arrangements in cities can affect commuting patterns, and how parking policies can impact urban design, land use and transport outcomes. 


\section{Acknowledgments}

I am grateful to my supervisors Dr. Mairéad de Róiste, Dr. Toby Daglish, and Dr. Yiğit Sağlam for their extensive support throughout my Ph.D. research.

I would like to thank the New Zealand Ministry of Transport for the Household Travel Survey dataset, and Sean Audain and Tom Pettit at Wellington City Council for their support in parking data collection.

I would like to thank Tom Lintern and other staff at homes.co.nz for the useful house prices dataset for the GWR. I am thankful to Kim Olivier for the original (subsequently amended) road network spatial dataset, and Richard Law for his research assistance in updating the network. I am thankful to Rosey Harris for assisting in parking data collection. 


\section{Table of contents}

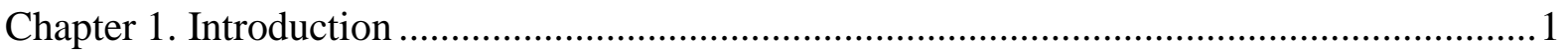

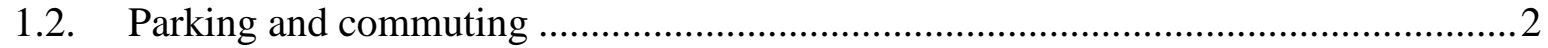

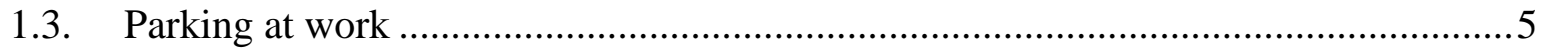

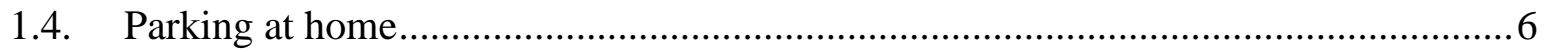

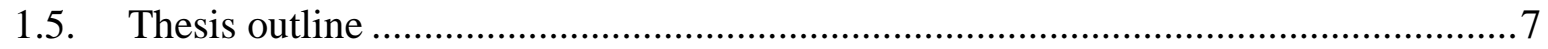

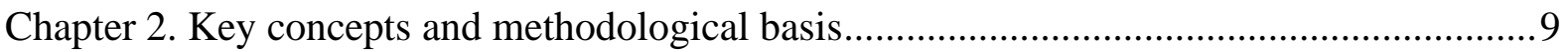

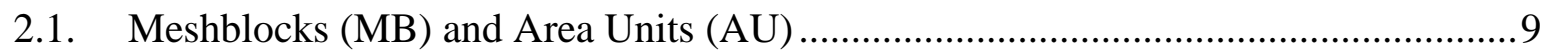

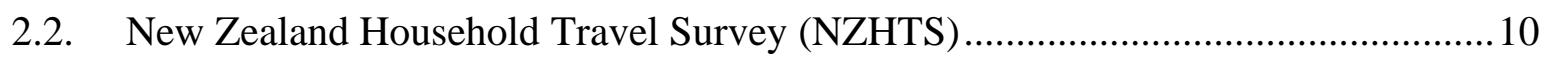

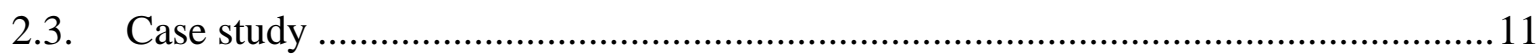

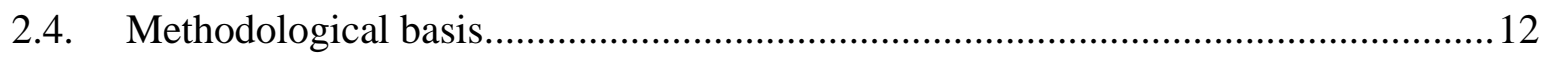

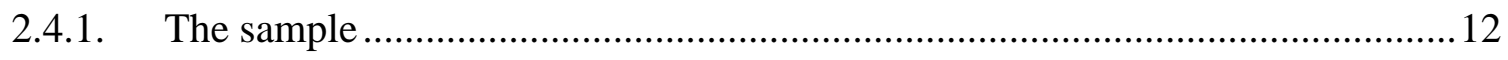

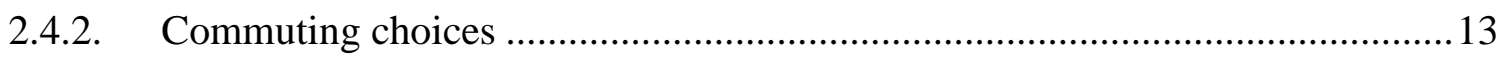

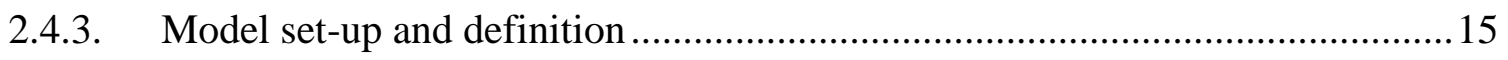

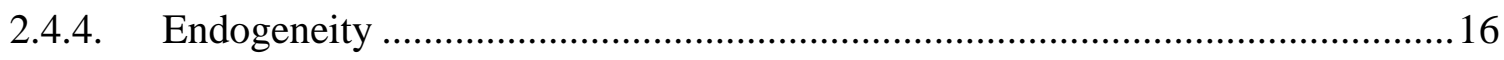

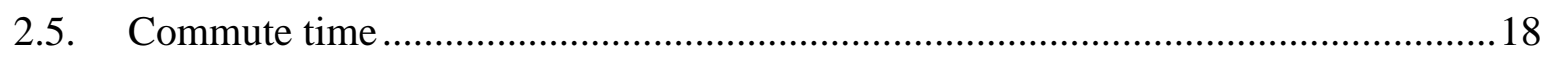

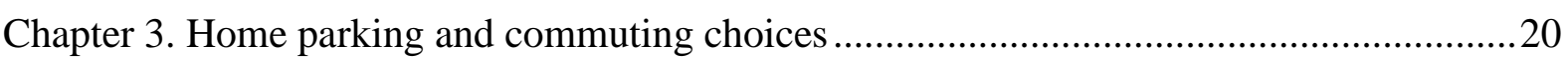

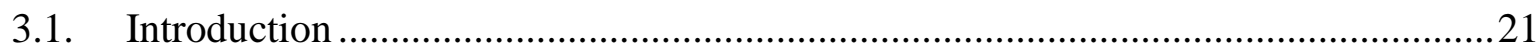

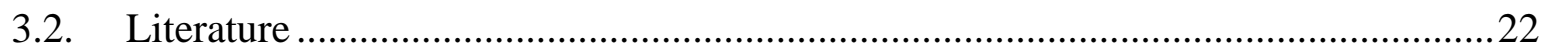

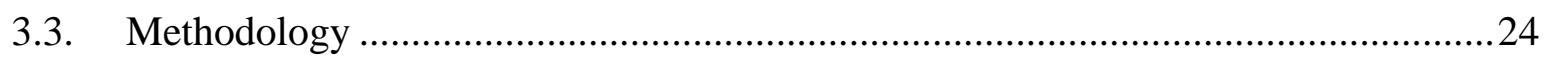

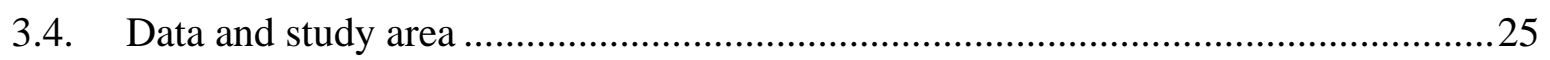

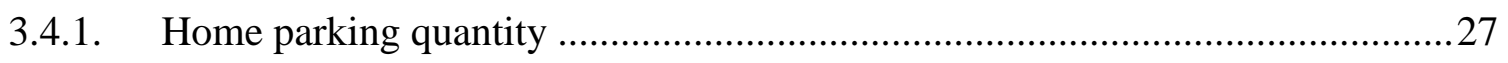

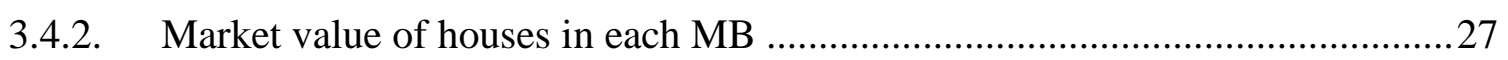

3.4.3. Number of dwelling in MB and the number of people in dwelling ..................27

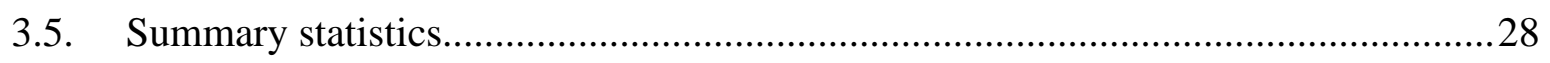

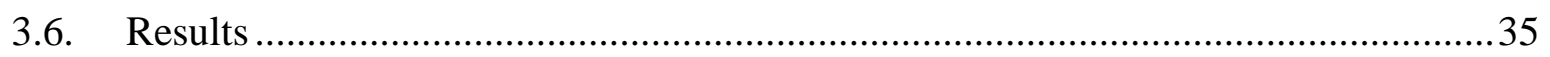

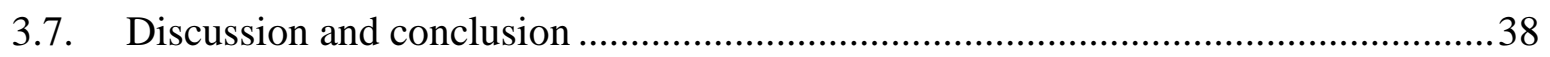

Chapter 4. Home parking type and car ownership.......................................................... 40

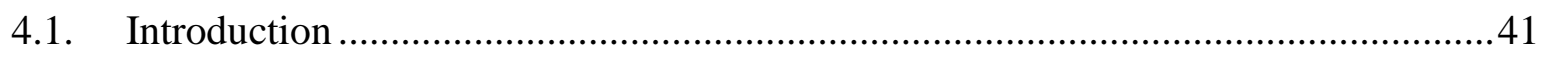

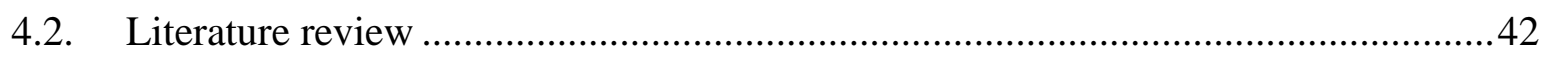

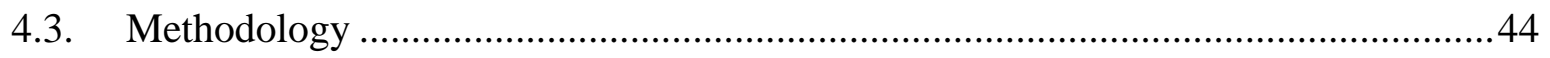

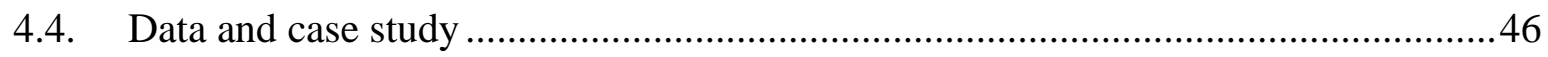

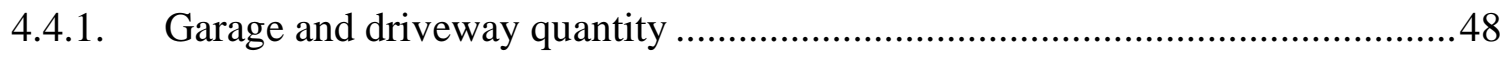

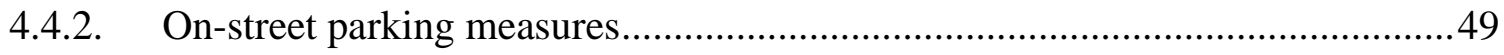




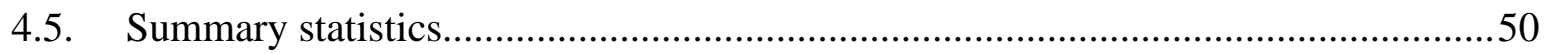

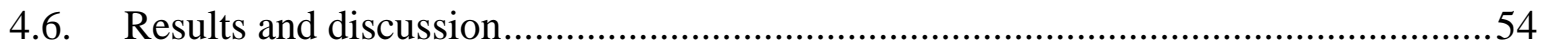

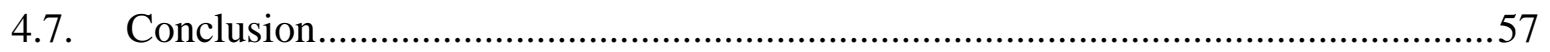

Chapter 5. Work parking alternatives and mode choice .......................................................60

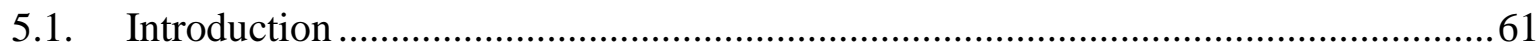

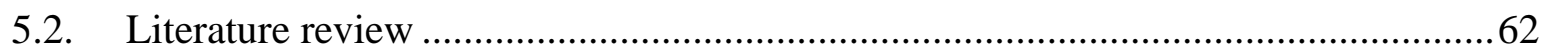

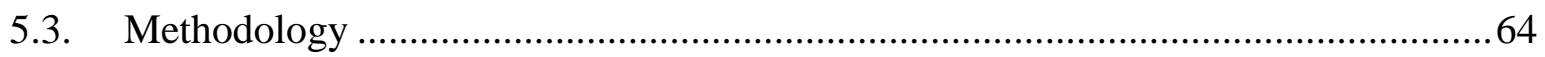

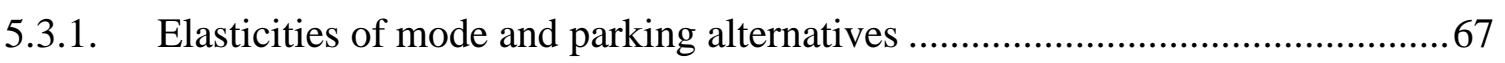

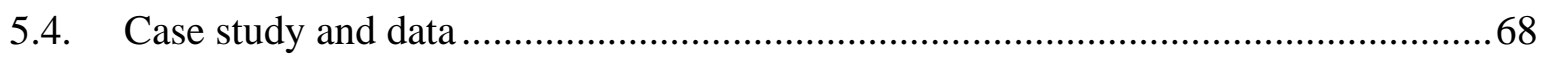

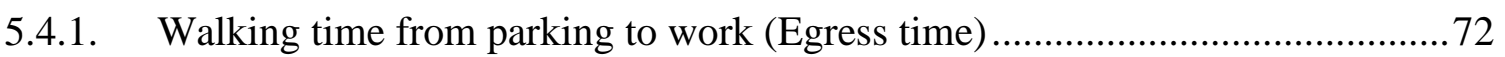

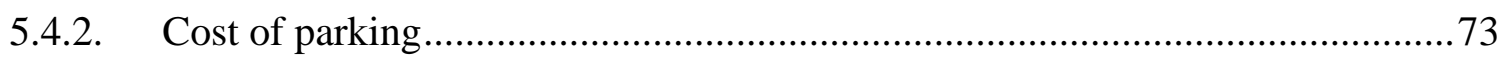

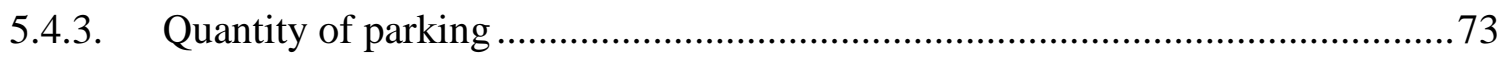

5.4.4. Existence of private off-street parking in the block ........................................ 73

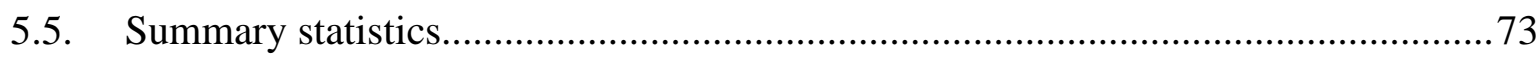

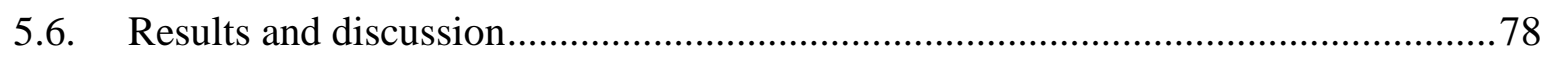

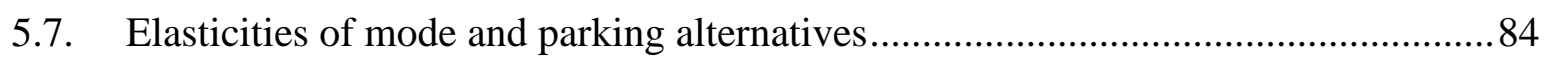

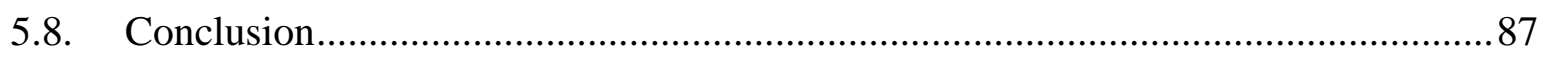

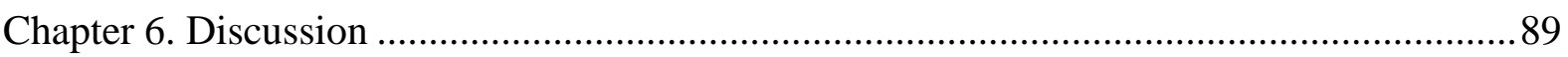

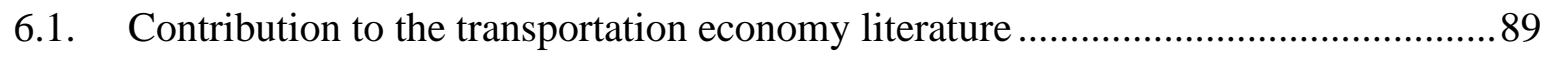

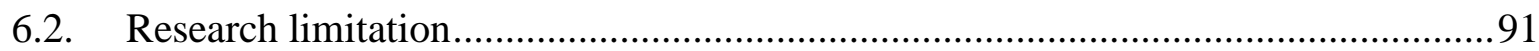

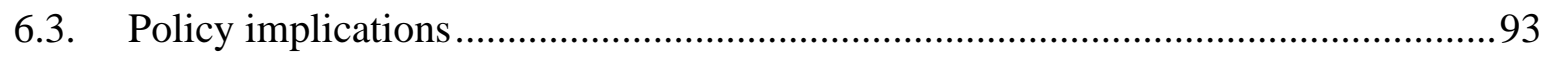

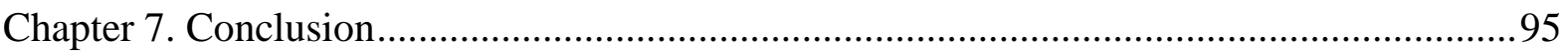

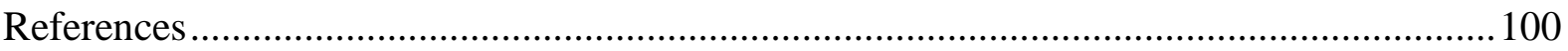




\section{List of tables}

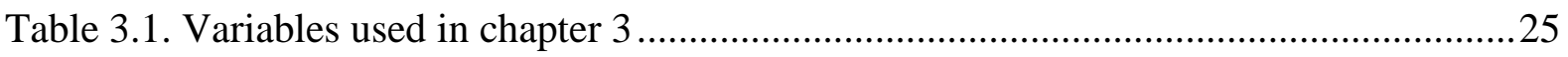

Table 3.2. Summary statistics for household heads ........................................................... 28

Table 3.3. Households in central areas and outside in Wellington City (\%) ..........................29

Table 3.4. Share of Wellington CBD workers in each car ownership category (\%) ...............31

Table 3.5. Share of households in each income and car ownership category (\%) ...................31

Table 3.6. Share of households in each category of number of full-time workers $(\%)$...........31

Table 3.7. Households with children by each home parking quantity category $(\%)$................32

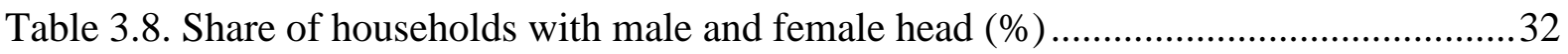

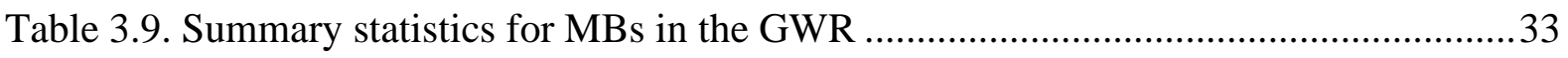

Table 3.10. Logit results for car ownership, commute mode and residential location choice. 36

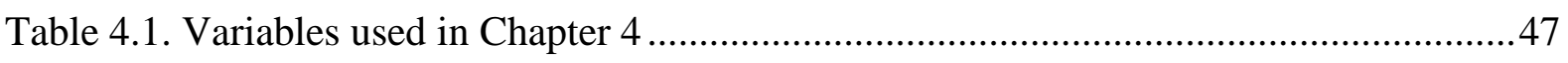

Table 4.2. Summary statistics of the variables used in the main regression...........................50

Table 4.3. Share of households in each location and garage quantity category $(\%)$...............51

Table 4.4. Share of households in each income category in NZD $(\%)$..................................53

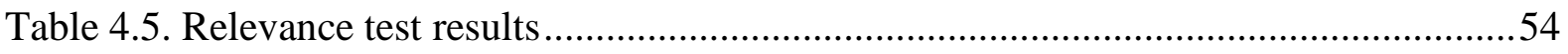

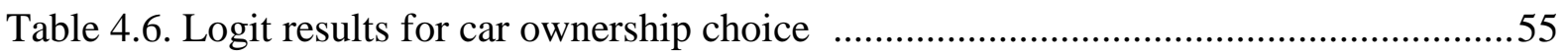

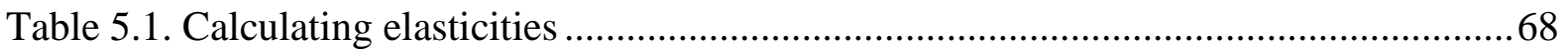

Table 5.2. Maximum walking distance or time between parking and work ...........................69

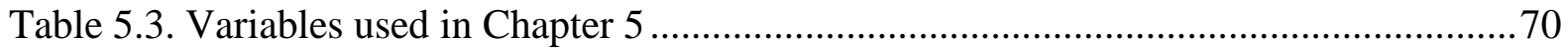

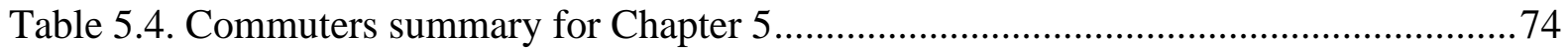

Table 5.5. Share of households' heads in car ownership categories $(\%)$................................ 76

Table 5.6. Share of drivers in each public off-street parking quantity category (\%)...............77

Table 5.7. NL estimates for mode and parking choices (maximum egress time $=$ five minutes)

Table 5.8. NL estimates for mode and parking choices (maximum egress time $=10$ minutes) .. 83

Table 5.9. Elasticities for maximum egress time = five minutes 85 


\section{List of figures}

Figure 2.1. The Greater Wellington Region (GWR) ..................................................... 11

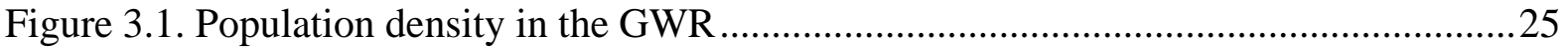

Figure 3.2. Households in each location and car ownership category $(\%)$.............................29

Figure 3.3. Number of households within home parking quantity categories by number of

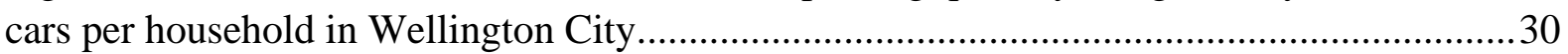

Figure 3.4. Drivers within home parking quantity categories in Wellington City (\%) ...........30

Figure 4.1. Home parking in (a) Wellington CBD, (b) Coupon parking zone, both (c) and (d)

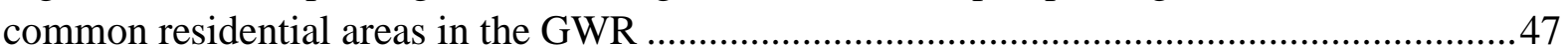

Figure 4.2. On-site parking quantity in the cities of the GWR ...........................................50

Figure 4.3. Share of households in each garage quantity category $(\%)$.................................51

Figure 4.4. Share of households in each driveway quantity category $(\%)$.............................52

Figure 5.1. Nest structure of mode choice and parking choice ............................................65

Figure 5.2. Wellington CBD (a), coupon parking area (b), rest of Wellington City (c)..........69

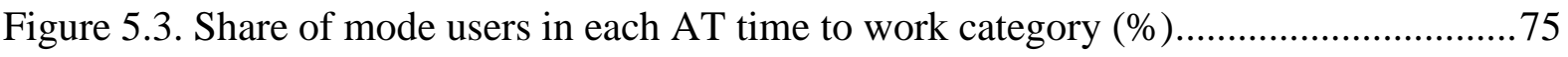

Figure 5.4. Share of drivers below and above average egress time for public off-street parking .77

Figure 5.5. Share of drivers below and above average of egress time for on-street parking... 78 


\section{Chapter 1}

\section{Introduction}

\subsection{Commuting}

Commuting is an often overlooked routine daily experience. However, this routine activity affects our lives considerably. Every week we spend time and energy, which are valuable resources, traveling to work. The commuting literature is dominated by research on cars when moving (see, for example, Beige \& Axhausen, 2017; Ding et al., 2017; He \& Zhao, 2017; Hu \& Schneider, 2017; Melo \& de Abreu e Silva, 2017; Moreno-Monroy \& Posada, 2017; Rüger et al., 2017). However, each car trip starts from a parking and terminates in a parking, and cars spend most of the day parked. A parked car has several externalities that impact travel behavior (e.g. slowing traffic). Parking affects traffic and overlooking parking in transport planning might limit the effectiveness of many traffic policies. $\mathrm{We}^{2}$ study home parking and work parking and estimate their impact on choices of car ownership and commute mode. For home parking, we answer the questions "How does the quantity of home parking affect car ownership and commute mode?", and "How do home parking type and quantity affect car ownership?". We focus on time costs of work parking as a relatively less studied parking dimension and answer the question "How does walking time from parking location to work impact parking type choice?". In home parking research, we include residential location choice for more realistic results and introduce novel instrumental variables to fix the endogeneity between parking and car ownership for studying home parking in the property scale. In work parking research, we consider mode choice along with parking alternatives, and use a novel measure for walking time from parking to work that considers demand for parking and is more reliable for long-term policymaking.

\footnotetext{
${ }^{2}$ I use the writing convention of 'we'/'our' in preference over 'I'/'my' and I am the sole author of this research.
} 
From an environmental and health standpoint, car trips are a source of greenhouse emissions, air pollution, noise pollution, and other externalities. Car trips are a big part of commuting trips in many countries. For example, in Auckland, Canterbury, and Wellington in New Zealand, car trips constitute $74 \%, 67 \%$, and 57\% of all trips to work between 2003 to 2010 (Milne et al., 2011). This share is $68.7 \%$ in Australia (Australian Bureau of Statistics, 2017) and 68.8\% in Canada (Statistics Canada, 2016). Every day, motor-vehicles add a significant amount of greenhouse gases to the atmosphere and contribute to climate change. Pollution affects both commuters and residents. Many studies explore the relationship between commuting and health (Ma et al., 2020; Nunes de Oliveira et al., 2020; Sattler et al., 2020; Xiao et al., 2020).

Commuting and urban form mutually affect each other (Acheampong, 2020; Bai et al., 2020; Fosgerau and Kim, 2019; Lee, 2020; Niedzielski et al., 2020; Zhu et al., 2020). Our travel behavior helps shape our cities and the built environment. Commuting is also influenced by land-use and urban form. Individuals living in marginal sprawl suburbs dominated by singlefamily houses appear to prefer driving to other modes due to longer distances between places and less efficient public transport and active transport.

Commuting behavior is heavily influenced by three interrelated choices: car ownership, commute mode, and residential location (Bhat \& Guo, 2007; Salon, 2009; Daglish et al., 2015). For example, several studies find commute time or distance as a factor negatively impact attractiveness of a residential location (Guevara \& Ben-Akiva, 2006, de Palmaet al., 2005). Commuters prefer to live closer to work. However, shorter commute time and access to better transport options increase house prices (Bajic, 1983; Cheshire \& Sheppard, 1995; Coulson \& Engle, 1987; Henneberry, 1998; So et al., 1997; Yiu \& Wong, 2005).

\subsection{Parking and commuting}

Urban transport and land use interact with each other in several ways and travel behavior is influenced by the built environment (Cervero \& Duncan, 2006; Næss, 2005, 2011, 2012). For example, households in outer residential suburbs make more car trips than households in central suburbs (Christiansen, Engebretsen, Fearnley, \& Usterud Hanssen, 2017). Many studies research this interaction from different aspects and attempt to provide some policy implications for a more effective urban policy (for example, see Bhat \& Guo, 2007; Cao \& Yang, 2017; Ding, Wang, Tang, Mishra, \& Liu, 2018; Feng, 2017; Lin et al., 2017; Zang et al., 2019). 
One of the key aspects of the transport-land use relationshipa (and also an important topic in urban planning) is transportation externalities (Euchi \& Kallel, 2021; Wangsness et al., 2020). Traffic congestion as a result of increasing modernization and car ownership rates is a source of environmental pollution (Dasgupta et al., 2021; Lu et al., 2021). Moreover, it damages the economy by wasting valuable time that otherwise could be used to enhance economic productivity (Cherkaoui et al., 2019; Vijayaraman \& Jesu Jayarin, 2021).

Parking is an important element in the interaction between transportation and land use, and a key topic in urban transportation (Davis et al., 2010; Khodaii et al., 2010; Shoup, 2006). Parking is a type of land use where each trip starts and ends. The imbalance between parking demand and supply is problematic and imposes significant costs on communities (Pierce \& Shoup, 2013; van Ommeren et al., 2021). There is some evidence that more parking motivates higher car ownership and car use (Guo, 2013a, 2013b; Weinberger, 2012; (Christiansen, Engebretsen, et al., 2017; Christiansen, Fearnley et al. 2017). Increasing car ownership and driving rates intensify traffic congestion (Shen et al., 2020; Zheng et al., 2021). Parking is a factor responsible for many transport externalities (Arnott \& Williams, 2017; My Thanh \& Friedrich, 2017; Shoup, 2006). Cruising for parking which is a consequence of cheap, overcrowded parking, leads to traffic congestion (Gallo et al., 2011), slowing down traffic (Liu et al., 2017), wasting time (Pierce \& Shoup, 2013; Qin et al., 2020), and more fuel consumption and greenhouse gas emissions (Barata et al., 2011). A review of cruising for parking in 11 cities around the world between 1927 to 2001 show that the share of vehicles cruising for parking (as a fraction of all traffic) is between 8 to $74 \%$, and the time spent while cruising for on-street parking is between 3.5 to 14 minutes (Shoup, 2006). The share of cruisers is $30 \%$ or even higher if considering trips to downtown on working days (Arnott \& Williams, 2017). These costs are imposed on all the community and not only drivers. For example, cruising for parking pollutes the environment that pedestrians use (Barata et al., 2011). High parking supply is a common practice in many cities (Pandhe \& March, 2012a). Nonetheless, the cost of providing parking is substantial. For example, Shoup (1999) estimates US\$10,000 for providing one aboveground parking space and US $\$ 25,000$ for providing one underground parking space.

In residential areas, the minimum parking requirement has been applied in many places in the world. This requirement is a key factor determining urban spatial structure and travel behavior (Shoup, 1999). There is some evidence that households in suburbs where minimum parking is mandatory tend to have more cars and make more car trips than households in suburbs with 
less parking supply (Weinberger et al., 2008, 2009). Moreover, parking provision leads to higher house prices and therefore limits house affordability (Chester et al., 2015; Guo \& Ren, 2013; Jia \& Wachs, 1999; Li \& Guo, 2014; Kladeftiras \& Antoniou, 2013). Due to the mandatory off-street parking supply, there will be limited options for households with various socioeconomic characteristics (Gabbe et al., 2020). For example, a low-income household without a car has to choose from expensive houses with two garages. Another consequence of these policies is that parking in city centers is largely underused in the evening and residential parking is mostly vacant during the day. Parking takes a significant amount of land that is underused for long periods. This is a social cost of parking.

There are many studies that show parking management is a key instrument for minimizing traffic congestion (Arnott et al., 1991; Arnott et al., 2015; Arnott \& Inci, 2006; Arnott \& Williams, 2017; Martens, Benenson, \& Levy, 2010; Verhoef, Nijkamp, \& Rietveld, 1995; Zakharenko, 2016). Lack of a proper understanding of parking in policy-making reduces the effectiveness of transportation policies and meeting sustainable urban transportation objectives (Pandhe \& March, 2012a). Parking is a limited resource and requires careful regulation to ensure its optimum use (Pierce et al., 2015).

Some research provides policy implications for regulating parking. Parking pricing is commonly researched. Cheap parking leads to overcrowded parking and roads, which imposes noticeable costs on urban transportation (e.g. traffic congestion), urban environment (e.g. air pollution), and the urban economy (Dorsey, 2005). Based on an economic analysis of parking pricing and congestion, Arnott \& Rowse (1999) suggest that parking fees should be equivalent to the costs of parking congestion externalities. Shoup (1999) suggests setting an optimal cost for on-street parking instead of using urban land to provide off-street parking. Su \& Zhou (2012) show that higher parking prices for drivers, a discount for carpoolers, or reducing the number of parking spaces would reduce the share of drivers.

The impact of reducing numbers of parking spaces on travel behavior is less studied than parking pricing. However, regulating parking prices without regulating parking supply would undermine the efforts in parking pricing. Parking availability is potentially a key factor discouraging car use (Shoup, 2005). O'Fallon et al. (2004) find restricting parking availability significantly discourages commuters from driving to work. Pandhe \& March (2012) explore the impact of parking restrictions on the preference for using public transport. They find that parking reduction would result in a high share of drivers shifting to public transport. Reducing 
parking supply through maximum parking requirements potentially reduces car ownership and the number of drivers (Christiansen, Engebretsen, et al., 2017). However, this policy is effective only if on-street parking availability is limited and on-street parking is not free of charge (Zhan Guo, 2013a; Zhan Guo \& Ren, 2013). This is in line with the recent urban planning policy statement "National Policy Statement on Urban Development" (NPS-UD) (New Zealand government, 2020). This policy aims to encourage non-driving modes through intensification (higher construction density) in main urban centers and increasing accessibility of public and active transport. In parking policy, minimum parking requirements are suggested to be removed in order to provide more housing options for households and enhance house affordability (New Zealand government, 2020).

In this research, we explore the relationship between parking and commuting choices at a regional scale, to provide a comprehensive view of the interaction between parking, transportation, and land use. Commuting is a trip from home parking to work parking. Therefore, we do not limit our study to parking at one end (residential parking or work parking) and study both to account for potential interaction between them. We focus on car ownership and commute mode as two key characteristics of travel behavior. We also study parking in relation to residential location. Residential location, car ownership, and commute mode are interrelated as main decisions that shape households' travel behavior. Our research provides empirical evidence for an effective and efficient parking policy in the Greater Wellington Region.

\subsection{Parking at work}

Parking at work is an important determinant of commuting mode choice and drivers' parking choice (Hensher \& King, 2001; Simićević, Vukanović, \& Milosavljević, 2013; Yan, Levine, $\&$ Marans, 2019). Parking costs has been the focus of much research on work parking (Bonsall and Palmer, 2004; Dell'Orco et al., 2003; Ruisong et al., 2009; Thompson and Richardson, 1998). However, the parking decision also illustrates a trade-off between monetary and time costs of parking. In a morning peak hour when commuters are likely to have wasted time in traffic congestion, minimizing walking time from parking to work is important. Drivers prefer to park a few blocks away from work (Choné \& Linnemer, 2012; De Nijs, 2012; Froeb et al., 2003; Kobus et al., 2013a; Lin and Wang, 2015). Walking is slower, and therefore more costly than driving. Drivers consider walking time from parking to work more costly than in-vehicle time (Abrantes and Wardman, 2011; Small, 2012). Consequently, drivers may choose a nearby, 
but relatively expensive, parking location. Time costs of parking are important factors affecting travel behavior and merit further research.

In the parking literature, parking conditions are studied in relation to drivers. Drivers respond to changes in parking features by shifting to other parking alternatives (see Fulman et al., 2020; Golias et al., 2002; Kobus et al., 2013). Parking is commonly believed to be relevant to drivers. However, choosing to drive over other modes partly depends on parking conditions at work. For an individual who works at a location where parking is restricted and not reasonably close to work, driving might not be attractive. Therefore, parking and commute mode choices should be considered simultaneously.

\subsection{Parking at home}

Home parking, as a place where most car journeys start and terminate, is rarely studied. However, cars are commonly parked at home longer than at work. Home parking is important for car ownership and commute mode. There is evidence that more residential parking encourages households to have more cars and drive to work more often (Guo, 2013a, 2013b; Weinberger, 2012). Therefore, overlooking home parking may reduce the effectiveness of parking policies applying in the city centres.

Home parking is an important determinant of house prices and, therefore, the residential location choice of households (Guo \& Ren, 2013; Taylor, 2020). Providing home parking because of minimum parking requirements increases construction costs and house prices (Chester et al., 2015; Guo \& Ren, 2013; Jia \& Wachs, 1999; Li \& Guo, 2014; Kladeftiras \& Antoniou, 2013; International Transport Forum, 2021). In addition to less affordable housing, minimum parking standards limit the choice of houses. For example, most houses in a neighborhood might have one or two garages as a result of minimum parking requirements. A house with off-street parking is often more expensive than a similar house without parking. Most housing options for a household without a car are houses with parking. Therefore the household pays extra for parking (Gabbe et al., 2020).

The cost of residential parking has been the focus of most home parking studies (e.g. Groote, Ommeren, \& Koster, 2016; Guo \& McDonnell, 2013; Seya, Nakamichi, \& Yamagata, 2016). Parking cost is important for travel behavior, nonetheless, it mostly covers on-street parking. A free-of-charge parking space on the property is a guaranteed space and is less likely to be affected by pricing policies. As noted in Shoup (2005), free parking imposes significant costs 
on the public and causes noticeable issues in commuting. In contrast with on-street parking where availability is limited by the demand from others, parking at a residential property is not subject to competition. Therefore, on-site home parking might be a significant motivation in car ownership and choosing to drive.

Home parking comprises various types including garage, driveway, and on-street parking. Each type has a distinct level of availability, convenience, and security. In the small literature studying home parking, most studies either use a proxy for home parking (Wong, 2013; Ritter and Vance, 2013; Potoglou \& Kanaroglou, 2008; Ryan \& Han, 1999) or they use access to home parking (Scorrano et al., 2020; Wu et al., 1999; Christiansen, Engebretsen et al., 2017). The quantity of each home parking type and its impact on travel behavior is rarely studied.

\subsection{Thesis outline}

The main objective of this thesis is to study home parking and work parking based on a model that clearly explains individuals' travel behavior. More accurately, this thesis answers three research questions each in a separate chapter. On home parking, we ask "How does the quantity of home parking affect car ownership and commute mode?" and "How do home parking types and quantity affect car ownership?". Our question regarding parking at work is "How does walking time from a parking location to work impact parking type choice?" Answers to these questions provide a comprehensive understanding of the role of parking in the commuting experience.

To support the overlapping methodologies and concepts, Chapter 2 discusses concepts relevant to all three questions and the underlying model developed to model individual commuter travel behavior. This chapter also covers the main data and sample selection process.

Chapter 3 focuses on the quantity of home parking and estimates its impact on car ownership and commute mode. In contrast to most parking studies (e.g. Albalate \& Gragera, 2020b; Guo, 2013a, 2013b), we account for residential location choice. We study commuters that live or work anywhere in a region to better account for the diversity of commuters, traffic conditions, and parking features. We also mitigate the endogeneity in house prices based on the control function approach (Petrin \& Train, 2010) and estimate the causal relationship between home parking quantity and car ownership and commute mode.

In Chapter 4, we research home parking in more detail. For each household, we estimate the impact of the number of garages and driveway spaces on car ownership. On-street parking is 
subject to demand from others, and we consider the chance of finding an on-street parking space as a measure for on-street parking. We mitigate the reverse causality between car ownership and home parking to estimate a causal relationship between the two.

Chapter 5 is a study of parking at work. Contrary to many parking studies that concentrate on parking cost (Bonsall and Palmer, 2004; Dell'Orco et al., 2003; Ruisong et al., 2009; Thompson and Richardson, 1998), the focus of this study is walking time from parking to work. Parking alternatives in our model cover most types of parking usually available in cities. Drivers may choose from public off-street parking, private off-street parking, and on-street parking. Based on a nested logit model, we design a joint model of mode choice and parking choice to account for the tradeoff between the two choice sets. The elasticities of preference for parking choice and mode choice against changes in main parking features are calculated. The elasticities show changes in parking features that would motivate commuters to change parking or shift to nondriving modes.

Finally, we summarize the key findings for these three studies in Chapter 6 and identify areas of future research. 


\section{Chapter 2}

\section{Key concepts and methodological basis}

This chapter has three parts. In the first part, we explain the underlying concepts of the research. We start with introducing Meshblocks (MB) and Area Units (AU) as key elements of residential location choice modelling. Then, we explain the New Zealand Household Travel Survey (NZHTS) where our sample comes from. This is followed by describing the case study.

The second part of the chapter details the methodological basis. First, commuting choices and the sample are defined. Then, we explain the Conditional Logit (CL) model that underpins our approach to answering our research questions, and how we use this model to estimate the impact of parking features on commuting choices. We also explain the concept of endogeneity and the method we use to mitigate it. Next, we explain the process of calculating travel time as an important variable in our model.

The underlying methodology is based on Daglish et al. (2015). However, we study a larger sample (commuters surveyed from 2003 to 2017), update data (e.g. road network, MBs and AUs), test instrumental variables, modify the model to fix endogeneity with our instrumental variables, collect data on parking, calculate parking measures and include parking variables in the model.

\subsection{Meshblocks (MB) and Area Units (AU)}

Statistics New Zealand publishes statistical information for a hierarchy of geographic units based on their size. A MB is the smallest geographical unit defined by Statistics New Zealand (Statistics New Zealand, 2016). MBs are usually small in urban areas (e.g. an urban block or part of the block), and larger in rural areas. They accommodate 0 to 1899 people 
(Statistics New Zealand, 2013a). An MB usually includes 30 to 60 dwellings and 120 dwellings at the most (Statistics New Zealand, 2016). MBs are aggregated to AUs. An AU is roughly analogous to a suburb with a population of 3,000 to 5,000 in urban areas (Statistics New Zealand, 2013b).

The MB and AU boundaries from 2017 were used as the most up-to-date version at the time we started this research. Non-terrestrial MBs and MBs associated with lakes and islands are excluded from our dataset.

\subsection{New Zealand Household Travel Survey (NZHTS)}

The New Zealand Household Travel Survey was conducted by the Ministry of Transport (MOT) from 1989 to present. Households were initially surveyed on two consecutive days. In 2015, MOT changed the method to survey each household for seven consecutive days. They reverted to two consecutive days again in 2018 to improve data quality and to ease the process for participants (New Zealand Ministry of Transport, 2020).

Sampling method for 2003 to 2014

A stratified sampling method is used for the NZHTS survey. Fourteen local government regions are considered as strata. In each stratum, there are urban areas with the population of over 10,000 people and rural areas which are less populated (Land Transport Safety Authority, 2000). MBs are randomly sampled within each region. The probability of each MB being selected is proportional to its population in the census 1991. In urban MBs, one in eight households is randomly surveyed. This portion is one in seven in rural areas (ibid). Two days were allocated to each household to provide their travel information. This method is designed to ensure a sufficient geographical coverage of the selected area and a good spread of the selected days in a week across the sample (ibid).

Sampling method for 2015 to 2017

Primary Sampling Units (PSU) are defined by Statistics New Zealand as its main sampling units for household surveys. The population and number of dwellings are more evenly distributed across PSUs than MBs (New Zealand Health Survey, 2016).

Approximately 20,000 PSUs cover all the country (New Zealand Health Survey, 2016). The first step of sampling is selecting 300 PSUs across the country. (1.5\% of all PSUs). The probabilities of selecting PSUs are proportional to the number of occupied dwellings from the 
most recent census.A coordinate sampling method is used in selecting PSUs to minimize double selection of them across different surveys.

The second step is selecting a random MB with at least nine houses in each PSU. There are usually one to five MBs in a PSU. One MB in each PSU is chosen to minimize survey costs. The probability of choosing MBs is proportional to the number of residents in MBs. Within each selected MB, 13 houses were sampled based on NZ Post Postal Address File (PAF) for residential addresses. An invite is sent to all eligible household members in the selected houses to participate in the survey and provide their trip data for seven consecutive assigned days (New Zealand Ministry Of Transport, 2018).

Each household is assigned a sample number and each person in the household is assigned a one or two digit number ( $\mathrm{n}$ ) that indicates that he/she is the $\mathrm{n}^{\text {th }}$ person in the household. The data from NZHTS is classified into address data (e.g. address and coordinates of each point), accident and alcohol data, household data (e.g. number of cars in the household), person data (e.g. income), trip data (e.g. start and end of trip, where parked), vehicle data, and trip chain data.

\subsection{Case study}

The Greater Wellington Region (GWR) in the southern part of the North Island of New Zealand and includes nine districts: Wellington City, Hutt City, Porirua City, Upper Hutt City, Kapiti Coast District, Masterton District, Carterton District, South Wairarapa District, and part of Tararua District (Figure 1) (Wellington Regional Council, 2013). The region had a population of 506,814 in 2018 (Statistics New Zealand, 2020).

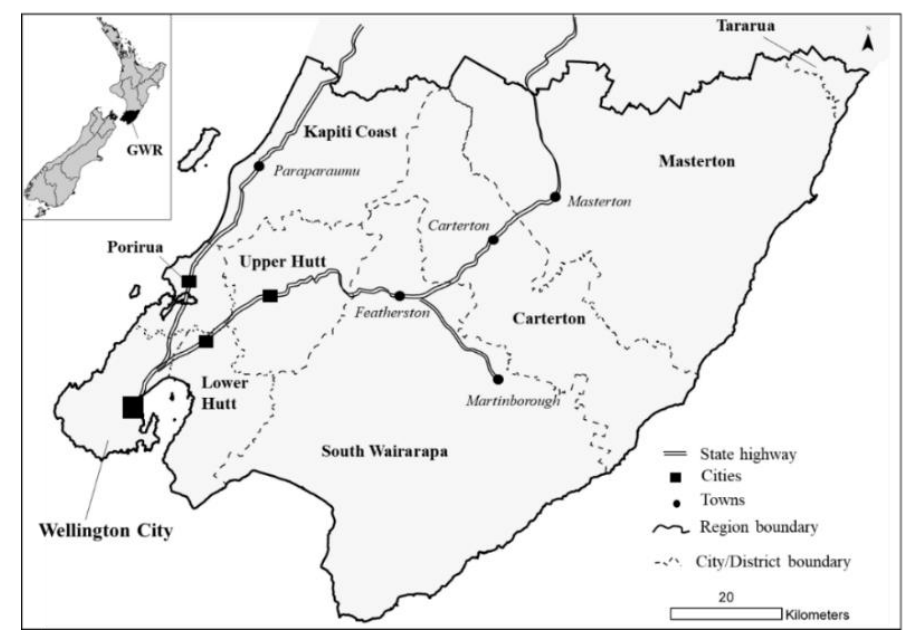

Figure 2.1. The Greater Wellington Region (GWR) 
Although most parking studies focus on urban areas (Christiansen, Engebretsen et al., 2017) or an individual city (Guo \& McDonnell, 2013), commuting is a regional issue. This study uses data from across the GWR. The GWR includes several urban and rural areas with a diverse range of socio-economic and spatial characteristics. This approach enables us to have a broader and more realistic view of commuting and to better capture the impact of parking on commuting choices.

\subsection{Methodological basis}

This section details commuting choices and the criteria and process of sample selection from the NZHTS dataset. Then, we explain the CL model, the concept of endogeneity, and how to mitigate it.

\subsubsection{The sample}

We use the NZHTS data for individuals in the GWR surveyed between 2003 to 2017 and working in a fixed place for their main work. Commuters with fixed work locations are assumed to optimize their home location taking travel time into account. An individual with a fixed workplace tries to optimize his/her residential location based on proximity to work and many other factors (e.g. socioeconomic characteristics, local amenities). If they have varying work locations, proximity to work would not be an important factor. Therefore, residential location is not chosen based on commuting experience and cannot be considered as a commuting choice. The purpose of each trip and journey is identified in the NZHTS dataset. We choose individuals whose journey purpose is identified as going to "main work". If the journey destination address number is not changed over travel days, that individual is considered as a commuter with a fixed workplace.

We consider commuters who work in the GWR, but sufficiently inside it that their residential choice set would be inside the GWR. We exclude households that work within 10 kilometers of the Northern border of the GWR (the only land border of the region). We further refine the sample when choosing the main commute mode for commuters (see section 2.4.2).

After all refinements, in Chapters 3 and 4 we study 1056 households who live and work in the GWR. For researching parking at work in Chapter 5, we study 577 households whose heads work in Wellington City and live in the GWR. Most of workplaces in the GWR are in Wellington City and we focus on workers in Wellington City in Chapter 5. 


\subsubsection{Commuting choices}

Commuters choose their residential location, commute mode, and car ownership. In this thesis, car ownership is defined as the number of private cars in a household provided in the NZHTS dataset. Car ownership categories comprise no car, one car, two cars, and three or more cars.

Commute mode choices comprise Active Transport (AT), Public Transport (PT), carpooling, and driving. AT includes walking and cycling. PT includes Walk-PT (i.e. walking to a PT stop, taking PT, and walking to work) and Drive-PT (i.e. driving to a PT stop, taking PT, and walking to work). We consider a main commute mode for each commuter based on trip details provided in the NZHTS dataset. Journeys from home to work are considered. The days where the commuter did not travel to their "main work" are not considered. Also, individuals only surveyed on weekends are removed. If no trip from home to work is available for a person, that person is not considered. A commuter may have several trips in a journey to work and use various modes in the journey. Also, they may choose different modes across the travel days. We identify a main commute mode for each commuter. On a trip day, the main mode is the mode with the longest travel distance. If the distances are the same between two or more modes, we prioritize the mode from the smallest group to the largest group as in Daglish et al. (2015) (1. walking or cycling, 2. Walk-PT or Drive-PT, 3. Carpool, 4. Drive). Within travel days, the main mode is identified as the mode that is used on most of the days. If the number of days is the same, the priority of walking or cycling, Walk-PT or Drive-PT, Carpool, Drive is used.

Due to the low cycling sample size, we combine walking and cycling together as AT. We apply a time penalty for cycling to ensure that the utility from walking is the same as the utility from cycling. We consider walkers and cyclists from the sample and consider travel time for each mode. The method of calculating travel time is explained in Section 2.5. We consider a two-choice logit (walking or cycling). The utility that individual $i$ receives from mode $j$ is

$$
U_{i j}=\beta_{1} \text { Commute }_{\text {time }} i j+\beta_{2} \text { Cycling }_{i j},
$$

in which, Cycling $g_{i j}$ is the dummy variable for cycling, Commute time $e_{i j}$ is travel time by mode $j$ (walking or cycling) and $\beta_{n}$ is the associated coefficient ( $n$ is number of explanatory variables). We want the utility of walking and cycling to be the same as shown in Equation (2.2) as

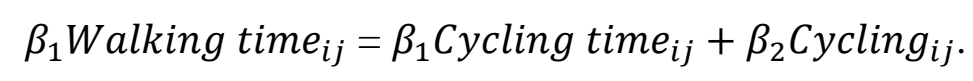


The ratio of $\frac{\beta_{2}}{\beta_{1}}$ is the difference between walking time and cycling time. This ratio indicates how long the cycling time should be for the utility for walking be equal to the utility of cycling. This ratio is the time penalty for cycling. We calculated this time penalty as 28.11 minutes.

The same method is used for calculating a time penalty for Drive-PT considering PT users from the sample. The time penalty for Drive-PT is calculated as 13.96 minutes.

The commuters whose main mode in the NZHTS dataset is reworded as "other household travel" and "non-household travel" are removed.

Residential location choice is considered in Chapter 4. Considering residential location choices at a property scale would significantly increase the number of choices. Computation would be significantly time-consuming. Therefore, we consider residential location choices at the MB scale. Assigning all MBs as possible residential locations for each commuter would cause two issues. First, MBs are usually small (30 to 60 dwellings). Hence, two neighboring MBs are likely to have similar features. This is called spatial autocorrelation (Haining, 2001; Lee, 2017) and exists when there is a relationship between similarity of values of a variable and the adjacency of spatial units (Lee, 2017). In this case, there is redundancy in data, which is against the assumption of independent observations (ibid, 2017).

Second, there are 5380 MBs in 204 AUs in the GWR. Assigning all 5380 MBs as individual residential locations would be computationally infeasible.

In this research, residential location choice is defined as one randomly selected MB in each AU. Statistics New Zealand assigns a unique number to each MB and AU. We refer to this unique number as ID for AU or MB. The process of assigning a random MB in each AU to a commuter is based on Daglish et al. (2015) and is described as follows.

1. Counting number of MBs in an $\mathrm{AU}(n)$.

2. Sorting AUs ascending based on their ID and subsequently sorting MBs ascending based on their IDs.

3. For each $\mathrm{AU}$, we associate $\mathrm{MBs}$ in that $\mathrm{AU}$ with integers from 1 to $n$ (inclusive). The resulting table includes MB IDs and the associated integer.

4. For each commuter in each $\mathrm{AU}$, we generate a random integer from 1 to $n$ (inclusive). 
5. The random numbers are converted to MB IDs based on the table created in the third step.

This approach speeds up the computation and avoids spatial autocorrelation. Moreover, our stratified sampling of one MB in each AU ensures an even distribution of choices in the GWR.

\subsubsection{Model set-up and definition}

This research uses a discrete choice model. An individual is modelled as achieving a utility from each choice of residential location, car ownership, and commute mode. The utility that individual $i$ receives from choice $j\left(U_{i j}\right)$ is calculated as

$$
U_{i j}=\sum_{n} \beta_{n} X_{i j n}+\varepsilon_{i j}
$$

in which $\beta_{n}$ is a coefficient, $X_{i j n}$ is explanatory variable $n$, for individual $i$ making choice $j$, and $\varepsilon_{i j}$ is the error term associated with individual $i$ making choice $j$ (which is logistically distributed) (Greene, 2003). Our discrete choice model (Equation 2.3) estimates a coefficient for each explanatory variable to find the direction and intensity of the impact of that variable on choices. The dependent variable in this research is a qualitative discrete variable that indicates the choice that each commuter makes. A response variable takes the value of 1 if the choice is observed in the data and 0 otherwise. We need to find a function that generates a probability of individual $i$ choosing choice $j$. A logistic regression model is an appropriate and commonly used random utility model (Gujarati, 2004; Greene, 2003) and is used in different subjects, including transportation (for example, see Guo, 2013a; Hamre and Buehler, 2014; Bridgelall, 2014).

There are two types of logit models for modelling multiple choices: Multinomial Logit (ML) and CL (Greene, 2003). In multinomial logit, the main interest is studying individuals' characteristics (e.g. demographics), and explanatory variables that vary across individuals (Hoffman and Duncan, 1988). In our research, we study travel behavior of commuters modelled as the choices of car ownership, commute mode and residential location. Also, if we use a ML model, each household characteristic (e.g. income) would require having $j$-1 number of coefficients ( $j$ is the number of choices). Therefore, if $j$ is large, this can significantly complicate the model and slows down the computation. Therefore, in Chapters 3 and 4 we use a CL model. The CL model is widely used in transportation and urban planning (for example, 
see Autant-Bernard, 2006; Becker et al., 2017; Boschman and van Ham, 2015; Friedman, 1981; Jourquin and Beuthe, 2019).

According to Greene (2003), we calculate the probability that person $i$ chooses choice $j\left(P_{i j}\right)$ as

$$
P_{i j}=\frac{e^{\sum_{n} \beta_{n} X_{i j n}}}{\sum_{l} e^{\sum m \beta_{m} X_{i l m}}}
$$

In which, $l$ is the set of choices $(l=1,2, \ldots, \mathrm{j}, \ldots, L)$ and $X_{i l m}$ is explanatory variable $m$. As commuters maximize their utility, we choose coefficients that maximize the probability that each person makes the choice that is observed in data. In this model, commuters' decisions are independent of each other. However, within a household, individuals' choices and travel behavior are likely to be affected by each other. To avoid this, we consider the head of households.

The likelihood function is the product of probabilities as

$$
\mathrm{L}=\prod_{i} P_{i}(j(i)),
$$

in which, $P_{i}(j(i))$ is the probability that individual $i$ chooses the actual choice $(j(i))$ observed in data. We use Maximum Likelihood (ML) method to estimate coefficients. To simplify calculations, we use a $\log$ function to calculate $\log$-Likelihood $(\log (\mathrm{L}))$ as

$$
\log (\mathrm{L})=\sum_{i} \log \left(P_{i}(j(i))\right) .
$$

Then, we use a BFGS (Broyden-Fletcher-Goldfarb-Shano) algorithm to maximize the LogLikelihood and estimate the coefficients (see Broyden (1970), Fletcher (1970), Goldfarb (1970), and Shanno (1970)). A Hessian matrix is the inverse of the variance-covariance matrix of the coefficients. The square root of values on the main diagonal of the inverse of the Hessian matrix are standard errors. The validity of results is tested using T-test values. In Chapter 5, we use a nested logit model which is explained in detail in Section 5.3.

\subsubsection{Endogeneity}

Louviere et al. (2005) present a broad definition of endogenous effect as "all effects that are not exogenous". They argue that endogeneity arises due to model misspecification. This is an important issue in choice modeling and threatens the validity of analysis and policy implications based on inconsistent estimates (Guevara \& Thomas, 2007).

Endogeneity has three main causes: omitted variables, measurement errors, and simultaneous determination (Guevara, 2015). Omitted variables refer to missing variables in the model that 
impact the utility. The parameters of the observed variables will then capture the impact of both observed and unobserved variables. Hence, the estimates can be biased upward or downward. When there is a systematic error in measuring a variable, these errors would act as an unobserved variable and cause biased estimation of the impact of the observed variable (Fernández-Antolín, Guevara-Cue, de Lapparent, \& Bierlaire, 2016). This is the second source of endogeneity.

The third cause of endogeneity refers to a situation in which the dependent and independent variables affect each other. An example of this type of endogeneity in commuting choice modeling exists between residential location and car ownership choice. A household with a high tendency for having multiple cars would prefer to live in a house with abundant parking. Similarly, home parking supply impacts preference for car ownership (Guo, 2013a). Estimating the causal impact of an independent variable on choices is difficult due to the reverse causality (Antonakis et al., 2010). This is the issue we face in Chapter 4.

We also face endogeneity in Chapter 3. In this chapter, we model utility for residential location, along with the utility for car ownership and commute mode, assuming house prices affect the demand for the location. However, the demand for the residential location might influence house prices. For example, houses with good views to a particular beach might be desirable for households and therefore, would be more expensive than houses without this feature. We include some variables that determine the demand for a residential location, however, there might be some missing or unobserved variables. In this case, the utility would correlate with the unobserved variables. This correlation results in biased or inconsistent estimation of coefficient for house prices.

Using Instrumental Variables (IVs) to deal with the endogeneity is a common practice in transport studies (Börjesson et al., 2019; Awaworyi Churchill \& Smyth, 2019; Mulalic \& Rouwendal, 2020; Sun et al., 2019). IVs are variables that satisfy two assumptions: the IV correlates with the endogenous variable (instrument relevance), and the IV does not correlate with $U_{i j}$ (utility of a choice) and therefore does not correlate with the error term $\left(\varepsilon_{i j}\right)$ (Wooldridge, 2013).

There are two approaches to use IVs. In the "Instrumental Variable approach", instrumentalvariable estimation, or Two-Stage Least Square (2SLS), the endogenous variable is replaced by its predicted values from the first stage regression on the IVs (Antonakis et al., 2010). 
The "Control function" (CF) approach (Hausman, 1978; Heckman, 1978; Petrin \& Train, 2010), or “Two-Stage Residual Inclusion" (Terza et al., 2008) is the second approach, in which an endogenous variable remains in the model and the residual calculated from the first-stage regression is added to the main regression as a new variable. Results estimated by this method are statistically more consistent than the results of 2SLS (Terza et al., 2008) and, more robust to the underlying distributional assumptions of the model (Guevara \& Hess, 2019). In this research, we use the $\mathrm{CF}$ approach to mitigate endogeneity.

\subsection{Commute time}

For calculating travel time, we should ideally have a point associated with the home location of commuters. For confidentiality, we are unable to divulge the exact home locations. Therefore, we consider the MB centroid. Land Information New Zealand provides property address points as street addresses (Land Information New Zealand, 2016). We use the "mean centre" tool in ESRI ArcMap 10.6 to identify a centre for each MB based on the address points in that MB. The nearest address point in the MB to the mean centre is taken as a home location. centre to more accurately represent a home location. This process replicates the approach taken in Daglish et al. (2015).

We measure travel time using a multimodal spatial transport network for driving, cycling, walking, and PT. The original network is adapted based on Daglish et al. (2015). We updated the network to account for the latest changes. For each commute mode, the optimum route from home to work is defined as the route with the shortest travel time with that mode.

In the driving network, speed depends on the road hierarchy. Drivers may drive from 20 kilometers per hour $(\mathrm{km} / \mathrm{h}$ ) on some local roads (e.g. alleys) to $100 \mathrm{~km} / \mathrm{h}$ on state highways. Road restrictions such as one-way roads and roads that are not allowed for drivers (e.g. pedestrian shortcuts) are also accounted for in the optimal route finding.

The speed of walking and cycling depends on the slope of road segments. Walkers and cyclists move slower uphill. Cyclists are assumed to follow similar road rules to drivers. Road restrictions (e.g. one-way road restrictions and roads not allowed for pedestrians or cyclists) are considered in calculating travel time.

The network carefully considers traveling with Public Transport (PT). There are four types of public transport in the GWR (bus, train, ferry, and cable car). The bus network covers all bus 
lines that measure bus transit time (considering one-way routes) from each edge of the network, and the time passengers wait to board in bus and fare zones that each commuter passes through his/her journey to work. To calculate the waiting time, "entrance lines" are used. Daglish et al. (2015) define an entrance line as a line that connects the walking network (bus station on the walking network) to the bus network and for each bus line, stores waiting time and number of fare zones. We consider five minutes for a bus, seven for a train, 10 minutes for a ferry, and 2.5 minutes for the cable car as waiting time (Daglish et al., 2015). Waiting time can then be included in total travel time. Like the bus network, in train, cable car, and ferry networks we estimate travel times and costs. ${ }^{3}$ However, there are some extra restrictions (including restricting ferry routes to those available on working days). PT services and their frequency vary in a day. The focus of this research is on commuters (who usually commute to work early in the morning and return in the evening). Travel times are measured for the peak hours (between 7 a.m. to 9 a.m.) based on Google Transit Feed Specification (GTFS).

Moreover, a journey to work by PT is not simply boarding at home and disembarking at work. Commuters may have to walk or drive for several minutes to the closest Public Transport (PT) station, board in, possibly shift to other PT, and walk to the workplace. So, in addition to considering different modes, we consider their chain as a realistic approach toward commuting. In this research, traveling on PT requires a mixture of modes and is considered as Walk-PT or Drive-PT. At the final stage, travel time is a sum of walking and PT times for the former and the sum of walk, PT, and drive times for the latter.

\footnotetext{
${ }^{3}$ Cable car is a special type of PT in Wellington city, connecting Wellington CBD to the wellington Botanic Garden. For more information, see https://www.wellingtoncablecar.co.nz/English/home.html
} 


\title{
Chapter 3
}

\section{Home parking and commuting choices}

\begin{abstract}
In mobility research, most researchers focus on traffic flows, with little effort to explore the impact of home parking on commuting choices. We ask, "How does home parking quantity affect households' choices of car ownership and commute mode?" using data derived from the New Zealand Household Travel Survey between 2003 and 2017. Choices of residential location, car ownership and commute mode are interdependent. We consider residential location choice along with car ownership and commute mode to account for this interaction and give more realistic results. We mitigate the endogeneity in house prices using a Control Function approach. Commuting is a regional issue. Limiting work trips to a single city might not properly capture the whole picture of commuting. We study commuters who live and work anywhere in the Greater Wellington Region in New Zealand to give more comprehensive and realistic results. Commute length is measured as travel time instead of distance, as getting to work on-time is important for commuters. The time required to travel the distance from home to work varies by commute mode and traffic situation. Hence, it is more likely that commuters consider travel time than distance when deciding for commute mode and residential location.

We find home parking quantity has a strong and positive impact on the proclivity of households to have cars and drive to their work. Home parking is the most important factor households consider when shifting from no car to one car. High home parking supply in most of the GWR (partly due to minimum parking requirements) encourages multiple car ownership. More parking in residential areas encourages more car trips to work, meaning higher demand for parking downtown. These results imply the influence of residential parking on work parking and suggests considering parking at residential areas and business centres simultaneously for improving the effectiveness of parking policies.
\end{abstract}




\subsection{Introduction}

Commuting can be viewed either as making trips between home and work or as changing parking location (i.e. from parking at home to parking at the workplace and vice versa). The first approach has been dominating commuting studies (e.g. Beige \& Axhausen, 2017; Ding et al., 2017; He \& Zhao, 2017; Hu \& Schneider, 2017; Melo \& de Abreu e Silva, 2017; MorenoMonroy \& Posada, 2017; or Rüger et al., 2017). However, every trip ends at a destination (i.e. home or work) where commuters usually spend between $1 / 3$ to $1 / 2$ of their day, while their cars are parked. Commuting is a combination of flows (trips) and places (parking) because cars are most likely to stay in places rather than moving.

There is little literature on the relationship between commuting and parking. Within the short literature on parking, most studies focus on parking downtown (Amer \& Chow, 2017; Richard Arnott \& Rowse, 2009; Franco, 2017), however, parking at home is also important. Cars are usually parked at home longer than at work parking location. Most car trips begin and, eventually, end with a car parked at home. According to Shoup (2005), a parked car produces externalities that are not necessarily less than a car in motion. On-street parking in a residential area takes at least one lane from the street and slows down commuting. Off-street home parking usually takes some amount of land in a property and is often is a reason for a higher house price. Home parking increases house prices and motivates driving (Manville, 2013). More car trips add to car-related externalities (e.g. traffic congestion, environmental pollution) in downtown. Moreover, access to suitable home parking has usually been one of the factors that commuters consider in deciding where to live and how to commute (Guo \& Ren, 2013; Weinberger, 2012). Access to more carparks at home may also encourage households to have more cars and, consequently, to drive to work.

A free on-site home parking location (e.g. garage or driveway) is a guaranteed space for a car. This parking location is not affected by parking pricing and most research focuses on availability or quantity of parking (for example, Christiansen, Engebretsen et al., 2017a; Guo, 2013a). In this study, we provide empirical evidence of the impact of residential parking quantity on households' choices of car ownership and commute mode. This research extends the literature in two dimensions. First, in contrast to most parking studies, we consider households' choices of residential location. Commuting is a multi-dimensional issue and choices of residential location, car ownership, and commute mode are interdependent. For example, a household with multiple cars may choose to live in a suburb with plentiful parking 
locations, or a household living close to work may be willing to walk. By taking this broader view, we mitigate endogeneity between home parking and car ownership. Second, instead of limiting study area to a city or workplaces to a city centre, we study commuters that live and work anywhere in the Greater Wellington Region (GWR). The GWR includes various areas in terms of parking regulations and availability and urban spatial structure (e.g. population density). This setting contributes to consider commuting in a more comprehensive picture and give more realistic results for policy making.

Commuters value their travel time. The time that is taken to travel the distance from home to work varies depends on commute mode. Each mode may encounter some traffic or topographic restrictions (e.g. one way roads, slope) that influence its speed. Travel time is an important factor commuters consider in deciding mode and the way to work. We use travel time as a proxy for commute length. In calculating commute time, we consider road restrictions (e.g. one-way roads, not for cars), a mixture of services and modes when traveling by Public Transport (PT), and the slope of the road. Moreover, our study area is a region (Greater Wellington Region (GWR) in New Zealand) which includes areas with different types of home parking, from congested central suburbs in Wellington City (the main city), where home parking is limited, to sprawling suburbs with wide roads and much available parking, as well as rural areas.

\subsection{Literature}

Most residential parking studies concentrate on parking cost (e.g. Guerra \& Daziano, 2020, Ostermeijer et al. 2019, de Groote et al., 2016; Guo \& McDonnell, 2013; Seya et al., 2016). Parking pricing policies often target on-street parking that is limited by competition from neighbors. On-site home parking (e.g. garage or driveway) is a guaranteed parking space that is less likely to be affected by parking pricing policies and competition from neighbors. Research on off-street home parking features (e.g. quantity) and their influence on travel behavior is a small part of the home parking literature. Ou et al. (2018) estimate home parking ratio (number of home parking spaces per household) trends by province and the year the neighborhood is built for 31 province/region in China. They also estimate the value of home parking for each type of Plug-in Electric Vehicle (PEV) ownership. Home parking may have an electricity plug for charging PEVs, which, in their research, is an important factor affecting households' willingness to own PEVs. 
Guo (2013a) estimates the impact of residential parking supply on car ownership in New York City. In contrast to the dominant literature, which considers household's income and demographic characteristics as important factors affecting car ownership, he concludes that residential parking supply has a significant impact on car ownership.

Christiansen, Fearnley et al. (2017) study the relationship between access to different home parking types and car ownership and usage in Norway. They calculate the percentage of households with access to each home parking type and car ownership category. A strong correlation between access to home parking and car ownership is observed in their sample. However, endogeneity between home parking and car ownership remains unsolved.

Relatedly, Guo (2013b) focuses on parking convenience and its impact on driving in New York City. He defines parking convenience as parking "certainty" and parking "ease". Parking certainty refers to the probability of finding a parking space at a desired place and a desired time, and parking ease is the convenience of moving the car in and out of the parking place (Guo, 2013b). The percentage of households using each type of parking (garage, driveway, and on-street) and the average time of use for each type are measured. He finds that access to offstreet home parking encourages households to drive more often. Among households with access to both off-street and on-street parking, those who parked on-street tend to make more car trips.

Christiansen, Engebretsen et al. (2017) study the influence of home parking availability on the propensity to drive in Norway, controlling for demographics, urban spatial structure, and travel features (e.g. travel distance). They find access to parking at home a motivation for driving, and distance from home to residential parking is a disincentive to choose a car. They consider trips with any purpose in studying the impact of home parking. Therefore, making a conclusion on the impact of home parking on commuters is difficult.

Weinberger (2012) researches home parking in relation to the choices of owning a car and driving for commuters in New York City working in the Manhattan centre. She finds a positive relationship between on-site home parking availability and the probability of owning a car and commuting by car.

In this paper, we consider a more comprehensive estimation of the impact of home parking on car ownership, considering choices of residential location along with commute mode and car ownership. Commuters choose their commute mode and residential location, as well as car ownership. These choices impact each other. A household living within walking distance of work may prefer to walk and have no car, whereas a household with a high number of cars may 
choose to live in a suburb with a high residential parking supply. The number of household cars influences their choices of where to live. There is an issue of "reverse causality" which is a source of endogeneity. This issue arises from excluding residential location from households' choices which is common in home parking literature (Christiansen, Fearnley et al., 2017; Guo, 2013a; Weinberger, 2012).

Moreover, commuting is a regional issue. Many people commute to a main city from nearby towns or vice versa. Hence, focusing on a single city or limiting workplaces to the city centre might not properly show the travel behavior of commuters. We study commuters living in a region (the GWR) to provide more comprehensive and realistic results. Commuters with similar distances to work may have different travel times due to different road and traffic restrictions. Hence, commute time is more accurate than travel distance in terms of commuters' perception of commute length. We calculate travel time taking into account road and traffic restrictions, along with a mixture of modes and services for PT.

\subsection{Methodology}

We use a CL model based on Daglish et al. (2015) to model home parking while accounting for residential location, car ownership, and commute mode choices. The model basis and commuting choices are explained in section 2.4. We face the issue of endogeneity in house prices as described in section 2.4.4. For each MB, we calculate the median house price. We then construct an IV by averaging all neighboring MBs median price. As MBs are reasonably small in urban areas, they have relatively similar features with their neighboring MBs. This IV is a good predictor of house prices, which also does not correlate with the error term. House prices of nearby MBs are not important for the individuals when choosing a house in a MB. We use a Control Function (CF) approach (Petrin \& Train, 2010) to regress house prices on average neighboring house prices and calculate residuals as

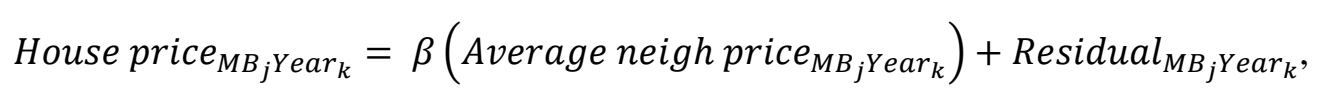

in which, House price $_{M B_{j} Y e a r_{k}}$ is house prices in $M B_{j}$ and year, , Average neigh price $_{M B_{j} Y e a r_{k}}$ is average house price of neighboring MBs for $M B_{j}$ and year ${ }_{k}$, and $\operatorname{Residual}_{M B_{j} \text { Year }_{k}}$ is part of

the price that is not explained by average neighboring prices. Hence, Residual $_{M B_{j} Y_{e a r}}$ represents unobserved features of $M B_{j}$ in year $k$. We calculate this variable from Equation (3.1) and add it to the main regression as an explanatory variable to control for unobserved variables. 


\subsection{Data and study area}

In this paper, we study 1,056 households from the NZHTS who live and work in the GWR as explained in section 2.4.1. Wellington City, as the main city of the region, has the highest population density (Figure 3.1). In this city, limited space is available for off-street residential parking, and on-street parking is restricted (including time limits and supply). Residential areas in Wellington CBD are mostly apartments, and on-street parking has a two-hour parking limit. Surrounding suburbs contain mostly houses, with better access to off-street parking, but coupon or residents' on-street parking applies a daily or yearly charge, respectively. Beyond the inner suburbs are low-density neighborhoods with plenty of space available for parking; mostly free of charge and without time limit. This parking condition is also observed in most residential areas outside Wellington City.

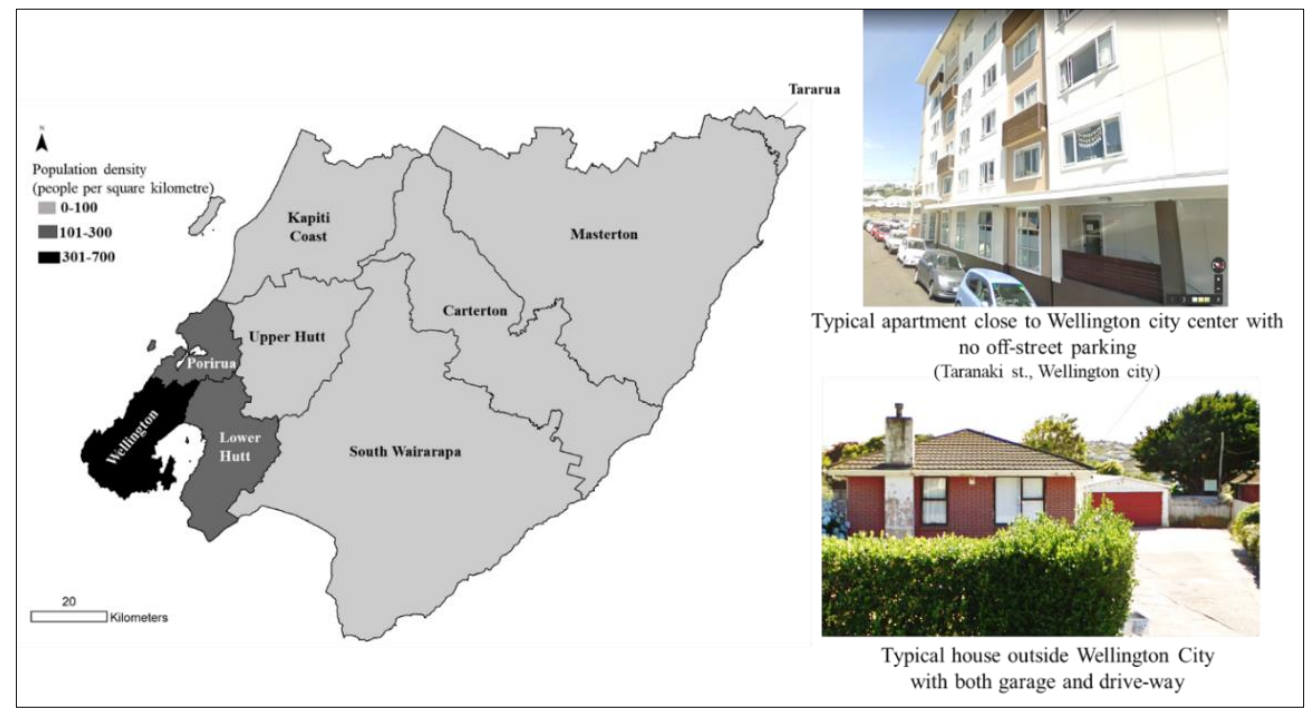

Figure 3.1. Population density in the GWR

(Source of photos: Google street view. Source of the map: Statistics New Zealand, 2020)

Table 3.1. Variables used in chapter 3

\begin{tabular}{|c|c|c|}
\hline Variable & Definition & Source \\
\hline Car ownership & $\begin{array}{l}\text { Number of cars in household (dummy for no car, one car, two cars, and three } \\
\text { or more cars) }\end{array}$ & NZHTS \\
\hline Commute mode & $\begin{array}{l}\text { Commute mode of the head of household in a journey to work. We consider } \\
\text { dummy for driving as the most relevant mode for home parking. }\end{array}$ & NZHTS \\
\hline D_City & Household lives in an MB in Wellington City & NZHTS \\
\hline D_City $\times$ Parking & $\begin{array}{l}\text { Household lives in Wellington City * percentage of households with off-street } \\
\text { parking in a MB }\end{array}$ & $\begin{array}{l}\text { WCC } \\
\text { NZHTS }\end{array}$ \\
\hline
\end{tabular}


Table 3.1. continued

\begin{tabular}{|c|c|c|}
\hline Variable & Definition & Source \\
\hline Commute time & $\begin{array}{l}\text { Travel time in a journey from home to work for each mode } \\
\text { (hour) }\end{array}$ & See section 2.5 \\
\hline Work_CBD & Head of household working in Wellington CBD (dummy) & NZHTS \\
\hline N_Full-time & Number of full-time workers in household & NZHTS \\
\hline HH_Child & Household with children (dummy) & NZHTS \\
\hline N_Children & Number of children in household & NZHTS \\
\hline Income & 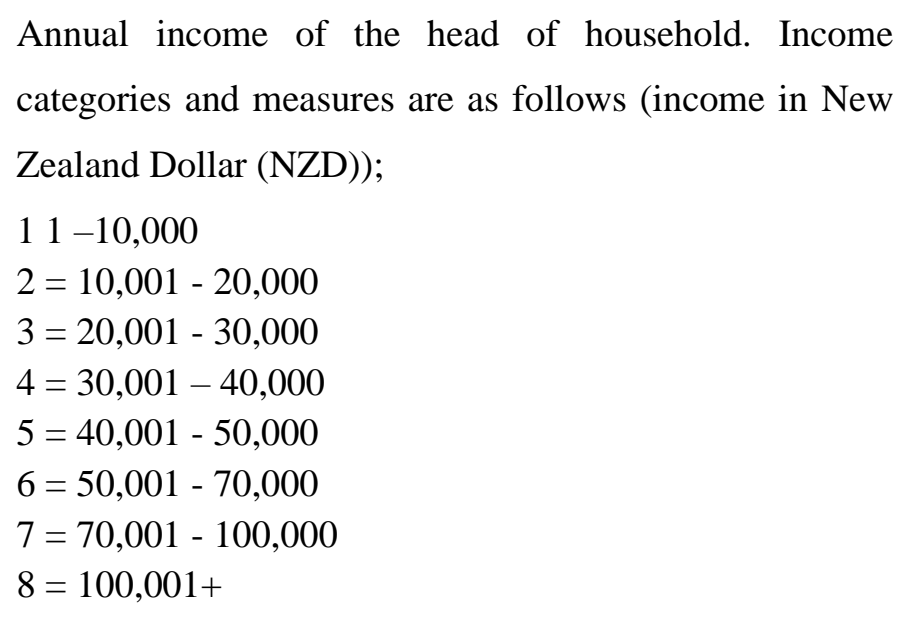 & NZHTS \\
\hline D_Female & Household with female head (dummy) & NZHTS \\
\hline D_MāoriPacific & Household with Māori or pacific head (dummy) & NZHTS \\
\hline House price & Median house price in MB (in NZD100,000) & Homes.co.nz \\
\hline North-Facing & $\begin{array}{l}\text { Percentage of residential land in a MB that faces North, } \\
\text { North-east or North-west }\end{array}$ & $\begin{array}{l}\text { Digital Elevation Model } \\
\text { (DEM) is adopted from the } \\
\text { University of Otago - National } \\
\text { School of Surveying (2017) }\end{array}$ \\
\hline N_Bedroom & Average number of bedrooms per dwelling in MB & Statistics New Zealand (2013) \\
\hline Drive time_Shops & $\begin{array}{l}\text { Driving time from } \mathrm{MB} \text { centroid to the centre of } \\
\text { neighborhood (minutes) }\end{array}$ & $\begin{array}{l}\text { Calculations based on (Daglish } \\
\text { et al., 2015) }\end{array}$ \\
\hline Floor area & $\begin{array}{l}\text { Median of floor area (area of ground level) of residential } \\
\text { properties in each MB (100 Square meters) }\end{array}$ & $\begin{array}{l}\text { Land Information New } \\
\text { Zealand (2020) }\end{array}$ \\
\hline N_Dwellings & $\begin{array}{l}\text { Number of occupied private dwellings in MB (unit=100 } \\
\text { dwellings) }\end{array}$ & Statistics New Zealand (2013) \\
\hline People per dwelling & $\begin{array}{l}\text { Average number of usual residents in each occupied } \\
\text { private dwelling in } \mathrm{MB}\end{array}$ & Statistics New Zealand (2013) \\
\hline
\end{tabular}

Table 3.1 details of variables used in this research. (Further description of some variables in

Sections 3.4.1, 3.4.2, and 3.4.3). 


\subsubsection{Home parking quantity}

Home parking is a feature of the built environment. Since residential location is represented by a $\mathrm{MB}$, home parking quantity is also measured at the MB scale as the percentage of households with off-street parking in each MB. In the logit model, we divide the home parking quantity by 100 to have the same scale as other variables. The presence of an off-street parking location at each dwelling (binary) is provided by Wellington City Council. In terms of home parking, the GWR could be divided into two distinct areas. Wellington City, as the main city in the region, has the most congested neighborhoods, with a high concentration of workplaces. There are restrictions on the residential parking supply. Outside of Wellington City, mostly low-density residential areas dominate, where almost all houses have a garage or driveway with considerably less competition for on-street parking, which is free of charge. Consequently, we include a dummy variable indicating whether a household lives in or outside Wellington City. We interact this dummy variable with our measure of parking quantity.

\subsubsection{Market value of houses in each MB}

Market value is an important factor in commuters' residential choice. To avoid unrealistically cheap or expensive houses, we focus on a median value. Few houses are sold in each MB in a year. Thus, the median sale price is not a good measure for all properties in a MB. Each property has a Ratable Value (RV) determined by a city or district council based on selling prices of similar properties in the same neighborhood. We use the following logic to calculate the market value of houses in an MB. The ratio of median sale price over median RV of sold houses in each MB and for each year gives an idea of the difference between market value and $\mathrm{RV}$. Then, we multiply this ratio by the median RV of that MB for that year to calculate our measure of market value. We obtain our dataset, consisting of median RV, median sale prices, and median RV of sold houses in each MB and each year for all of the GWR from 2003 to 2017 from homes.co.nz.

\subsubsection{Number of dwelling in MB and the number of people in dwelling}

The number of occupied private dwellings in a MB and the number of usual residents in a MB are provided by Statistics New Zealand (2013). The number of people per dwelling is more accurate than population density because it excludes non-residential areas. Moreover, there are some cases where open areas without residential use (e.g. farms and undeveloped land) are classified as residential areas. Our measure excludes these areas. 


\subsection{Summary statistics}

Table 3.2 details summary statistics for household heads in our sample. Having a car and driving is a popular choice among commuters. Most households $(81.6 \%)$ have one or two cars, and $67 \%$ drive to work. Less than a quarter of commuters (18.6\%) take PT.

Table 3.2. Summary statistics for household heads

\begin{tabular}{|c|c|c|c|c|c|}
\hline Variable & Mean & S.D. & Minimum & Maximum & Number of observations \\
\hline No car (dummy) & 0.04 & 0.19 & 0 & 1 & 1056 \\
\hline One car (dummy) & 0.41 & 0.49 & 0 & 1 & 1056 \\
\hline Two cars (dummy) & 0.41 & 0.49 & 0 & 1 & 1056 \\
\hline Three or more cars (dummy) & 0.14 & 0.35 & 0 & 1 & 1056 \\
\hline Drive (dummy) & 0.67 & 0.47 & 0 & 1 & 1056 \\
\hline Carpool (dummy) & 0.08 & 0.27 & 0 & 1 & 1056 \\
\hline PT (dummy) & 0.19 & 0.39 & 0 & 1 & 1056 \\
\hline AT (dummy) & 0.07 & 0.26 & 0 & 1 & 1056 \\
\hline D_City & 0.39 & 0.49 & 0 & 1 & 1056 \\
\hline Parking & 94.47 & 13.78 & 10 & 100 & 1053 \\
\hline Driving time & 0.48 & 0.41 & 0.01 & 2.18 & 1056 \\
\hline PT time & 0.71 & 0.42 & 0.00 & 6.22 & 1056 \\
\hline AT time & 1.17 & 0.79 & 0.00 & 7.49 & 1056 \\
\hline Income & 5.19 & 1.97 & 0 & 8 & 990 \\
\hline N_Full-time & 1.41 & 0.70 & 0 & 4 & 1056 \\
\hline Work_CBD & 0.41 & 0.49 & 0 & 1 & 1056 \\
\hline D_Female & 0.50 & 0.50 & 0 & 1 & 1056 \\
\hline D_MāoriPacific & 0.10 & 0.30 & 0 & 1 & 1056 \\
\hline HH_Child & 0.37 & 0.48 & 0 & 1 & 1056 \\
\hline N_Children & 0.71 & 1.01 & 0 & 5 & 1056 \\
\hline House price & 3.84 & 1.49 & 0.98 & 10.86 & 783 \\
\hline North-Facing & 41.34 & 33.06 & 0.00 & 100.00 & 1056 \\
\hline N_Bedroom & 3.10 & 0.40 & 1.10 & 4.50 & 1051 \\
\hline Drive time_Shops & 3.57 & 2.96 & 0.07 & 28.81 & 1056 \\
\hline Floor area & 1.46 & 0.39 & 0.62 & 2.98 & 1052 \\
\hline N_Dwellings & 0.55 & 0.27 & 0.00 & 1.14 & 931 \\
\hline People per dwelling & 0.20 & 0.68 & 0 & 2.94 & 1056 \\
\hline
\end{tabular}


Outside Wellington City, the GWR is dominated by residential suburbs where almost all houses have off-street parking. High home parking supply in these areas makes a considerable difference in car ownership and commute mode. Two or more cars are noticeably more common outside Wellington City (Figure 3.2).

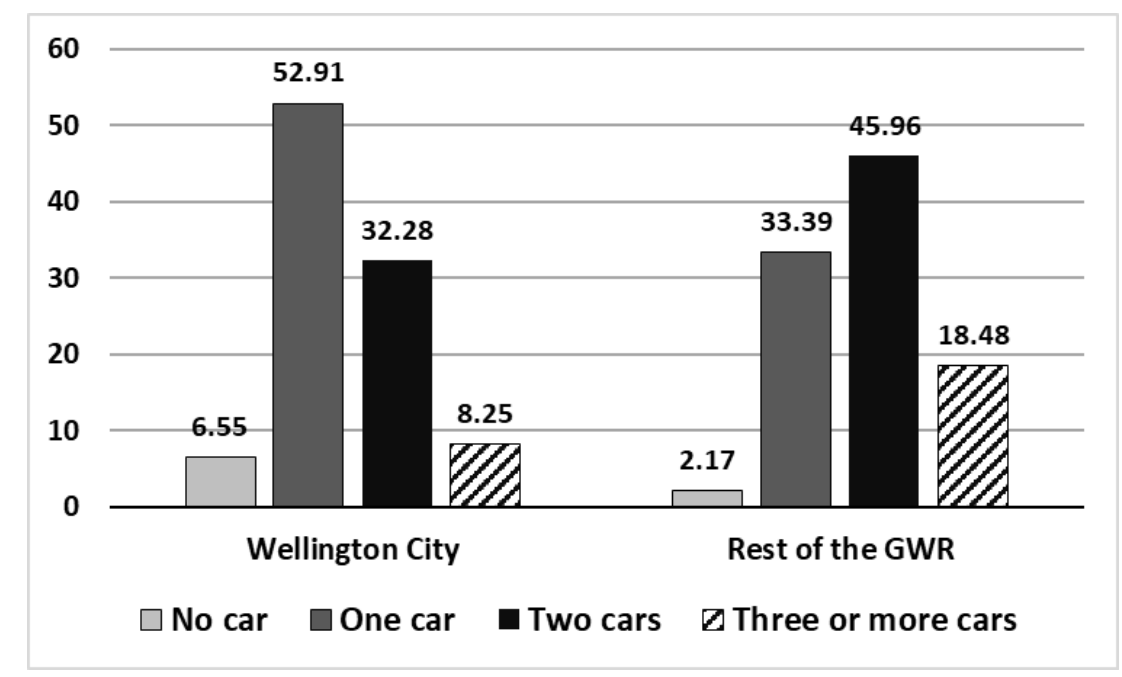

Figure 3.2. Households in each location and car ownership category (\%)

(Source: NZHTS)

Driving is more popular outside Wellington City. Almost three quarters (72.5\%) of households living outside the city drive to work.

In Wellington City, home parking is less in central areas (i.e. CBD and the surrounding coupon parking zone) than outside this area. On average, $66.9 \%$ of households in our sample in central areas have home parking. This share is $82.8 \%$ of households who live outside the central area in Wellington City where on-street parking is mostly free of charge. Two or more cars is the choice of $43.6 \%$ of households outside the central areas in the city, while $89.5 \%$ of people in central areas have one car maximum (Table 3.3).

Table 3.3. Households in central areas and outside in Wellington City (\%)

\begin{tabular}{lccccc}
\hline & No car & One car & Two cars & Three or more cars & Total \\
\hline Wellington City Central areas & 28.95 & 60.53 & 7.89 & 2.63 & 100 \\
Outside in Wellington City & 4.28 & 52.14 & 34.76 & 8.82 & 100 \\
\hline
\end{tabular}

(Source: NZHTS)

Outside the central areas in Wellington City, $61.8 \%$ of households in our sample drive to work, which is almost four times greater than the share of drivers in central areas $(15.8 \%)$.

In Wellington City, 76\% of commuters live in $\mathrm{MBs}$ where more than three quarters of households have home parking. Two or more cars is observed for $45 \%$ of these households. 
The number of commuters in MBs with more than $75 \%$ home parking with two or more cars is more than seven times the number of multiple car owners in MBs with 50\% to $75 \%$ parking (Figure 3.3).

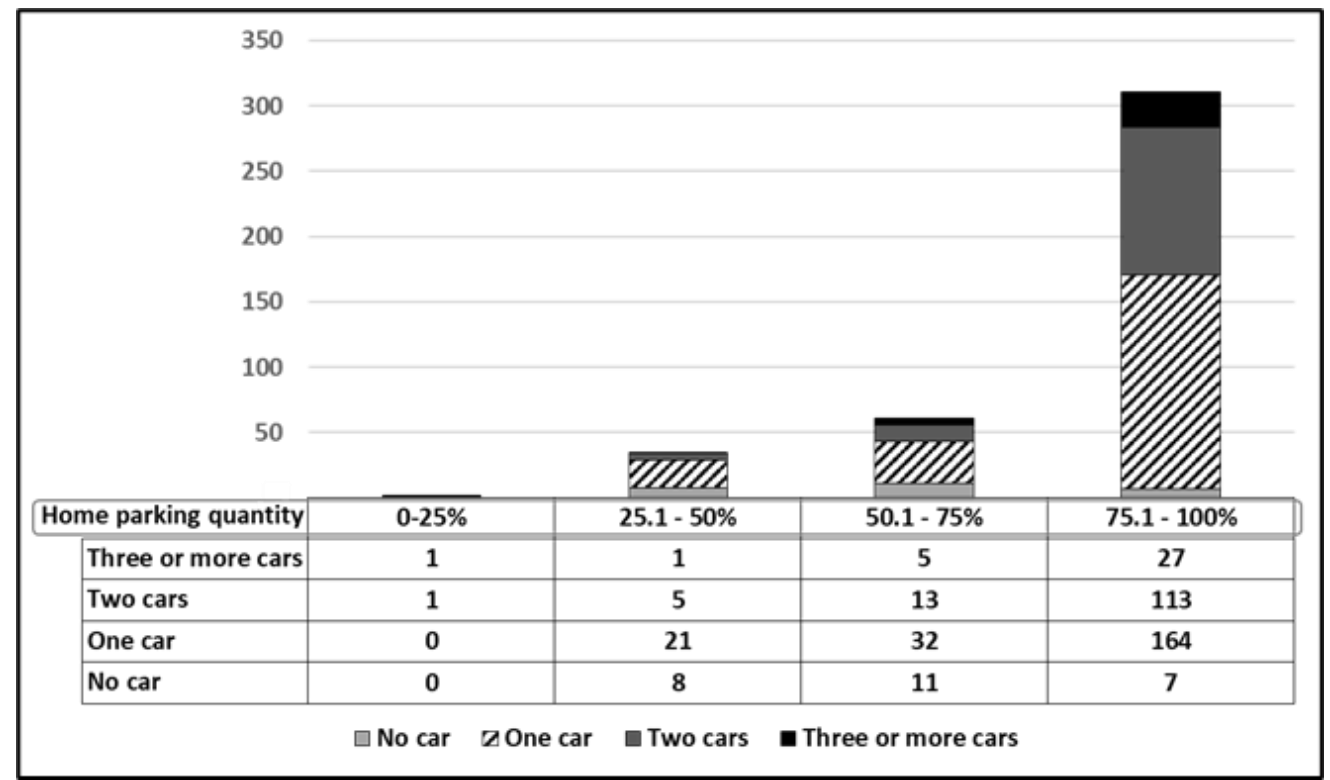

Figure 3.3. Number of households within home parking quantity categories by number of cars per household in Wellington City (Source: NZHTS and WCC)

MBs with the highest home parking supply $(75.1 \%-100 \%)$ are the origin of $85.6 \%$ of car trips (Figure 3.4).

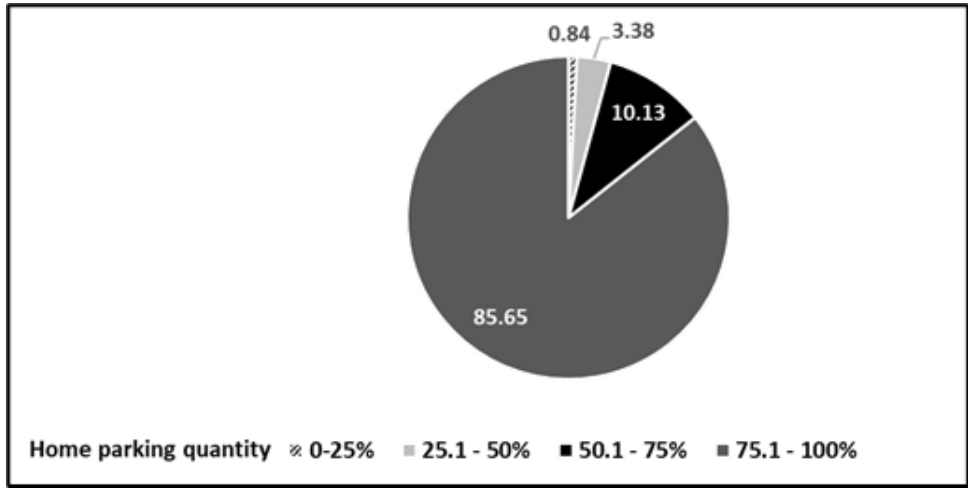

Figure 3.4. Drivers within home parking quantity categories in Wellington City (\%) (Source: NZHTS and WCC)

The compact Wellington CBD is the destination of $42 \%$ of commuters from across the region. Due to parking restrictions in the CBD (e.g. higher parking costs or parking competition) driving is not a popular commute mode (41.7\% of CBD workers). A majority of households (56.6\%) whose head works in Wellington CBD have no or one car (Table 3.4). 
Table 3.4. Share of Wellington CBD workers in each car ownership category (\%)

\begin{tabular}{cccccc}
\hline & No car & One car & Two cars & Three or more cars & Total \\
\hline $\begin{array}{c}\text { Works in Wellington } \\
\text { CBD }\end{array}$ & 6.19 & 50.46 & 33.94 & 9.4 & 100 \\
\hline
\end{tabular}

(Source: NZHTS)

All commuters are considered in calculating summary statistics for commute time for each mode. For example, average AT time is the average AT time for all commuters and not only AT users. On average, driving is the fastest mode in the GWR, followed by PT.

An average household head earns NZD40,000 to NZD50,000 per year. Share of households with no car is higher among households that earn below average income and share of three or more car owners is higher among households earn above average income (Table 3.5). There is not a noticeable difference in terms of share of drivers below and above average income $(64.7 \%$ of household with heads above the average income drive, while this share is $67.8 \%$ for household with heads below average income). Driving is slightly more common among households below average income.

Table 3.5. Share of households in each income and car ownership category (\%)

\begin{tabular}{lccccc}
\hline Income & No car & One car & Two cars & Three or more cars & Total \\
\hline 0 - NZD 20,000 & 6.61 & 42.98 & 39.67 & 10.74 & 100 \\
NZD20,001 - NZD50,000 & 5.59 & 43.09 & 38.56 & 12.77 & 100 \\
NZD50,001 - NZD100,000 & 2.43 & 42.7 & 38.38 & 16.49 & 100 \\
NZD100,000+ & 0.00 & 32.52 & 52.03 & 15.45 & 100 \\
\hline
\end{tabular}

(Source: NZHTS)

In our sample, more full-time workers in a household indicates higher car ownership (Table 3.6). Many households with no or one full-time worker have at most one car $(68 \%$ of households without a full-time worker and $54 \%$ of households with one full-time worker). In households without a full-time worker, share of one car owners $(61.3 \%)$ is noticeably higher than the share of households without a car (6.7\%), indicating a high preference for car ownership in the GWR. Owning multiple cars is a popular choice for households with more than one full-time worker (69.4\% of these households).

Table 3.6. Share of households in each category of number of full-time workers (\%)

\begin{tabular}{lccccc}
\hline Number of full-time workers & No car & One car & Two cars & Three or more cars & Total \\
\hline No full-time worker & 6.67 & 61.33 & 25.33 & 6.67 & 100 \\
One full-time worker & 5.51 & 48.48 & 36.69 & 9.32 & 100 \\
Two or more full-time workers & 1.54 & 29.01 & 47.69 & 21.76 & 100 \\
\hline
\end{tabular}

(Source: NZHTS) 
Most households with one child (60\%) have two or more cars. Many (69.3\%) of households with more than one child have multiple cars. Households with children are also responsible for making more car trips. A high share of driving is observed for households with children (74\%). This high share of drivers and multiple-car owners is possibly a reason that $92.8 \%$ of households with children live in areas where more than $75 \%$ of houses have on-site parking.

Table 3.7. Households with children by each home parking quantity category (\%)

\begin{tabular}{llllll} 
& $0-25 \%$ & $25.1-50 \%$ & $50.1-75 \%$ & $75.1-100 \%$ & Total \\
\hline Households with Children & 0 & 2.58 & 4.64 & 92.78 & 100 \\
\hline
\end{tabular}

(Source: NZHTS and WCC)

We do not observe a noticeable difference in terms of the share of car ownership between male and female commuters (Table 3.7). The share of drivers is $66.7 \%$ for female commuters and $66.6 \%$ for male commuters.

Table 3.8. Share of households with male and female head (\%)

\begin{tabular}{lccccc} 
& No car & One car & Two cars & Three or more cars & Total \\
\hline Female & 3.61 & 42.97 & 39.16 & 14.26 & 100 \\
Male & 4.15 & 39.06 & 42.08 & 14.72 & 100 \\
\hline
\end{tabular}

(Source: NZHTS)

On average, a household lives in a MB where the median house price is NZD383,924.5. This is the average house price across the survey period (2003 to 2017). In Wellington City, households who live in suburbs where at least three quarters of households have home parking, pay NZD32,360.50 more. Households who live in Wellington CBD or the surrounding suburbs (central suburbs) to minimize their commute time and enjoy a central location pay NZD646,061.4 on average. In the southern hemisphere, living in a North-facing house is desirable. An average commuter lives in MBs with $41.3 \%$ North-facing residential land. Households above this average pay NZD16,567.6 more than households living in MBs at or below the average. Typically, households live in big houses with three bedrooms and less than four minutes (3.6 minutes) drive to the neighborhood's shopping centre. Average walking and cycling speed in our commuting network are calculated as $4.7(\mathrm{~km} / \mathrm{h})$ and $19.1(\mathrm{~km} / \mathrm{h})$ respectively. Assuming that drivers drive $30 \mathrm{~km} / \mathrm{h}$ in local roads to access local amenities, an average commuter lives 22.9 minutes walking or 5.6 minutes cycling to the centre of neighborhood. 
Table 3.8 details summary statistics for MBs in the GWR. Wellington City includes $38 \%$ of MBs. Home parking quantity in Wellington City varies considerably among MBs. Residential blocks in the CBD are dominated by apartments where, on average, $57.8 \%$ have parking on the property. This proportion rises to $60.4 \%$ in the suburbs surrounding the CBD (coupon parking zone) and is $81.4 \%$ for the rest of the city.

Table 3.9. Summary statistics for MBs in the GWR (house prices are in NZD100,000)

\begin{tabular}{|c|c|c|c|c|c|}
\hline Variable & Mean & S.D. & Minimum & Maximum & Number of observations \\
\hline D_City & 0.38 & 0.48 & 0 & 1 & 5380 \\
\hline Parking & 92.40 & 17.34 & 0 & 100 & 5189 \\
\hline Drive time_Shops & 4.46 & 6.50 & 0.01 & 134.23 & 5380 \\
\hline N_dwellings & 0.35 & 0.22 & 0 & 3.03 & 4721 \\
\hline N_Bedroom & 3.06 & 0.54 & 1 & 8.5 & 4812 \\
\hline Floor area & 1.50 & 1.66 & 0.14 & 81.84 & 5380 \\
\hline People per dwelling & 0.19 & 0.67 & 0 & 6.30 & 5380 \\
\hline North-Facing & 34.08 & 33.14 & 0 & 100.00 & 5380 \\
\hline House price (2003) & 2.59 & 1.43 & 0.06 & 23.86 & 3192 \\
\hline House price (2004) & 2.94 & 1.60 & 0.19 & 25.63 & 3184 \\
\hline House price (2005) & 3.29 & 1.67 & 0.31 & 20.53 & 3189 \\
\hline House price (2006) & 3.69 & 1.84 & 0.10 & 40.14 & 3171 \\
\hline House price (2007) & 4.16 & 1.90 & 0.43 & 23.19 & 3098 \\
\hline House price (2008) & 4.08 & 1.80 & 0.29 & 25.27 & 2556 \\
\hline House price (2009) & 4.06 & 1.82 & 0.40 & 25.62 & 2753 \\
\hline House price (2010) & 4.21 & 1.93 & 0.53 & 29.19 & 2592 \\
\hline House price (2011) & 4.13 & 1.79 & 0.43 & 18.95 & 2648 \\
\hline House price (2012) & 4.20 & 1.87 & 0.18 & 28.66 & 2841 \\
\hline House price (2013) & 4.30 & 1.86 & 0.43 & 17.65 & 2845 \\
\hline House price (2014) & 4.37 & 1.97 & 0.58 & 22.00 & 2728 \\
\hline House price (2015) & 4.52 & 2.10 & 0.11 & 27.03 & 2932 \\
\hline House price (2016) & 5.31 & 2.46 & 0.59 & 25.90 & 2912 \\
\hline House price (2017) & 6.03 & 2.61 & 0.84 & 24.77 & 2719 \\
\hline
\end{tabular}

There is a trade-off between home parking and commute time savings in Wellington City. Wellington CBD includes most workplaces in the GWR. Closer to the CBD, households are less likely to have a high parking supply. Households outside the CBD, mostly in spacious 
suburbs outside the coupon parking zone, have more parking at home but are farther from work (Figure 3.5).

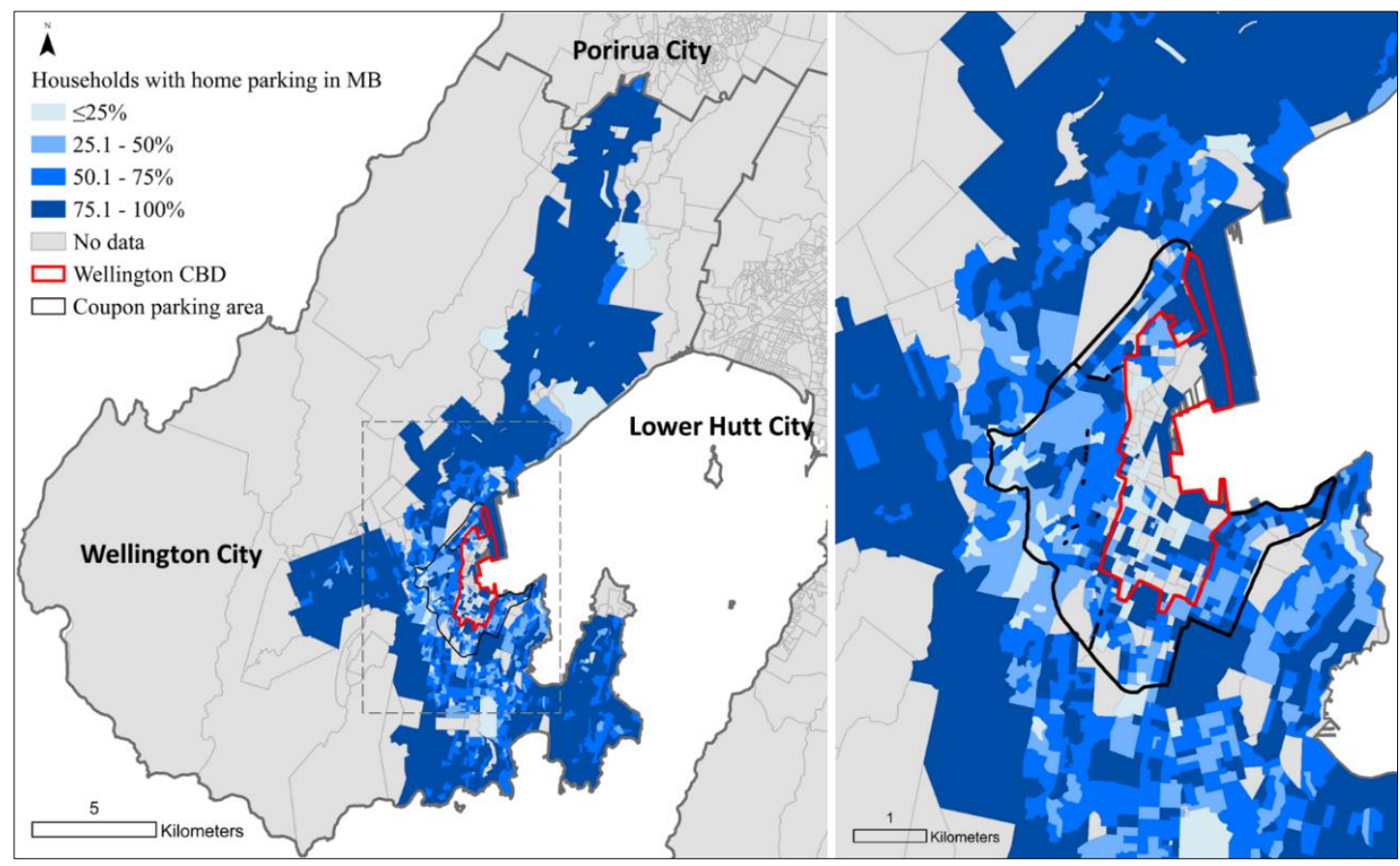

Figure 3.5. Home parking quantity in Wellington City (Source of home parking quantity: WCC and NZHTS)

House prices are higher in Wellington City, particularly, in suburbs close to the CBD (Figure 3.6).

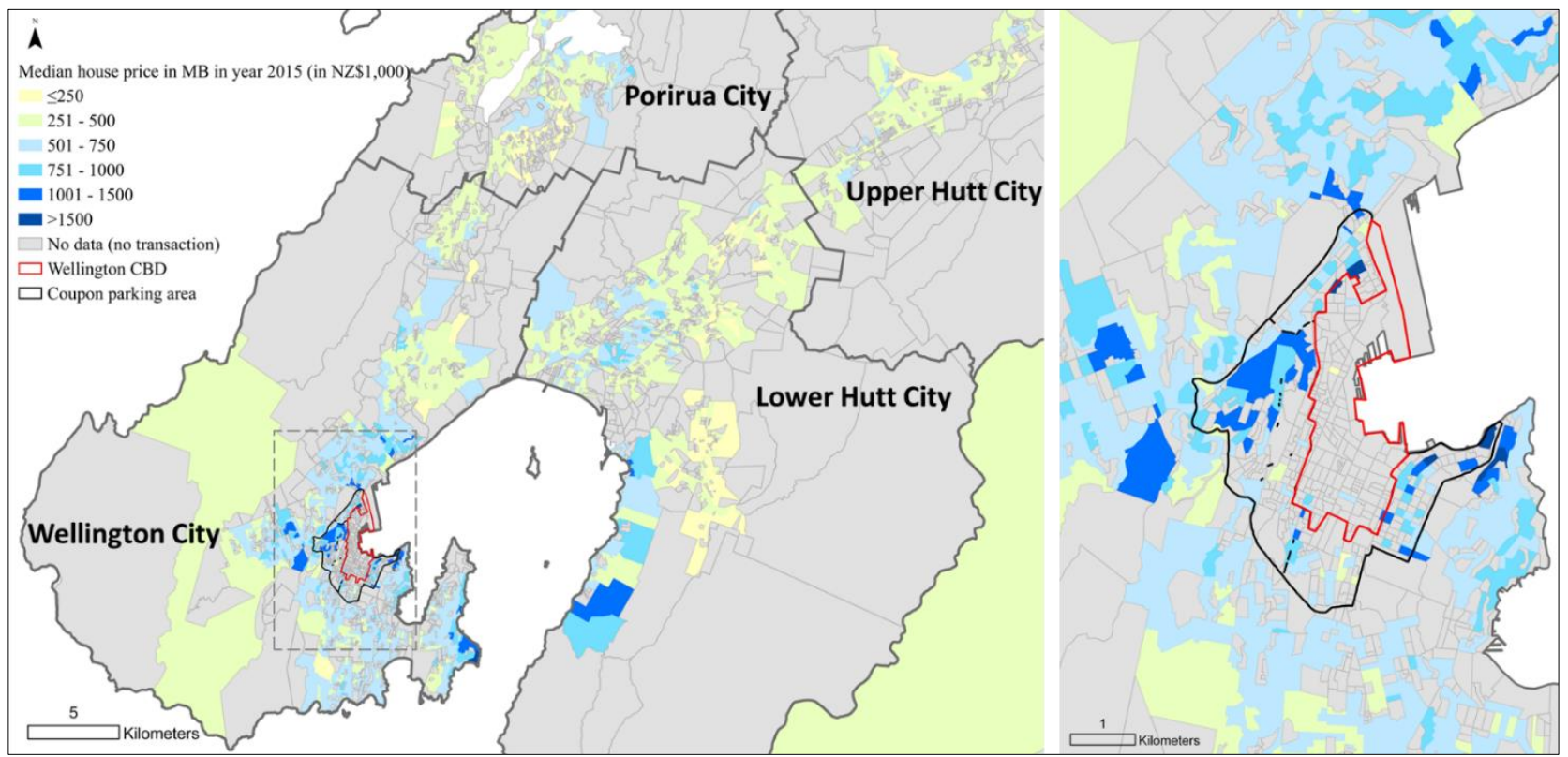

Figure 3.6. Median house prices in NZD1000 by MB in main urban areas in the GWR (Source of house price: Homes.co.nz) 
On average, there are 34.6 dwellings in a MB (or 30 dwellings as the median). Eighty one percent of MBs with more than an average number of dwellings are in urban areas (i.e. Wellington City, Porirua City, Lower Hutt City, and Upper Hutt City).

\subsection{Results}

Table 3.9 shows our Conditional Logit (CL) results. Households in Wellington City have fewer cars than households in other council areas. More than two cars is generally not a popular choice in the GWR. We find home parking a significant motivation for car ownership. Our estimates for the impact of home parking quantity on car ownership are bigger than the estimates reported in relevant literature (Christiansen, Fearnley et al., 2017; Guo, 2013a; Weinberger, 2012). The exponential of the coefficient of a variable is the change in the odds ratio given a one-unit change in the variable. ${ }^{4} \mathrm{~A} 10 \%$ ( 0.1 unit) increase in home parking quantity increases the odds ratio of owning one car, two cars and three or more cars by $41 \%$ $\left(e^{3.46 \times 0.1}=1.41\right), 84 \%\left(e^{6.10 \times 0.1}=1.84\right)$, and $38 \%\left(e^{3.20 \times 0.1}=1.38\right)$ respectively. The two statistically significant determinants for owning one car are home parking and living in Wellington City (which is a measure for the home parking difference between the city and outside). This indicates that access to home parking is more important than many other factors for owning a car.

In line with the literature (Yang et al., 2017; Nolan, 2010; Matas \& Raymond, 2008; Yagi \& Managi, 2016; Ha et al., 2019; Ritter \& Vance, 2013), we find income is an important determinant of car ownership. However, home parking has the greatest influence on vehicle ownership. Income is not a significant factor for owning one car, and the impact of home parking on having two cars is more than twice the impact of income.

\footnotetext{
${ }^{4}$ The odds ratio is the ratio of probability of making a choice over probability of making other choices. The odds ratio of choice $j$ for person $i\left(\frac{P_{i j}}{1-P_{i j}}\right)$ is calculated as $\frac{P_{i j}}{1-P_{i j}}=e^{\beta_{1} X_{1 i j}+\beta_{2} X_{2 i j}+\cdots+\beta_{n} X_{n i j}}$, or $\frac{P_{i j}}{1-P_{i j}}=$ $e^{\beta_{1} X_{1 i j}} \times e^{\beta_{2} X_{2 i j}} \times \ldots \times e^{\beta_{n} X_{n i j}}$. If $X_{1 i j}$ increases by one unit, the new odds ratio $\left(\frac{Q_{i j}}{1-Q_{i j}}\right)$ is calculated as $\frac{Q_{i j}}{1-Q_{i j}}$ $=e^{\left(\beta_{1} X_{1 i j}+1\right)} \times e^{\beta_{2} X_{2 i j}} \times \ldots \times e^{\beta_{n} X_{n i j}}$, or $\frac{Q_{i j}}{1-Q_{i j}}=e^{\beta_{1} X_{1 i j}} \times e^{\beta_{1}} \times e^{\beta_{2} X_{2 i j}} \times \ldots \times e^{\beta_{n} X_{n i j}}$. Therefore, $\frac{Q_{i j}}{1-Q_{i j}}=\frac{P_{i j}}{1-P_{i j}} \times e^{\beta_{1}}$. The odds ratio is multiplied by $e^{\beta_{1}}$.
} 
Table 3.10. Logit results for car ownership, commute mode and residential location choice (Parameter estimate (t-test))

\begin{tabular}{|c|c|c|c|c|}
\hline Variables & One car & Two cars & Three or more cars & Drive \\
\hline Constants & $0.88(1.27)$ & $-0.55(-0.76)$ & $-3.49(-3.95)^{* *}$ & $1.56(4.01)^{* *}$ \\
\hline D_City & $-3.13(-3.65)^{* *}$ & $-6.26(-5.54)^{* *}$ & $-3.80(-3.16)^{* *}$ & $-3.11(-4.38)^{* *}$ \\
\hline D_City $\times$ Parking & $3.46(3.33)^{* *}$ & $6.10(4.69)^{* *}$ & $3.20(2.28)^{*}$ & $3.10(3.99)^{* *}$ \\
\hline Income & $1.51(1.69)$ & $2.51(2.74)^{* *}$ & $2.77(2.70)^{* *}$ & $1.41(3.01)^{* *}$ \\
\hline N_Full-time & $0.46(1.44)$ & $1.12(3.42)^{* *}$ & $1.87(5.18)^{* *}$ & $0.00(-0.02)$ \\
\hline N_Children & $0.41(1.31)$ & $0.80(2.56)^{*}$ & $0.96(2.95)^{* *}$ & \\
\hline D_Female & $0.34(0.81)$ & $0.23(0.54)$ & $0.61(1.27)$ & $-0.01(-0.05)$ \\
\hline D_MāoriPacific & $-0.64(-1.24)$ & $-1.01(-1.85)$ & $-0.77(-1.23)$ & $-0.49(-1.65)$ \\
\hline Work_CBD & & & & $-2.09(-10.07)^{* *}$ \\
\hline HH_Child & & & & $0.64(3.19)^{* *}$ \\
\hline & & Residential location & & Residential location \\
\hline & & choice & & choice \\
\hline \multicolumn{2}{|l|}{ Log (House price) } & $-1.64(-5.89)^{* * *}$ & Income $\times$ N_Dwellings & $-0.74(-1.18)$ \\
\hline \multicolumn{2}{|c|}{ Income $\times \log ($ House price $)$} & $2.07(4.99)^{* *}$ & People per dwelling & $3.56(2.58)^{* *}$ \\
\hline \multicolumn{2}{|c|}{ Log (Commute time) } & $-0.41(-3.20)^{* *}$ & Income $\times$ People per dwelling & $-7.26(-3.22)^{* *}$ \\
\hline \multicolumn{2}{|c|}{ Income $\times \log ($ Commute time $)$} & $0.31(1.63)$ & Floor area & $0.29(3.69)^{* *}$ \\
\hline \multicolumn{2}{|l|}{ North-Facing } & $1.02(8.04)^{* *}$ & D_City & $4.80(6.28)^{* *}$ \\
\hline \multicolumn{2}{|c|}{ N_Bedroom $\times$ N_Children } & $0.18(2.21)^{*}$ & D_City $\times$ Parking & $-5.00(-5.30)^{* *}$ \\
\hline \multicolumn{2}{|l|}{ Drive time_Shops } & $-4.41(-4.14)^{* *}$ & Residual & $0.61(0.89)$ \\
\hline \multicolumn{2}{|l|}{ N_Dwellings } & $3.07(7.12)^{* *}$ & Residual $\times$ Income & $-1.67(-1.85)$ \\
\hline
\end{tabular}

${ }^{* *}$ significant at $99 \%$ confidence interval, ${ }^{*}$ significant at $95 \%$ confidence interval)

Full-time workers usually commute every day and consider commuting costs (e.g. parking, commute time) more than part-time workers. More full-time workers in a household means higher car ownership. Every additional full-time worker in a household increases the probability of the household to own two or three or more cars by $3.1\left(e^{1.12}=3.1\right)$ and $6.5\left(e^{1.87}\right.$ $=6.5$ ) times, respectively.

Owning multiple cars partly depends on number of children in the household. Parents may drop-off children at school on their way to work. This is probably a reason for owning cars. However, the impact of the number of children on car ownership is less than the influence of income and number of full-time workers. This implies that multiple car ownership is also a popular choice for households without children. Driving is a popular commute mode, particularly for households living outside Wellington City. This popularity is probably due to 
the fact that driving is more reliable and convenient than other modes for some households. For households who live in the city the probability of driving over other modes is $96 \%\left(e^{-3.11}\right.$ $=0.044)$ less than households in other council areas. However, in the city, home parking positively impact the probability of driving, and its influence is greater than the estimates in the relevant literature (Christiansen, Fearnley et al., 2017; Weinberger, 2012). Home parking availability is the strongest determinant of driving and car ownership in our model.

Based on our results, a household with a higher income is more likely to drive to work.. Nonetheless, the influence of income is less than half of the impact of home parking. High earners are less sensitive to petrol and parking costs than the low earners. They may choose to drive as a convenient mode. However, our results imply that households decide to drive mostly because they have access to parking at home.

Driving to Wellington CBD is expensive due to parking restrictions, parking competition, and traffic congestion. There is a two-hour time limit on on-street parking, and parkers pay for parking in competitive public off-street parking buildings or lots. Working in the CBD noticeably decreases the probability of driving over other modes $(88 \%)$.

Residential location is also an important commuter choice. People usually like to live closer to their workplaces but there is a trade-off between commute time and house price. The utility of household $i$ from choice $j\left(U_{i j}\right)$ is calculated as

$$
U_{i j}=\delta_{1}(\log (\text { House Price }))_{i j}+\delta_{2}(\log (\text { House Price }) . \text { Income })_{i j}+
$$

$\delta_{3}(\log (\text { Commute time }))_{i j}+\delta_{4}(\log (\text { Commute time }) . \text { Income })_{i j}+\delta_{5}$ Controls $_{i j}+\varepsilon_{i j}$,

which is another explanation of our main regression model (Equation (2.1)). The ratio of $\frac{\delta_{3}+\delta_{4}\left(\text { Income }_{K}\right)}{\delta_{1}+\delta_{2}\left(\text { Income }_{K}\right)}$ gives us an idea of how much more a household in the income level of $K$ is willing to pay to get closer to the household head's workplace, all other variables constant. A household with a median income (income $=0.6$ in our measure) is willing to live in a house worth $0.6 \%$ more to reduce the household head's commute time by $1 \%$. For example, suppose this household owns a NZD500,000 house 20 minutes from the household head's workplace. The household is willing to live in a house that costs NZD500,000*0.0063 = NZD 3,150 more to reduce commute time by 0.2 minutes. In other words, this household might move to an NZD657,500 house to live 10 minutes closer to work, all other features constant. 
In our sample, households who live in Wellington CBD or the surrounding suburbs (central suburbs) to minimize their commute time and enjoy a central location, pay NZD646,061 on average. This is NZD262,137 more than average house price in our sample.

Income is important for residential location choice. Low-income households tend to live in cheaper houses. Well-paid commuters live in more expensive houses. Living in suburbs with more areas facing North is desirable. Sunshine is important in choosing a residential location. Many suburbs have a commercial centre including supermarkets, bars, cafes, etc. Living close to the suburbs' centres is desirable in our case study.

Households with more children prefer to live in MBs where houses have a higher number of bedrooms. MBs with a high number of dwellings and people per dwelling are desirable. However, high earner households significantly prefer to live in less crowded MBs. There is a positive relationship between size of house and probability of choosing that house. MBs with houses of higher median floor area are generally desirable.

\subsection{Discussion and conclusion}

Home parking has been the focus of little research. However, there is evidence that home parking is an important determinant of car ownership and propensity for driving (Christiansen, Fearnley et al., 2017; Guo, 2013a, 2013b; Weinberger, 2012). We study the relationship between home parking quantity and choices of car ownership and commute mode on a regional scale, including a network of interconnected urban and rural areas. We also consider choice of residential location, which is not considered in the home parking literature. A sample of 1056 households in the GWR was taken from the New Zealand Household Travel Survey between 2003 and 2017. Our regional scale enables us to investigate the impact of parking in two different settings: the relatively dense urban setting of inner Wellington City suburbs, and lowdensity suburban and rural areas. The latter is the origin of many more car trips because of high residential parking supply. Generally, as we get farther from Wellington CBD, home parking supply increases and households are more likely to own a car and drive to work.

The results of this study show that home parking quantity has a strong impact on car ownership and mode choice. The influence of home parking on commuting choices is greater than the impact of demographics. Minimum on-site parking requirement and low-density structure of neighbourhoods in the GWR lead to a strong preference for car ownership and driving. As Manville (2013) argues, providing off-street parking increases house price and reduces cost of 
driving. In Wellington City, high supply of off-street parking is mostly seen in suburbs where residents enjoy free on-street parking (see Figure 3.5). Many households in these neighbourhoods prefer two cars. In addition, availability of free on-street parking and its ease of use might motivate households to park on-street and use their on-site parking for other purposes (e.g. storage). This adds to congestion in the neighbourhood. These are consequences of regulating off-street parking separately from on-street parking and not as a whole. Removing minimum parking requirements might be helpful, as suggested in Guo \& Ren (2013). Based on our results, reducing home parking supply in MBs considerably decreases the probability for owning cars and driving. Households would limit their cars to the numbers they really need or prefer car-sharing as their commute mode. However, according to Guo (2013a), and Guo \& Ren (2013) abundant free on-street parking encourages wasteful use of road space, greater car ownership, greater congestion and more greenhouse gas emission.

More car trips increase demand for parking at business centres. There is a mutual relationship between parking at home and work that is overlooked in most parking literature. Understanding this link will help urban planners to set more efficient parking regulations. Although we account for workplace parking through workplace location in the $\mathrm{CBD}$, this area requires further work. We have considered home parking quantity in this study. Other aspects of parking such as different types (e.g. garage, driveway and on-street) provide different levels of security, safety, convenience, and availability. Therefore, parking type may affect mode choice and car ownership in distinct ways. Estimating the impact of home parking type on car ownership is the focus in Chapter 4. 


\title{
Chapter 4
}

\section{Home parking type and car ownership}

\begin{abstract}
Home parking is often overlooked in transport studies. Parking forms a small subset of the transport literature and most parking studies focus on parking at work. Home parking can motivate car ownership and impact car trips. In contrast with work parking, residential parking is less regulated. In this research, we study the impacts of three different types of home parking (garage, driveway, and on-street) on car ownership. Our sample contains 1056 households from the New Zealand Household Travel Survey in the Greater Wellington Region (GWR). Using the Control Function approach in a (CL) model, we account for the endogeneity between car ownership and parking. Our on-street parking measure accounts for both parking quantity and demand.

We find on-street parking is an important determinant for owning one car. Having a garage or driveway is a motivation for owning multiple cars. The impact of home parking on car ownership is higher than the influence of income. The high supply of residential parking encourages high car ownership even for households whose head works in the Wellington CBD with restricted parking at work. This implies the impact of home parking on work parking and suggests the need for an integrated parking policy. Driving is noticeably the fastest mode in the GWR and drive time positively affects car ownership.
\end{abstract}




\subsection{Introduction}

The parking literature is dominated by parking at work, including pricing and regulations (Ma \& Zhang, 2017), parking supply (Arnott et al. 2015; Van Ommeren et al., 2014; Wang et al., 2018) and its relationship with mode choice (Bridgelall, 2014; Franco, 2017; Hamre \& Buehler, 2014; Pandhe \& March, 2012b). Home parking as a place where cars spend most of the day also merits research. Some evidence suggests a high supply of residential parking motivates households to have a high number of cars and drive more often (Guo, 2013a \& 2013b). Thus, home parking implicitly impacts households' externalities (e.g. traffic congestion, environmental pollution). Understanding the effect of home parking on car ownership would contribute to parking policies to limit these externalities.

Home parking is a garage, driveway, or on-street parking. Each type of home parking has a distinct level of availability and ease of use. A convenient on-street parking space is usually subject to competition from neighbors. Thus, its capacity is limited by demand and, in some cases, price. According to Guo (2013b), an inverse relationship exists between on-street parking demand and car ownership. On the other hand, garage and driveway spaces are often free of charge and without competition.

This study draws on 1056 households in the Greater Wellington Region (GWR) between 2003 and 2017. Compared to Chapter 3, in this chapter we study home parking in more detail and focus on home parking type. We use a CL model to estimate the impact of the quantity of each home parking type on car ownership. Endogeneity between car ownership and parking is a major issue for this topic. The number of cars in households might be a function of home parking availability. Meanwhile, households choose a house with a certain number of parking spaces to satisfy their car ownership preferences. Therefore, without mitigating the endogeneity, the estimates would be inconsistent, and establishing a causal relationship between parking and car ownership is difficult.

We design our model to address endogeneity using the Control Function (Hausman, 1978; Heckman, 1978; Petrin \& Train, 2010). Compared to the commonly used "Two-Stage Least Square (2SLS) (Albalate and Gragera, 2020; Jiang et al., 2017a), the estimated parameters using Control Function are statistically more consistent (Terza et al., 2008) and more robust to the underlying distributional assumptions of the model (Guevara \& Hess, 2019). 
Our Instrumental Variables (IVs) and the endogenous variables both represent quantity of each home parking type (i.e. number of garages or number of driveway spaces). For each parking type, we use the average parking quantity of that type per household in MB which is small (30 to 60 dwellings usually). These IVs may perform better for predicting parking quantity of a typical house This is novel to the home parking literature. We also consider the property's ground level floor area and land area as the second IVs for the garage and driveway respectively. These IVs are also new to the literature and are the most relevant house features for home parking. Garage is considered as a part of building outline and driveway supply depends on the land area available in the property.

We use a measure for on-street parking that accounts for parking quantity, competing parking demand from neighbors, and the on-street space in front of the on-site parking entrance. We study the impact of home parking type on car ownership in a region with varying home parking availability and regulation. Residential areas in Wellington City centre have restricted parking. In suburbs around the city centre, households pay for on-street parking as resident or coupon parking. Households living farther from the city centre have higher supply of off-street parking and free on-street parking. Results of this study shed light on a new and detailed understanding of the impact of home parking type and quantity on car ownership.

\subsection{Literature review}

Home parking is the focus of a small literature on estimating household car ownership. Some studies use a proxy for home parking, such as living in urban areas (Ritter \& Vance, 2013b), living in single family house (Potoglou \& Kanaroglou, 2008), type of house (Soltani, 2017), or number of households and jobs in the residential area (Ryan \& Han, 1999). These studies show the impact of the proxies on car ownership. However, they do not address the direct effect of home parking on car ownership. Others use access to home parking instead of quantity of home parking (Scorrano et al., 2020; Wu et al., 1999). The number of parking spaces at home and the type of parking are important for car ownership. Each home parking type offers a distinct level of convenience, availability, and security. Moreover, there is some evidence that the quantity of home parking is a determinant of car ownership (Guo, 2013a). Therefore, access to parking is an aggregate measure and does not capture the impact of each parking type separately.

The studies that focus on the quantity of home parking face the endogeneity issue between home parking and car ownership. The reverse causality between parking and car ownership is 
a major issue in this topic. Without accounting for this issue, results can be biased or inconsistent. Added to this, the direction of impact would not be clear. This endogeneity does not seem to be accounted for in some research (e.g. Christiansen, Fearnley et al., 2017).

Most research that mitigates this endogeneity studies parking at an aggregate scale (e.g. neighborhood). For example, Jiang et al. (2017a) study the number of parking lots per household in a neighborhood in Jinan, China and the share of illegal on-street parking. They use Principal Component Analysis to identify the main components that represent households' attitudes of car ownership and residential location. They include these components as additional explanatory variables in their model to control for endogeneity. Albalate and Gragera (2020) study home parking quantity and car ownership "per 1000 inhabitants" in Barcelona, Spain and calculate variations in the number of registered cars in each neighborhood as the "neighborhood fixed effect". They include this variable in their main regression to mitigate the reverse causality between parking and car ownership. Ostermeijer et al. (2019a) estimate the impact of the implicit cost of outside private parking on car ownership in the Netherlands. They use the median construction year of properties in a parking district (2000 properties) as an IV and use the $\mathrm{CF}$ approach to address the endogeneity.

Unfortunately, these IVs or variables to mitigate endogeneity might not be applicable for studying home parking in detail and at a single property scale. They are at a large scale and do not provide sufficient variation at a smaller scale (e.g.within a neighborhood or district).

Guo (2013a) divides households into two subgroups based on the possession of off-street or on-street parking, assuming that households with the same parking type have similar travel preferences. He observes similar on-site parking design in most of his sample in New York City. Many households have their garage in their backyard connected to a street via a driveway. It is expected that households with off-street parking in this sample have a similar attitude toward travel behavior. Therefore, this research design may not be confidently applicable to samples with noticeable variations in parking design, and the author mentions that the results may not be transferrable to newer cities with high residential parking supply.

Our research is designed to contribute to the literature in the following ways. We use distinct, novel IVs to study each home parking type. We calculate the average number of garage or driveway spaces per household in a MB (Statistics New Zealand, 2017) as IVs for garage and driveway respectively. MBs usually include 30 to 60 dwellings (ibid, 2017). This is the closest 
scale to a single property in the home parking literature. These might strongly correlate with the household's parking quantity. Property floor area and land area are the second IVs for garage and driveway, respectively. These variables are the most relevant house feature to home parking and novel to the literature. Our sample includes houses with a variety of home parking designs and locations (e.g. facing street or in the backyard) which contributes to more realistic results.

Our measure for on-street parking is the chance of finding an on-street parking space based on the number of neighbors that have access to that space (this variable is defined in section 4.4.2). This measure clearly accounts for quantity and demand from neighbors for on-street parking. We also consider an on-street parking space in front of the garage or driveway of a household. This might be used by the household.

Commute distance is used a proxy for commute length in most of the literature (e.g. Ostermeijer et al.2019; Potoglou \& Kanaroglou, 2008; Ritter \& Vance, 2013). We use commute time to better represent commuters' perception of commute length. We consider the ratio of driving time to Public Transport (PT) travel time and the ratio of driving time to Active Transport (AT) travel time to account for the interaction between commute mode and car ownership.

\subsection{Methodology}

This paper uses a CL model to estimate the effect of quantity of each home parking type on households' car ownership. There is an endogeneity between car ownership and home parking. The current number of cars in a household impact their choice of residential location. This is a common concern in this field (Christiansen et al., 2017b; Guo, 2013a, 2013b). We choose IVs and use $\mathrm{CF}$ approach in this research to address this endogeneity.

It is common in the literature to use measures for the neighborhood parking supply as IV. For example, Ostermeijer et al. (2019a) use median construction year of properties in parking zones. Guo (2013a) uses dummies for attached and detached house, median age of buildings and the percentage of black and Hispanic people in a census tract. We use average number of each home parking type per household in MB as a measure to better predict quantity of home parking of the household. To the best of our knowledge, no study has used this as an IV.

Our IVs are new to the literature and more efficient. Instead of using same IVs for all parking types, we choose distinct IVs for each parking type to better capture exogenous part. Our IVs for garage are the average number of garage spaces per household in the household MB, and 
the property's floor area. This IV is closer than others in the literature (e.g. Guo, 2013a; Ostermeijer et al., 2019) to the household's number of garages because it directly measures garage supply in a small area around the household. Furthermore, when choosing a house, the households do not take into account the neighbors' home parking supply. The second IV (floor area) is the most relevant house feature to predict the garage supply. Garage is part of the residential building outline. When choosing a house, households usually take into account the number of garages separately to the property's floor area. Therefore, these IVs predict the garage supply, whereas it is highly unlikely that they correlate with the households' car ownership attitude.

Our IVs for driveway spaces are the average number of driveway spaces per household in a MB and the property's land area. Similar to the IVs for garage, these IVs also predict the number of driveway spaces and do not correlate with the households' car ownership preference. Households do not take into account the neighbors' driveway supply when choosing a home. From a car ownership perspective, households consider the number of driveway spaces rather than land area or amount of empty land in the property (which could be a garden or backyard). We test off-street parking IVs against a test of relevance and a Sargan test (Wooldridge, 2013). To test for relevance, we regress garage or driveway quantity on their IVs and the exogenous variables as

$$
\begin{aligned}
\text { Garage }_{i} & =\beta I V_{G_{i}}+\beta^{\prime} I V_{G_{i}}^{\prime}+\sum_{j} \sigma_{j} X_{j}+\mu_{i}, \\
\text { Driveway }_{i} & =\delta I V_{D_{i}}+\delta^{\prime} I V_{D_{i}}^{\prime}+\sum_{k} \theta_{k} Z_{k}+\mu_{i}^{\prime},
\end{aligned}
$$

where for household $i$ with $j$ exogenous variables for garage and $k$ exogenous variables for driveway, $I V_{G_{i}}$ and $I V_{G_{i}}^{\prime}$ are the two IVs for garage, $I V_{D_{i}}$ and $I V_{D_{i}}^{\prime}$ are two IVs for driveway, $\beta$, $\beta^{\prime}, \delta$, and $\delta^{\prime}$ are the coefficients, $X$ and $Z$ are exogenous variables, $\sigma$ and $\theta$ are coefficients for exogenous variables, and $\mu_{i}$ and $\mu_{i}^{\prime}$ are the residuals for garage and driveway, respectively. The Null hypothesis is that there is no correlation between the IVs and the endogenous variable. For (4.1), we can write it as

$$
H_{0}: \beta=\beta^{\prime}=0
$$

and for (4.2) as

$$
H_{0}: \delta=\delta^{\prime}=0,
$$

For each parking type, we then calculate the sum of square residuals $\left(S S R_{u}\right)$ and sum of square residuals before adding the IVs $\left(S S R_{r}\right)$. We test the null hypothesis based on Fstatistic value which is calculated as 


$$
F=\frac{\left(S S R_{r}-S S R_{u}\right) / P}{S S R_{u} /(N-K-1)}
$$

where $P$ is the number of IVs, $K$ is the number of explanatory variables in (4.1) or (4.2), and $N$ is number of observations. The $F$ distribution has two degrees of freedom: $d f_{1}$ and $d f_{2}$. The first degree of freedom is $P$, and the second degree of freedom is $N-K-1$. A F-statistic value greater than the critical value in $d f_{1}$ and $d f_{2}$ proves correlation between the IVs and the endogenous variable (ibid, 2013).

IVs should not correlate with the error term. The test used to investigate this condition is called a Sargan test, Hansen-Sargan test, or simply J-test (Basmann, 1960; Hansen, 1982; Sargan, 1958). From Equations (4.1) and (4.2), we calculate fitted values for garage and driveway as

$$
\begin{gathered}
\text { Fitted }_{\text {Garage }}=\beta I V_{G_{i}}+\beta^{\prime} I V_{G_{i}}^{\prime}+\sum_{j} \sigma_{j} X_{j}, \\
\text { Fitted }_{\text {Driveway }}=\delta I V_{D_{i}}+\delta^{\prime} I V_{D_{i}}^{\prime}+\sum_{k} \theta_{k} Z_{k} .
\end{gathered}
$$

In a linear regression, we regress car ownership on Fitted Garage $_{\text {and }}$ Fitted Driveway $_{\text {, and }}$ exogenous variables as

$$
\text { Car ownership }_{i}=\lambda \text { Fitted }_{\text {Garage }_{i}}+v \text { Fitted }_{\text {Driveway }_{i}}+\sum_{n} \mathrm{~b}_{n} Q_{\text {in }}+\gamma_{i},
$$

in which, we include exogeneous variables for garage and driveway used in (4.6) and (4.7) as $Q_{i n}$. We calculate the residuals vector $\left(\gamma_{i}\right)$. We regress $\gamma_{i}$ on all IVs and the exogenous variables as

$$
\gamma_{i}=\rho I V_{G_{i}}+\tau I V_{G_{i}}^{\prime}+\varphi I V_{D_{i}}+\omega I V_{D_{i}}+\sum_{n} c_{n} Q_{i n}+\phi_{i}
$$

in which, $\rho, \tau, \varphi$, and $\omega$ are the coefficients and $\phi_{i}$ is the error term. The null hypothesis is that the coefficients of all IVs are $0(\rho=\tau=\varphi=\omega=0)$. The J-statistic is calculated as $J=m F$ and used to test the hypothesis, where $m$ is the number of IVs, and $F$ is $F$-statistic (see (4.5)). If the $J$-statistic is less than the critical value of a chi-squared distribution with $q$ degrees of freedom $\left(\chi_{q}^{2}\right)$, we conclude that the instruments are exogenous. The degrees of freedom $(q)$ are calculated as the number of IVs minus the number of endogenous variables (Hanck et al., 2019).

\subsection{Data and case study}

The GWR has a range of home parking supply and regulation areas. Residents in the congested Wellington Central Business District (CBD) rarely have on-site parking, and on-street parking is limited to two hours (Figure 4.1.a). In the inner suburbs, some households have off-street parking. On-street parking is provided as resident parking (NZD195 per year) (Wellington City 
Council, 2020b) or coupon parking (NZD120 per year for residents) (Wellington City Council, 2020a) (Figure 4.1.b). The rest of the region is dominated by neighborhoods with low population density, where high supply of on-site and free on-street parking is common (Figure 4.1.c and 4.1.d).

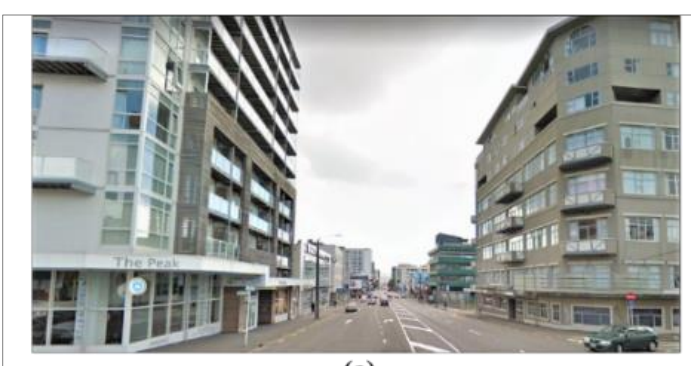

(a)

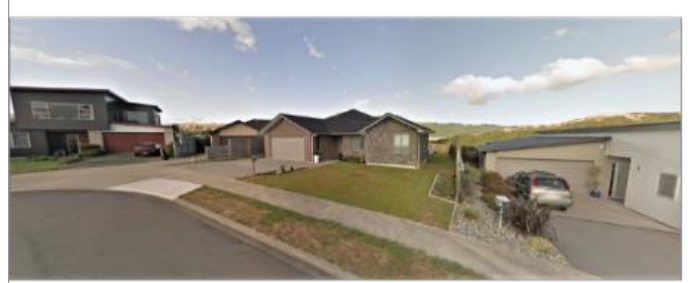

(c)

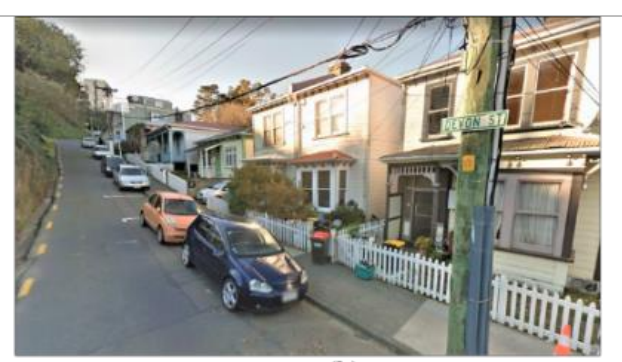

(b)

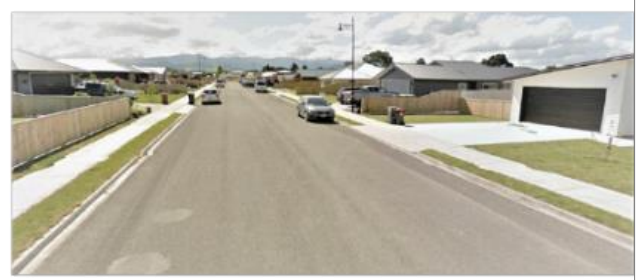

(d)

Figure 4.1. Home parking in (a) Wellington CBD, (b) Coupon parking zone, both (c) and (d) common residential areas in the GWR (Photos: Google street view and Google Earth)

We use data for 1056 households in the GWR who work in a fixed place for their main work.

Table 4.1 details variables used in this research followed by further introduction of some variables in Sections 4.4.1 and 4.4.2.

Table 4.1. Variables used in Chapter 4

\begin{tabular}{|c|c|c|}
\hline Variable & Definition & Source \\
\hline Car ownership & $\begin{array}{l}\text { Number of cars in household (dummy for no car, one car, } \\
\text { two cars, and three or more cars) }\end{array}$ & NZHTS \\
\hline Garage & Number of garage spaces in house & $\begin{array}{l}\text { Google Satellite View } \\
\text { Google Street View } \\
\text { Homes.co.nz }\end{array}$ \\
\hline Driveway & $\begin{array}{l}\text { Number of driveway spaces means number of cars that } \\
\text { could be fitted in the driveway }\end{array}$ & $\begin{array}{l}\text { Google Satellite View } \\
\text { Google Street View } \\
\text { Homes.co.nz }\end{array}$ \\
\hline On-street & $\begin{array}{l}\text { Chance of finding an on-street parking space within } 50 \\
\text { meters of household (percent) }\end{array}$ & $\begin{array}{l}\text { On-street parking lines drawn } \\
\text { based on observations in } \\
\text { Google Satellite View }\end{array}$ \\
\hline Drive time & Driving time from home to work in hours & $\begin{array}{l}\text { Calculations in ESRI ArcMap } \\
\text { based on Daglish et al. (2015) }\end{array}$ \\
\hline PT time & $\begin{array}{l}\text { Travel time with public transport from home to work in } \\
\text { hours }\end{array}$ & $\begin{array}{l}\text { Calculations in ESRI ArcMap } \\
\text { based on Daglish et al. (2015) }\end{array}$ \\
\hline
\end{tabular}


Table 4.1. continued

\begin{tabular}{|c|c|c|}
\hline Variable & Definition & Source \\
\hline AT time & $\begin{array}{l}\text { Travel time with active transport (i.e. walking or cycling) } \\
\text { from home to work in hours }\end{array}$ & $\begin{array}{l}\text { Calculations in ESRI ArcMap } \\
\text { based on Daglish et al. (2015) }\end{array}$ \\
\hline Income & $\begin{array}{l}\text { Annual income of the head of household. Income categories } \\
\text { and measures are as follows (income in NZD); } \\
\begin{array}{l}1=1-10,000 \\
2=10,001-20,000 \\
3=20,001-30,000 \\
4=30,001-40,000 \\
5=40,001-50,000 \\
6=50,001-70,000 \\
7=70,001-100,000 \\
8=100,001+\end{array}\end{array}$ & NZHTS \\
\hline N_Full-time & Number of full-time workers in household & NZHTS \\
\hline N_Children & Number of children in household & NZHTS \\
\hline Work_CBD & Working in Wellington CBD (dummy) & NZHTS \\
\hline Avg_Garage_HH & Average number of garage spaces per household in MB & $\begin{array}{l}\text { Google Satellite View } \\
\text { Google Street View } \\
\text { Homes.co.nz }\end{array}$ \\
\hline Avg_Driveway_HH & Average number of driveway spaces per household in MB & $\begin{array}{l}\text { Google Satellite View } \\
\text { Google Street View } \\
\text { Homes.co.nz }\end{array}$ \\
\hline Floor area & The area of the ground floor of the house $\left(\mathrm{m}^{2}\right)$ & $\begin{array}{l}\text { Land Information New } \\
\text { Zealand (2020a) }\end{array}$ \\
\hline Land area & The area of the property $\left(\mathrm{m}^{2}\right)$ & $\begin{array}{l}\text { Land Information New } \\
\text { Zealand (2020b) }\end{array}$ \\
\hline Distance_road & $\begin{array}{l}\text { Distance between property's address point and the closest } \\
\text { road (meter) }\end{array}$ & $\begin{array}{l}\text { Address points are obtained } \\
\text { from Land Information New } \\
\text { Zealand (2016) }\end{array}$ \\
\hline Slope & $\begin{array}{l}\text { The elevation difference between the property's address } \\
\text { point and the snapped address point to the closest road, } \\
\text { divided by the distance between the two }(\%)\end{array}$ & $\begin{array}{l}\text { Elevation of address points is } \\
\text { based on Land Information } \\
\text { New Zealand (2017) }\end{array}$ \\
\hline D_City & Household lives in a MB in Wellington City (dummy) & NZHTS \\
\hline HH_children & Household with children (dummy) & NZHTS \\
\hline N_working & Number of workers in household & NZHTS \\
\hline
\end{tabular}

\subsubsection{Garage and driveway quantity}

We use Google Satellite View and Google Street View to collect the number of garages and driveway spaces for each household in our sample. In cases where photos show the existence 
of a garage or driveway but are not clear enough to measure the number of spaces, the homes.co.nz website is used. ${ }^{5}$

To measure driveway spaces, we divide the length or width of the driveway by 5.5 or 2.5 respectively ( 5 meters for car length, 2 meters for car width and 0.5 meter for the distance between the cars) to calculate number of usable driveway spaces. The maximum cars per household in the NZHTS sample is six. Thus, we truncate this variable at six.

\subsubsection{On-street parking measures}

Given two meters is the average width of a car, households may park on one side of a street where it is at least seven meters wide, and two sides of the street if it is at least 9.5 meters wide. In ESRI ArcMap 10.6.1, we draw on-street parking lines along the curb at one side of the street for the former and two sides of streets for the latter case. We exclude areas where parking is not permitted, in front of garages/driveways or obstacles (e.g. fire hydrant). In most cases, drivers park lengthwise along the road. However, in a few cases, on-street parking can also be perpendicular to the street (angled parking). Depending on the direction of parking, each segment of available parking with the length of 5.5 meters or 2.5 meters is recorded as a parking space.

In contrast to on-site parking, on-street parking is public and subject to competition from neighbors. There is some evidence that most households prefer to park within 50 meters of their house (Christiansen, Fearnley et al., 2017; Guo, 2013a). We use the chance of finding an on-street space within 50 meters of a house as our measure for on-street parking. For each onstreet parking space, we calculate the chance of parking in that space as the inverse of the total number of households with access to that space.

To denote the chance the household can park in that space, we calculate average of the chances for all on-street spaces around the household as their chance of finding an on-street parking. Households with on-site carpark who live on a street that is at least seven meters wide have an on-street parking space in front of their garage or driveway entrance. This is an on-street parking space without competing demand from others. This space is included in the on-street parking measure. The chance of finding on-street parking is measured in percentage and we divide it by 100 so that it has the same scale as other variables.

\footnotetext{
${ }^{5}$ One issue with using these online images is that in a few cases, the home location point for actual participants in the NZHTS is in a non-residential parcel or a road. This point is then moved to the closest residential parcel.
} 


\subsection{Summary statistics}

Table 4.2 shows summary statistics for the variables used in the main regression. High offstreet parking (i.e. garage plus driveway spaces) is observed in the GWR (Figure 4.2).

Table 4.2. Summary statistics of the variables used in the main regression

\begin{tabular}{lccccc}
\hline Variable & Mean & S.D. & Minimum & Maximum & Number of observations \\
\hline D_one car & 0.41 & 0.49 & 0.00 & 1.00 & 1056 \\
D_two cars & 0.41 & 0.49 & 0.00 & 1.00 & 1056 \\
D_three or more cars & 0.14 & 0.35 & 0.00 & 1.00 & 1056 \\
Garage & 1.11 & 0.78 & 0.00 & 5.00 & 1056 \\
Driveway & 2.73 & 1.95 & 0.00 & 6.00 & 1056 \\
On-street & 0.16 & 0.09 & 0.00 & 1.00 & 1056 \\
Drive time & 0.19 & 0.17 & 0.00 & 1.87 & 1056 \\
Drive time over PT time & 0.24 & 0.09 & 0.06 & 0.68 & 1056 \\
Drive time over AT time & 0.14 & 0.03 & 0.06 & 0.25 & 1048 \\
Income & 5.19 & 1.97 & 0.00 & 8.00 & 990 \\
N_Children & 0.71 & 1.01 & 0.00 & 5.00 & 1056 \\
N_Full time & 1.41 & 0.7 & 0.00 & 4.00 & 1056 \\
Work_CBD (dummy) & 0.41 & 0.49 & 0.00 & 1.00 & 1056 \\
\hline
\end{tabular}

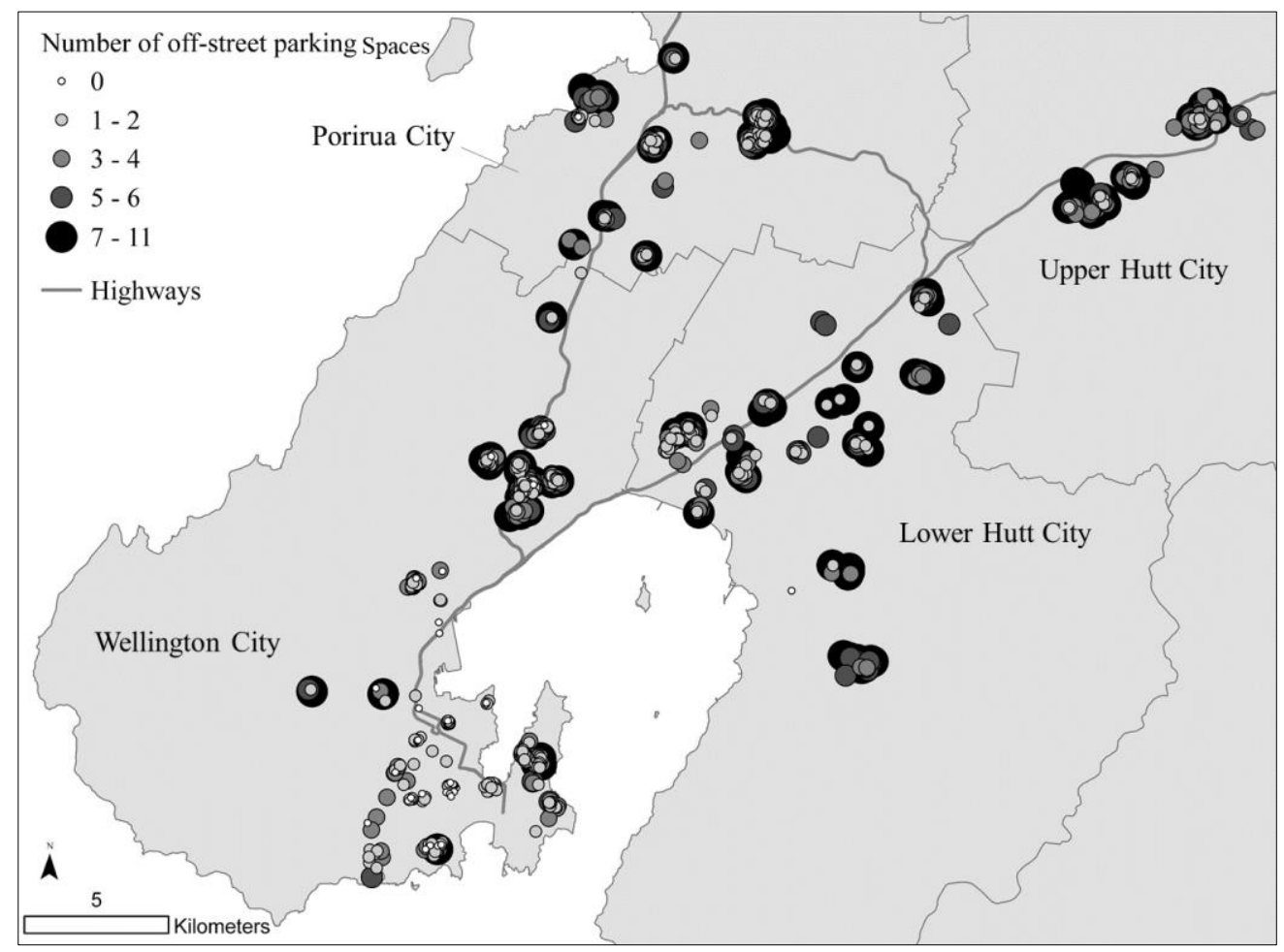

Figure 4.2. On-site parking quantity in the cities of the GWR

(Source of on-site quantity: Google Satellite View, Google Street View, Homes.co.nz) 
The median household has one garage space. One or more garages is observed in $83.5 \%$ of the sample. In Wellington City, as the most populated area in the GWR, the share of households without a garage is more than twice the share of households without a garage outside the city (Table 4.3). In Wellington City, only $19.9 \%$ of households have two or more garages, outside the city the share of multiple garage holders is almost twice that of Wellington City (37.9\%) (Table 4.3).

Table 4.3. Share of households in each location and garage quantity category (\%)

\begin{tabular}{lllll}
\hline & \multicolumn{4}{c}{ Number of garages } \\
\hline & 0 & 1 & $2+$ & Total \\
\cline { 2 - 5 } Wellington City & 35.19 & 44.90 & 19.90 & 100 \\
Rest of the GWR & 13.82 & 48.29 & 37.89 & 100
\end{tabular}

(Source of garage quantity: Google Satellite View, Google Street View, Homes.co.nz)

Having a garage is a motivation for having a high number of cars. The share of multiple car owners grows as the number of garages increases (Figure 4.3). Two or more cars is the choice of $53.8 \%$ of households with one garage, and $68.1 \%$ of households with two or more garages (Figure 4.4). Having one car is a popular choice in the GWR. Almost half of households $(51.3 \%)$ without garages have one car.

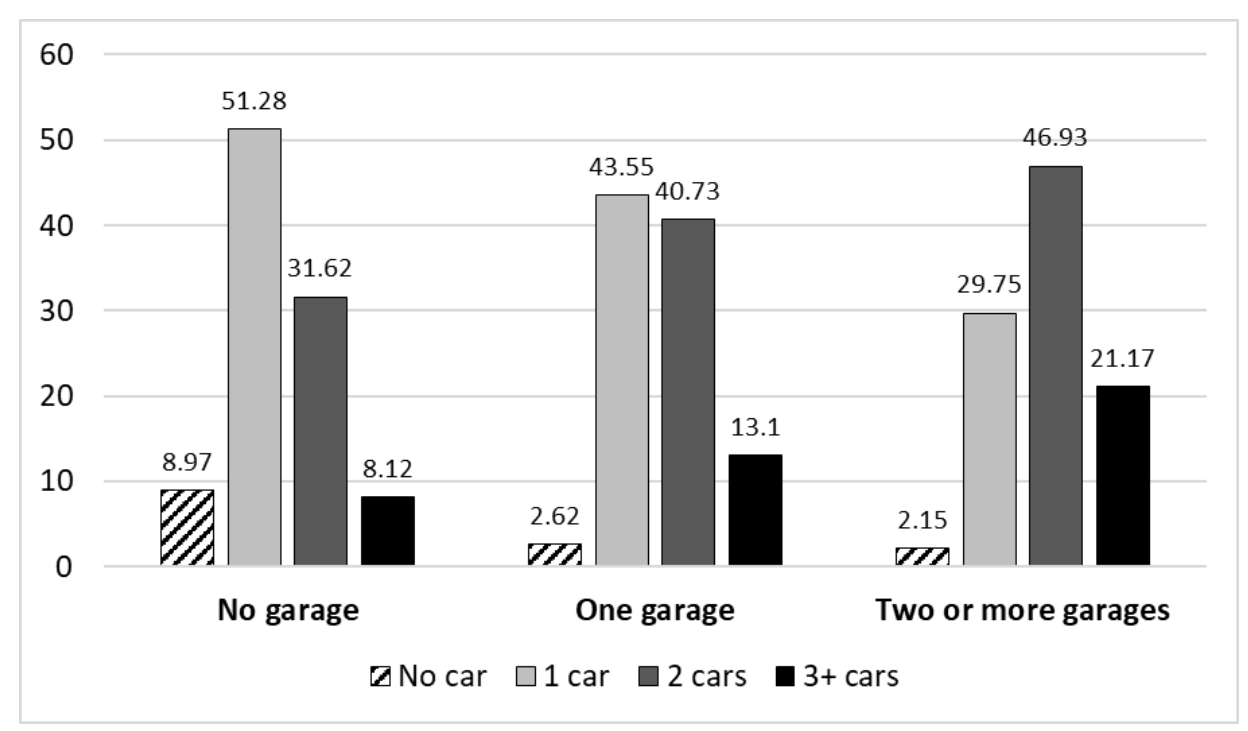

Figure 4.3. Share of households in each garage quantity category (\%)

(Source of garage quantity: Google Satellite View, Google Street View, Homes.co.nz)

On average, a household has 2.7 driveway spaces (two driveway spaces is the median). In our sample, $66.8 \%$ of households have at least two driveway spaces. Having a driveway spaces 
encourage higher car ownership in our sample. The share of households with two or more cars is higher in the categories of two or more driveway spaces (Figure 4.4). A high share of one car ownership among households without driveways is observed. This is possibly due to the fact that $93.9 \%$ of households without driveway have access to on-street parking and $53.1 \%$ owning one or more garages. Moving from no to one driveway space is accompanied by a considerable increase in the popularity of two cars. A noticeable increase in the share of households with three or more cars is observed when number of driveway spaces increases from two to higher quantities.

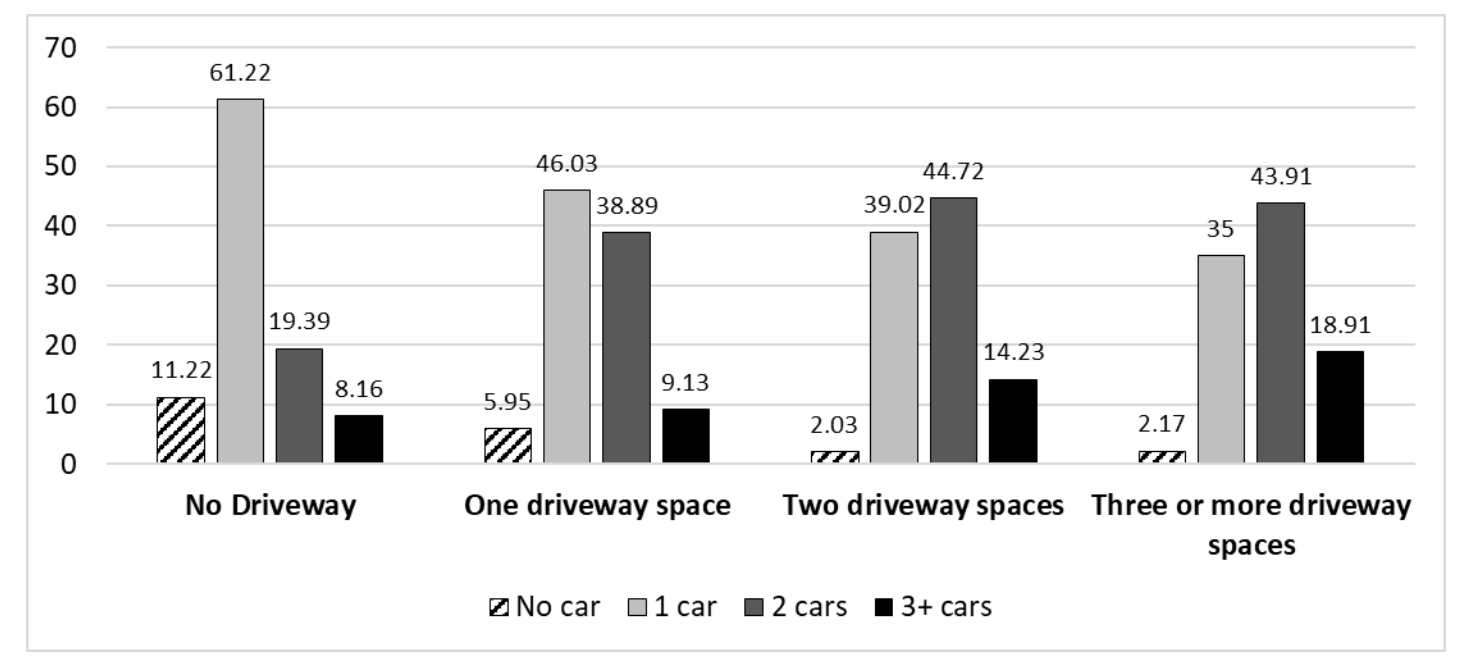

Figure 4.4. Share of households in each driveway quantity category (\%)

(Source of driveway quantity: Google Satellite View, Google Street View, Homes.co.nz)

On-street parking is available for almost all commuters (93\%). Most households (89.4\%) enjoy free on-street parking. The average household has 14.4 on-street parking spaces (13 spaces is the median) around their residence. However, the availability of parking is limited by demand from others. The chance of finding an on-street parking varies across the region. In Wellington City, the average chance is $14.9 \%$, and rises to $16.4 \%$ outside the city. The chance of finding an on-street spot is calculated based on potential demand for each space when all households use on-street parking. Due to high supply of on-site parking, some commuters may not park on-street. For households who live in busy streets where they can find at most one space out of ten (mostly in Wellington CBD and the surrounding coupon parking area), having a high number of cars is an expensive choice. Thus, $60.5 \%$ have no or one car. In suburbs where the maximum probability for finding an on-street parking is only $10 \%$ higher, most households $(95.5 \%)$ have a car and $54.3 \%$ have multiple cars. 
Commute time is important for car ownership. Driving is the fastest mode in our sample in the GWR. Driving is 4.2 times faster than PT and 7.1 times fster than AT. On average, households in our sample, live 11.40 minutes' drive from their work. Most households (64.8\%) who live farther than this from work have two or more cars. This is $15.2 \%$ more than the share of multiple car owners in households live at or closer than the average to work. The majority of households $(64.5 \%)$ who live farther from work have at least three on-site parking spaces and live in areas where the chance of finding on-street parking is above $10 \%$. Living closer to work (below average) is a motivation for having fewer cars. In this category, half of households $(50.4 \%)$ are either households without a car or single-car owners.

An average household earns NZD40,000 to NZD50,000 per year. Income is believed to be important for car ownership (Dargay \& Gately, 1999; Dargay, 2001). In our sample, when income increases, the share of carless households reduces. The shares of multiple car owners among households who earn NZD50,001 - NZD100,00 and more than NZD100,000 are more than the share of multiple car owners among households who earn below average income (Table 4.4).

Table 4.4. Share of households in each income category in NZD (\%)

\begin{tabular}{lrrccc}
\hline Income & No car & One car & Two cars & Three or more cars & Total \\
\hline $0-20,000$ & 6.61 & 42.98 & 39.67 & 10.74 & 100 \\
$20,001-50,000$ & 5.59 & 43.09 & 38.56 & 12.77 & 100 \\
$50,001-100,000$ & 2.43 & 42.7 & 38.38 & 16.49 & 100 \\
$100,000+$ & 0.00 & 32.52 & 52.03 & 15.45 & 100 \\
\hline
\end{tabular}

(Source: NZHTS)

The number of cars may depend on the number of workers in a household. Full-time workers usually commute more often than part time workers. For households with two or fewer fulltime workers, one or two cars is noticeably popular (83.3\%). A majority of households $(56.9 \%)$ with more full-time workers prefer more than two cars. Forty percent of commuters in our sample work in Wellington CBD where parking is competitive and restricted. More than half of households (56.9\%) who work in the CBD do not have car or have only one car. Others who work outside the CBD often benefit from free or cheap on-street parking at work. Two or more cars is the choice of $63.3 \%$ of households working outside the CBD.

Owning a private vehicle is important for households with children. Without a child, most households $(51.6 \%)$ prefer no or one car. Having only one child makes a noticeable difference. Sixty percent of households with one child have at least two cars. 


\subsection{Results and discussion}

The results of the test of relevance and the Sargan test are shown in Table 4.5. IVs are highlighted. The F-statistics for garage spaces and driveway spaces are greater than the critical vales of $\mathrm{F}$ distribution, and statistically significant correlation between the endogenous variables and their IVs is found. The value of the J-statistic with two degrees of freedom is calculated as 2.9 which is below the critical values for the chi square distribution with two degrees of freedom (7.4). Thus, we cannot reject the null hypothesis that the IVs are exogenous. Hence, we can conclude that the IVs are independent from the error term.

Table 4.5. Relevance test results

\begin{tabular}{|c|c|c|c|c|c|}
\hline \multicolumn{3}{|l|}{ Dependent variable $=$ number of garages } & \multicolumn{3}{|c|}{ Dependent variable $=$ number of driveway spaces } \\
\hline Variables & $\beta$ & $\mathrm{T}$ & Variables & $\beta$ & $\mathrm{T}$ \\
\hline Intercept & 0.03 & 1.90 & Intercept & 0.18 & 4.01 \\
\hline Avg_Garage_HH & 0.17 & 6.44 & Avg_Driveway_HH & 0.39 & 7.43 \\
\hline Floor area & 0.32 & 9.06 & Land area & 1.03 & 5.00 \\
\hline Slope & 0.03 & 0.71 & Distance_Road & 0.58 & 6.24 \\
\hline Drive Time & 0.17 & 3.43 & D_City & -0.15 & -6.55 \\
\hline N_Children & -0.03 & -0.74 & N_Working & 0.16 & 2.46 \\
\hline Work_CBD & -0.04 & -4.22 & Work_CBD & -0.04 & -1.95 \\
\hline HH_children & 0.01 & 0.75 & & & \\
\hline F statistic (calculated) & \multicolumn{2}{|c|}{74.87} & F statistic (calculated) & \multicolumn{2}{|c|}{35.61} \\
\hline $\begin{array}{l}\text { F distribution critical value in } \mathrm{df}_{1}=2 \\
\text { and } \mathrm{df}_{2}=1048 \\
(95 \% \text { confidence interval) }\end{array}$ & \multicolumn{2}{|c|}{19.50} & $\begin{array}{l}\text { F distribution critical value in } \\
\mathrm{df}_{1}=2 \text { and } \mathrm{df}_{2}=1049 \\
(95 \% \text { confidence interval })\end{array}$ & \multicolumn{2}{|c|}{19.50} \\
\hline
\end{tabular}

Table 4.6. shows the logit results of this research. We find a significant and positive relationship between home parking quantity and car ownership. This is consistent with most studies of home parking (Ao et al., 2019; Guo, 2013a; Jiang et al., 2017). The exponential of the coefficient of an explanatory variable associated with a choice is the amount of change in the odds ratio of that choice over the reference group, given changes in the value of the explanatory variable. For example, the exponential of the variable "Garage*One car" is the amount of change in the odds ratio of one car over no car. Owning two cars is 7 times more attractive than no cars when there is one garage at home. This ratio rises to 48.4 when two garages are available. Double garages increase the chance of having three or more cars over no cars by 75.2 times. This is a strong impact on the probability of owning multiple cars in the GWR. Having multiple garages is common in suburbs. According to the results of this study, 
limiting garage supply to one space through introducing maximum parking requirements would considerably reduce car ownership.

Driveway spaces are important for owning three or more cars. It indicates that households prefer to park their cars in a garage with a driveway used as a supplement. Although driveway impact is less than a quarter of the garage's impact, driveway has a noticeable influence on owning more than two cars. Households with two driveway spaces are 3.1 times more likely to have three or more cars than no cars. This choice is 5.5 times more likely than no car when owning three driveway spaces. Having two or more driveway spaces is common in our sample ( $61.5 \%$ of urban households and $89.9 \%$ of rural households). This indicates that the current housing style in the GWR encourages having many cars.

Table 4.6. Logit results for car ownership choice (parameter estimate (t-test))

\begin{tabular}{|c|c|c|c|c|c|c|}
\hline Variables & One car & & Two cars & & or more cars & \\
\hline Constants & $-1.15(-0.92)$ & & $-4.74(-3.58)$ & $* * *$ & $-8.05(-5.47)$ & $* * *$ \\
\hline Garage & $0.81(1.00)$ & & $1.94(2.35)$ & ** & $2.16(2.45)$ & $* *$ \\
\hline Driveway & $0.15(0.60)$ & & $0.41(1.53)$ & & $0.57(2.00)$ & $* *$ \\
\hline On-street & $8.65(3.06)$ & $* * *$ & $8.39(2.92)$ & $* * *$ & $8.13(2.71)$ & *** \\
\hline Income & $0.29(2.86)$ & $* * *$ & $0.39(3.71)$ & $* * *$ & $0.45(3.91)$ & *** \\
\hline Drive time & $5.21(1.41)$ & & $6.63(1.78)$ & * & $6.73(1.75)$ & * \\
\hline Drive time over PT time & $-5.04(-1.08)$ & & $-6.71(-1.41)$ & & $-7.01(-1.39)$ & \\
\hline Next to work $\times$ Drive time over AT time & $0.03(0.01)$ & & $-0.28(-0.08)$ & & $-1.21(-0.30)$ & \\
\hline N_Full time & $0.47(1.62)$ & & $1.35(4.52)$ & $* * *$ & $2.15(6.62)$ & $* * *$ \\
\hline N_Children & $0.31(1.27)$ & & $0.79(3.19)$ & $* * *$ & $0.91(3.54)$ & $* * *$ \\
\hline Work_CBD & $-0.42(-0.82)$ & & $-0.97(-1.85)$ & * & $-1.40(-2.46)$ & ** \\
\hline Residual for garage & $-0.19(-0.48)$ & & $-0.62(-1.49)$ & & $-0.68(-1.53)$ & \\
\hline Residual for driveway & $-0.10(-0.61)$ & & $-0.26(-1.56)$ & & $-0.28(-1.58)$ & \\
\hline
\end{tabular}

Notes: ${ }^{* * *}$ significant at $99 \%$ confidence interval. ${ }^{* *}$ significant at $95 \%$ confidence interval. ${ }^{*}$ significant at $90 \%$ confidence interval.

Demand for or chance of on-street parking is rarely considered in the home parking car ownership literature. Guo (2013a) finds a negative relationship between the crowding level of a street (their measure for on-street parking demand) and car ownership. Our measure for onstreet parking (the chance of finding an on-street parking space within 50 meters of house based on demand from neighbors) is new to the literature and positively affects car ownership. Onstreet parking is the only home parking type that has significant impact on owning one car. Every $10 \%$ increase in the chance of finding an on-street parking more than doubles (2.3 times) 
the probability of owning one car over no car. A resident parking permit provides a higher chance of on-street parking space for households in the busy streets near the CBD. This type of parking increases the chance of finding on-street parking and consequently, the inclination for more car ownership in these neighborhoods. This may result in disrupted traffic and longer cruising time for workers such as tradesmen in the CBD and inner suburbs (coupon parking area). The inner neighborhoods are close to the CBD and enjoy good PT coverage and service. Therefore, reducing the resident parking supply would reduce car ownership of the households in these suburbs and encourage them to shift to non-driving modes, while potentially making it easier for tradesmen to find parks.

Chance of finding an on-street parking space also noticeably influences motivation for having two or more cars. This influence is slightly less than the impact on having one car. It is probably because households with multiple cars prefer to park in an on-site parking location. A high chance of on-street parking encourages more car ownership and hence, reduces the effectiveness of restricting off-street parking on reducing car ownership (Guo, 2013a; Guo \& Ren, 2013). Therefore, off-street and on-street parking should be considered holistically for improving the effectiveness of parking and traffic policies.

Consistent with the literature (Dargay \& Gately, 1999; Guerra, 2015; Nolan, 2010; Whelan, 2007; Yagi \& Managi, 2016), we find a positive and statistically significant impact of income on car ownership. However, income is noticeably less important than the home parking situation. Having a garage has a 5 times larger impact on owning two cars than income. Having a driveway is also more important than the household income for owning three or more cars.

A positive relationship between commute distance and car ownership is found in the literature (for example, see Potoglou \& Kanaroglou (2008)). We find the same relationship between commute time and inclination for car ownership. Longer driving time to work increases probability of having a car. Every eight minutes longer the commute is, the preference for having two cars rather than no car approximately doubles (2.4 times). A longer commute is slightly greater motivation for owning three or more cars. We do not find a significant relationship between the driving time and proclivity to own one car. It is perhaps because having one car is relatively cheap at least in terms of home parking. Many households (95.6\%) have at least one off-street parking space at home. In the busy streets near Wellington CBD, residents also have access to resident parking permit. 
In long commute times, AT is less likely to be a sensible mode for households. In our sample, the average AT travel time for commuters who walk, or cycle is 23.5 minutes. Almost three quarters of these households live closer than 23.5 minutes to their work. We use a "Next to work" dummy variable to focus on households living closer than this time to work. Shorter AT time discourages these households from having multiple cars. However, it is not a significant impact. Driving is noticeably faster than other modes in the GWR and households prefer to drive to save time. Therefore, owning a car is mostly related to drive time.

The direct relationship between the number of full-time workers in a household and car ownership is in line with the literature (Dargay \& Hanly, 2007; Jiang et al., 2017; Potoglou \& Kanaroglou, 2008). The impact of this variable on owning multiple cars is considerably greater than having one car. The influence of number of full-time workers in a household on owning two cars is 2.9 times more than its impact for having one car. This share is 4.6 if comparing the impacts on three or more cars and one car. Full-time workers prefer to have their own car rather than have fewer cars and share.

Household with children are more likely to own cars (Jiang et al., 2017; Nolan, 2010). We find this variable important for owning multiple cars. Having two children increases the odds ratio of owning two cars over no car by 4.9 times.

Commuters who work in Wellington CBD are less likely to have multiple cars. This is probably due to restricted (e.g. time limited) and competitive parking at the CBD. However, the number of garages at home has a larger impact and motivates commuters (including CBD workers) to own two or more cars. Therefore, regulating parking at work is not sufficient for reducing car ownership and the associated externalities. Parking at home and at work should be considered holistically to make an integrated parking policy.

\subsection{Conclusion}

City centres are usually subject to more up to date and accurate parking policies than other areas. Parking in residential areas is often considered less important, and less effort has focused on its regulation. In this research, we focus on home parking and explore the impact of each home parking type on car ownership using a sample of 1056 households surveyed in the NZHTS between 2003 to 2017 in the GWR. We use a CL model to estimate the impacts and control for reverse causality between car ownership and parking through the $\mathrm{CF}$ approach (Hausman, 1978; Heckman, 1978; Petrin \& Train, 2010). 
Our results show a positive and statistically significant impact of home parking on car ownership, even after controlling for the reverse causality between car ownership and parking. There is high supply of home parking in the GWR. As a result of applying minimum parking requirements many houses have garage or driveway. Households may park on-street in front of their garage or driveway. Therefore, this policy provides a private on-street parking in addition to the on-site parking. This additional on-street parking increases the chance of households finding on-street parking and, according to this research, increases the probability of owning more cars. Off-street parking is already oversupplied in the GWR. For example, $71.4 \%$ of households in our sample have at least one on-site parking space more than their number of cars. Minimum parking norms continue to encourage owning more cars. In contrast with on-street parking (which is limited by demand form neighbors and could be regulated in the short-term) on-site parking is part of private property and takes longer to be affected by new regulations.

Maximum parking requirements are believed to contribute to reducing car ownership (Guo, 2013a, 2013b). According to this study, introducing maximum parking requirements on garages and driveways would considerably reduce the inclination for owning more than one car. Nonetheless, parking requirements usually target designed on-site parking (e.g. garages). In some cases, in the GWR, there are long driveways and some households may park in the open space around their house. This alternative use of space would limit effectiveness of any policy aimed at controlling parking supply. According to the results of our study, a driveway is an important determinant of having three or more cars. Also, the availability of on-street parking, as argued by Guo (2013a) and Guo and Ren (2013), limits the effectiveness of maximum parking requirements. This suggests an integrated policy for off-street and on-street parking in residential areas.

According to our research, living closer to work encourages lower car ownership. Households living in Wellington CBD or inner suburbs enjoy better PT coverage and AT is a sensible option for them. Some of these households have off-street home parking and on-street resident parking permits provide priority parking for residents. This parking availability may counteract the impact of commute time and with more car ownership in central suburbs, less on-street parking would be available for commuters work in these areas. These commuters waste more time cruising for parking and add to externalities, such as traffic congestion and greenhouse gas emissions. 
The impact of home parking (garage and driveway) on car ownership is stronger than the influence of working in the CBD. High home parking supply may reduce the effectiveness of CBD focused transportation policies to reduce private vehicle traffic in the CBD. An integrated parking policy which takes into account parking in both residential areas and the CBD may be more efficient. 


\title{
Chapter 5
}

\section{Work parking alternatives and mode choices}

\begin{abstract}
Little research models parking choice and mode choice simultaneously. However, parking availability undoubtedly affects commute mode choice. Overlooking mode choice in modeling parking choice might result in biased estimation of impacts. We design a joint model of parking choice and mode choice based on a Nested Logit model. We use novel demand-based measures for parking features and estimate their impacts on the parking behavior of drivers. We analyze trip data for 577 commuters living in the Greater Wellington Region (New Zealand) and working in Wellington City. We find that walking time from public off-street parking to work significantly discourages commuters for choosing public off-street parking. Walking time from an on-street parking to work is also a significant disincentive in choosing on-street parking. Public off-street parking cost does not significantly affect parking choice. However, cost of onstreet parking is important. Elasticities show that the changes in the probabilities of choosing another parking type are close to the changes in probabilities to choose non-driving modes, if any parking feature changes. These small differences in elasticities indicate the potential for achieving lower car use through parking restrictions and improving non-driving modes.
\end{abstract}




\subsection{Introduction}

Parking policies are intended to improve the parking condition by influencing commuters' travel behavior. Many parking studies focus on the parking choices of drivers (Chaniotakis \& Pel, 2015a; Hunt \& Teply, 1993; Meng, Du, Chong Li, \& Wong, 2018; Qin et al., 2020; Waraich \& Axhausen, 2012). In the literature (Bonsall \& Palmer, 2004; Ibeas et al., 2014; Kobus et al., 2013; Ruisong et al., 2009), parking policies are commonly assumed to be relevant to drivers and drivers react to new policies through changing their parking behavior (e.g. shifting to another parking type or location). However, mode choice is not independent of parking. Parking features at work might affect commuters' decisions about commute mode. Therefore, analyzing the mode choice in tandem with parking decisions should lead to more realistic results and policy outcomes.

Moreover, parking policies and research are dominated by the cost of parking (Gillen, 1977; Lei Ouyang, 2017; Nourinejad and Roorda, 2017). There is evidence that walking time from parking to work has a bigger impact on parking choice than parking cost (Hilvert et al., 2012) and commuters value walking time to their final destination more than in-vehicle time (Abrantes and Wardman, 2011; Small, 2012) and parking search time (Axhausen and Polak, 1991). In a congested city centre where commuters are time sensitive, finding a parking space close to work is important.

Competition for public parking affects the chance commuters have of finding parking spaces. A convenient but heavily used parking space might not be very useful to commuters. Instead, they might drive to a less convenient location where they have a higher probability of finding an empty space. Thus, commuters' perception of walking time from parking to work or the cost of parking can be strongly related to their chance of finding a free parking space. However, in most parking choice research, walking time or distance, and parking cost are measured without considering the probability of finding a parking space (for example, see Fulman et al., 2020; Hilvert et al., 2012; Soto et al., 2018).

Unlike many studies, we focus on the non-monetary cost of parking and calculate a measure for walking time from parking to work and parking cost that incorporates the probability of a commuter finding a parking space. We design a joint model of mode choice and parking choice to account for the tradeoff between the two choice sets. Parking choices include multiple types of off-street and on-street parking. Our results show the significant impact of walking time from parking to work and the insignificant impact of parking cost for public off-street parking 
choices. For on-street parking choice, the impact of parking dollar cost is bigger than the influence of the on-street parking quantity and walking time from parking to work. The results provide a new understanding of parking choices in relation to mode choice.

\subsection{Literature review}

\section{Competition for parking and the commuter's perception of parking features}

Public parking is subject to competition from other drivers. In the literature, some proxies are used for this competition including searching time (Hilvert et al., 2012; Ottomanelli et al., 2011), cruising time (Qin et al., 2020), waiting time (Hilvert et al., 2012; Hunt and Teply, 1993; Wang et al., 2015), or parking occupation rate (Fulman et al., 2020). The chance drivers have of finding a parking space, as a measure for this competition, is rarely considered in the literature. Moreover, the measures used in the literature represent the parking demand at the time of the survey or observation. Parking demand is dynamic and varies over time. For example, there is usually higher demand for parking on a rainy day, or a driver may arrive at the CBD later than they arrived on the survey day and have a lower chance to find a parking space.

Moreover, in the parking literature, competition for parking is considered as a different variable from walking time or distance to the final destination and parking cost (Chaniotakis and Pel, 2015b; Hunt, 1988). However, competition may affect drivers' perception of time and monetary costs of parking. Drivers may value walking time from a particular parking location to work based on their chance of finding a parking space in that location. The drivers save time in searching for parking in a quiet parking and might be more willing to walk from that parking location to work. A crowded parking lot next to work, or a crowded cheap parking lot might not be attractive. Including the chance to find a parking space in consideration of the time and monetary cost of parking measures should lead to more realistic results.

\section{Parking choice and mode choice}

Commuters may respond to a new parking policy in various ways, including shifting to another parking alternative, changing their trip schedule, or commute mode. Many studies model parking location choice (see for example Golias et al., 2002; Kobus et al., 2013). Other possible responses to parking policy change (e.g. shifting to non-driving modes) are overlooked. For instance, increasing walking time from parking to work or increasing parking fees may encourage some drivers to shift to public transport, or cycling to work. 
Few studies model parking choice and mode choice simultaneously. Hensher and King (2001) estimate the impact of parking features on choice among six parking-mode alternatives for commuters working in Sydney CBD. Three parking alternatives are in the CBD. The other three alternatives include parking outside the CBD and taking public transport to the CBD, taking public transport, and cancelling the trip to the CBD.

Simićević et al. (2013) estimate the impact of changes in parking cost and time limits on commute mode and parking choice in Serbia. Walking time from parking location to work location is not included in their model.

Changes in parking features at work might be responded to by shifting to carsharing. Passengers in a car enjoy the same short commute time as drivers and are usually less involved in finding a parking location than drivers. Some commuters in small or middle size cities may consider walking or cycling to work (active transport). Also, active transport is widely encouraged through several urban planning policies and projects aiming to enhance the walkability of cities and bicycle use around the world (Bicalho et al., 2019; Fishman, 2016; Gonzalez-Urango et al., 2020; Shaheen et al., 2010; Zhou et al., 2019). The absence of carpooling, walking, and cycling in mode choice modelling might limit the transferability of the results.

Yan et al. (2019) explore mode and parking choices of faculty and staff in University of Michigan, Ann Arbor, and find egress time (walking time from parking to the destination) more important than parking search time and cost. In their work, the case study is a campus where parking is subsidized and parking users are similar in terms of familiarity with parking regulations, parking duration, and availability of transit after parking. Parking options are the same type (paid off-street parking). More generally, parking policies often target cities where individuals with various socio-economic characteristics and compete for a variety of parking choices and pay market prices for parking. Therefore, as the authors also note, the results of this research cannot confidently be applied to parking policies for a general location with heterogeneous users.

Our research contributes to parking and modal choice studies in several ways. We consider all possible non-driving modes (e.g. walking, cycling, public transport and carpooling) along with driving in order to have a more comprehensive set of commuters' choices. 
Parking alternatives in our model cover most commonly available parking options in cities. Drivers may choose from public off-street parking, private off-street parking, and on-street parking. Instead of sampling parking stations, we consider all off-street and on-street parking in the city to cover all possible options.

Probability of parking in a parking space is measured based on the number of address points within a maximum walking time of the parking space. This measure captures potential competition from all individuals who work or live nearby. Our measure does not depend on a particular time of observation and is more reliable for long-term policy considerations.

Some studies consider the exact parking space or building where each driver is parked at the time of the survey (Yan et al., 2019; Hensher and King, 2001). However, the chosen parking building or space may vary over the week depending on parking availability and the time at which the driver arrives. Commuters consider all parking near their work and may choose any of them depending on the parking situation on the day. For example, a driver who chose a particular on-street parking space on the survey day may change to another space with different features in the next day. We consider parking type (and not the exact parking location) as a measure for parking choice to account for this possibility. For each commuter, the features of each parking type are the average of parking features of that type near their work.

Within a maximum walking time to each commuter's work, we calculate walking time from each parking space to the commuter's work. Then, we calculate the weighted average of the walking times with respect to the probability of finding a space in each parking location. Similarly, our measure for parking cost is the weighted average of parking cost with respect to the probability of finding a parking space in each location.

\subsection{Methodology}

Commuters can choose AT, PT, carpooling, or driving as their commute mode. The four parking alternatives are public off-street, private off-street, on-street without time limit, and “other" parking types. ${ }^{6}$ We use a CL to model mode and parking choices.

In a CL model, the ratio of the probability of choosing an alternative over probability of choosing other alternative should not change if any other alternative is added to the model (Greene, 2003). This property is called Independence of Irrelevant Alternatives (IIA) and must

\footnotetext{
${ }^{6}$ This is a category in the NZHTS including non-specified parking type and drivers who parked in an on-street parking location with time limit.
} 
hold among choices (Greene, 2003). We use the Hausman-McFadden test (Hausman and McFadden, 1984) to test for IIA comparing the full model (including all parking and mode alternatives) and a restricted model (where parking alternatives are chosen in nest once driving has been selected as a modal choice). This test statistic is calculated as

$$
H M=\left(\beta_{r}-\beta_{f}\right)^{\prime}\left(V_{r}-V_{f}\right)^{-1}\left(\beta_{r}-\beta_{f}\right),
$$

in which $\beta_{r}$ and $\beta_{f}$ are estimated parameters of the restricted and full models, respectively. $V_{r}$ and $V_{f}$ are the variance-covariance matrix of the restricted and full models respectively (Hensher et al., 2013). $H M$ has a chi-squared distribution with $K$ degrees of freedom. $K$ is the number of variables in the restricted model. If $H M$ statistic is greater than the upper tailed chisquared critical value at $1-\alpha$ ( $\alpha$ is the significance level) at $K$ degrees of freedom, we would reject the IIA assumption (Greene, 2003). In that case, we should use a Nested Logit (NL) model. In the NL model, the commute modes are nests, and the four parking options are alternatives. The nest structure is shown in Figure 5.1.

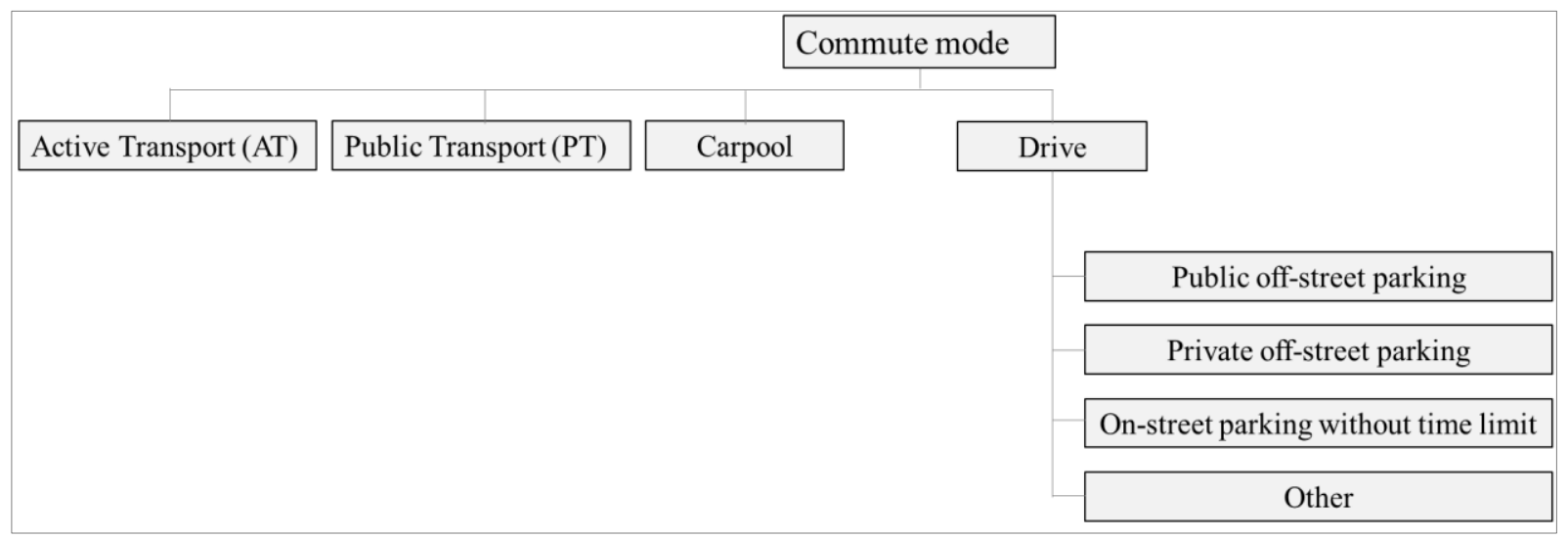

Figure 5.1. Nest structure of mode choice and parking choice

There is only one alternative in nests AT, PT, and Carpool. In econometrics, a nest with one alternative in a NL model is called a degenerate branch. It is only a name referring to the structure of the nest and does not mean theses branches receive less attention in the estimation. Later we show that the probability of choosing a parking alternative depends on the probability of choosing the nest 'Drive', which depends on the probability of choosing non-driving modes. Our model is a partially degenerate NL (Louviere et al., 2000). The utility of individual $i$ from alternative $r$ in nest $K\left(U_{i r}\right)$ is calculated as

$$
U_{i r}=V_{i K}+W_{i r}+\varepsilon_{i k}+\mu_{i r}
$$


in which, $V_{i K}$ and $W_{i r}$ are observed components of utility from nest $k$ and alternative $r$ in nest $K$ respectively. $\varepsilon_{i K}$ and $\mu_{i r}$ are unobserved components of utilities from nest $K$ and alternative $r$ respectively. The observed components are calculated as

$$
\begin{gathered}
V_{i K}=\sum_{m} \delta_{m} Z_{i m K}, \\
W_{i r}=\sum_{n} \theta_{n} G_{i n r},
\end{gathered}
$$

in which, $Z_{i m K}$ are the nest-specific variables, $G_{i n r}$ are the alternative specific variables, $\delta$ and $\theta$ are coefficient vectors (Train, 2009).

In this model, the probability of choosing alternative $\mathrm{r}$ in nest $K\left(P_{\text {ir }}\right)$ is calculated as

$$
P_{i r}=P_{i K} \times P_{i r \mid i K}
$$

in which, $P_{i K}$ is the probability of choosing nest $K$ (marginal probability) and $P_{i r \mid i K}$ is the probability of choosing alternative $r$, given nest $K$ is chosen (conditional probability). In a NL model with $q$ nests and $K(k)$ as the set of choices in nest $K$, the probabilities are calculated as

$$
\begin{gathered}
P_{i K}=\frac{\exp \left(V_{i K}+\lambda_{K} I_{i K}\right)}{\sum_{h=1}^{q}\left(V_{i h}+\lambda_{h} I_{i h}\right)}, \\
P_{i r \mid i K}=\frac{\exp \left(W_{i r} / \lambda_{K}\right)}{\sum_{j \in R(K)} \exp \left(W_{i j} / \lambda_{k}\right)},
\end{gathered}
$$

in which, $I_{i k}$ is called the Inclusive Value (IV) for nest $K$ and is calculated as

$$
I_{i K}=\ln \sum_{j \in R(K)} \exp \left(W_{i j} / \lambda_{k}\right)
$$

The estimated value for $\lambda_{k}$ as the coefficient of IV, shows the degree of independence of alternatives in the nest $k$ (Train, 2009).

There are two methods to estimate parameters in a NL model: sequential and simultaneous. In the sequential method, the NL is decomposed into two CLs. Starting from the lower model (alternatives), parameters are estimated at this level. Based on the estimated parameters, IV is calculated for each nest. Subsequently, parameters are estimated for the upper model (mode choice) (Louviere et al., 2000). This method has some drawbacks. The estimates are consistent but inefficient. Moreover, the values in the variance-covariance matrix of estimates are 
incorrect and small (Amemiya, 1978; Ryoo and Lee, 2004). Standard errors in the nest-level estimation are underestimated (Amemiya, 1978; Train, 2009). Therefore, the estimated t-test values in the upper model are biased upward (Train, 2009).

In the simultaneous estimation, parameters for the upper and lower models are estimated simultaneously. The estimated parameters in this method are consistent and efficient (Ryoo and Lee, 2004; Train, 2009). We adopt simultaneous estimation in this research. In this method, $P_{\text {ir }}$ is calculated based on Equation (5.5). The log likelihood is calculated based on $P_{\text {ir }}$ and maximized using the BFGS (Broyden- Fletcher-Goldfarb-Shano) algorithm (see Broyden (1970), Fletcher (1970), Goldfarb (1970), and Shanno (1970)).

According to Greene (2003) and Louviere et al. (2000), in simultaneous estimation of a partially degenerate NL model, one of the alternatives is considered as reference. For example, Batley and Hess (2016) use an NL model to study commuting choices. The respondents are assigned three choices of journey. In their nest structure, the first journey is a degenerate choice, while the other two are nested. The first journey is the reference in their NL model. We have data on parking features for public off-street and on-street parking. Due to the small number of observations and difficulties in interpreting the "Other" group, we set private off-street parking as the reference in the lower model. Non-driving modes are compared with driving in the upper mode.

Some commuters may not have access to on-street parking, and some may not have access to a public off-street parking location within their maximum walking time. We set the utility and probability of on-street parking as zero for the first group and set the utility and probability of public off-street parking as zero for the second group.

\subsubsection{Elasticities of mode and parking alternatives}

We calibrate a joint mode and parking choice model. One of the benefits of this model is the ability to assess commuters' responses to changes in parking features. We estimate elasticities to interpret the percentage change in the probability of choosing an alternative given a $1 \%$ change in an explanatory variable. If the explanatory variable is an attribute of the alternative, that is termed a direct elasticity, and if relevant to another alternative, it is named a cross elasticity (J. J. Louviere et al., 2000). We calculate elasticities for each individual based on Forinash and Koppelman (1993) as shown in Table 5.1. We calculate an elasticity for each alternative given a change in the alternative $b$ 's attribute $\left(Z_{b}\right)$, where alternative $b$ is in nest $K$. 
Table 5.1. Calculating elasticities

\begin{tabular}{lc}
\hline Alternative considered & Elasticity \\
\hline Alternative a not in nest $\mathrm{K}$ & $-P_{b} \beta_{z} Z_{b}$ \\
Alternative $\mathrm{b}$ in nest $\mathrm{K}$ & {$\left[\left(1-P_{K}\right) P_{b \mid K}+\frac{1}{\lambda_{K}}\left(1-P_{b \mid K}\right)\right] \beta_{z} Z_{b}$} \\
Alternative c in nest $\mathrm{K}$ & $-\left[P_{b}+\frac{1-\lambda_{K}}{\lambda_{K}} P_{b \mid K}\right] \beta_{z} Z_{b}$ \\
\hline
\end{tabular}

In Table $1, P_{b}$ is the probability of choosing alternative $b, \beta_{z}$ is the correspondent coefficient for $Z_{b}, P_{b \mid K}$ is the probability of choosing alternative $b$ conditional on choosing nest $K, \lambda_{K}$ is the coefficient of the IV for the nest $K$.

We use the probability-weighted sample enumeration method (Parady, 2015; Yan et al., 2019) to calculate direct elasticities as

$$
E_{X_{i j k}}^{P(j)}=\frac{\sum_{i} P_{i j}(j) E_{X_{i j k}}^{P(j)}}{\sum_{i} P_{i j}(j)},
$$

and cross elasticities as

$$
E_{X_{i l k}}^{P(j)}=\frac{\sum_{i} P_{i j}(j) E_{X_{i l k}}^{P(j)}}{\sum_{i} P_{i j}(j)}
$$

in which, $E_{X_{i j k}}^{P(j)}$ is direct elasticity of alternative $j, E_{X_{i l k}}^{P(j)}$ is the cross elasticity of alternative $j$ with respect to change in alternative $l$ 's attribute, $P_{i j}(j)$ is the estimated probability of choosing alternative $j$ by the individual $i$, and $X_{i j k}$ and $X_{i l k}$ are the attributes of alternatives $j$ and $l$ respectively.

\subsection{Case study and data}

We study 577 heads of households who live in the GWR and have a fixed workplace in Wellington City. Wellington City has various zones in terms of parking regulations. Our sample covers all these zones to have more realistic results. The compact Wellington Central Business District (CBD) contains most of the workplaces, and limited residential locations. There is a high demand for parking and many drivers pay to park in a public off-street building or lot. On-street parking has a two-hour time limit and drivers using it pay per hour.

Fewer workplaces are in the suburbs surrounding the CBD. In the suburbs, few off-street parking buildings are available and users pay monthly for coupon parking. In the suburbs' centres, time limits apply on on-street parking. Commuters who work here also compete with 
residents for on-street spots. The rest of Wellington City is dominated by residential neighborhoods. Abundant free on-street parking is available for commuters and residents to park. Moreover, employer-provided off-street parking at work is common (Figure 5.2).

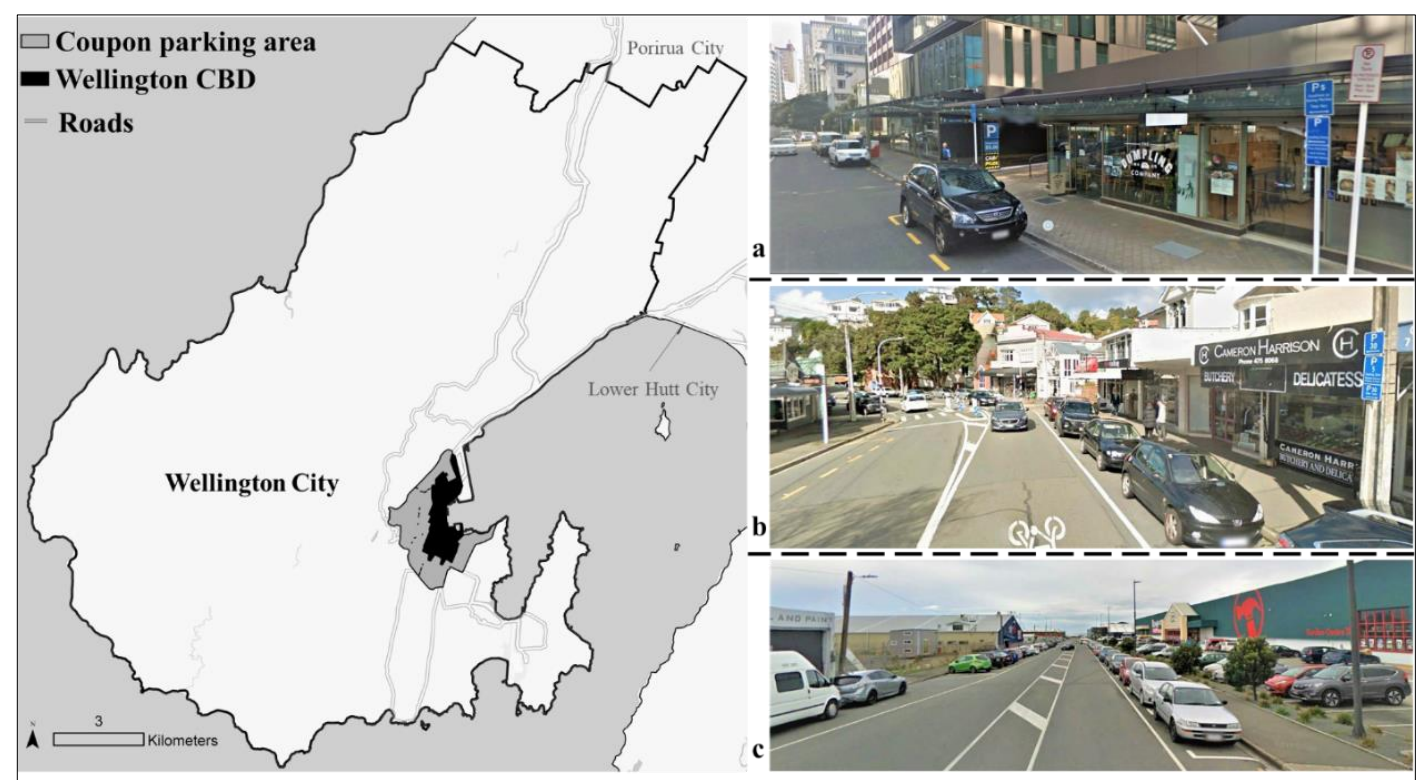

Figure 5.2. Wellington CBD (a), coupon parking area (b), rest of Wellington City (c) (Source: CBD and coupon parking zones: Wellington City Council, (2019b) and (2019a); Images: Google Earth)

Parking features are the main explanatory variables in the model. To collect data on parking, we find the maximum walking time that drivers are willing to walk from parking to their work (maximum egress time). According to the literature (Pandhe and March, 2012; Chaniotakis and Pel, 2015; Van Der Waerden et al, 2017; Hensher and King, 2001), walking distance from parking to work is between 50 to 700 meters (Table 5.2). Considering the average walking speed as $4.6(\mathrm{~km} / \mathrm{h})$, this distance range is converted as one to 14 minutes. Hensher and King (2001) suggest a range of 1 to 25 minutes of egress time.

Table 5.2. Maximum walking distance or time between parking and work

\begin{tabular}{lll}
\hline Distance or time from parking to the final destination & Case study & Source \\
\hline 300 meters & Australia & Pandhe and March (2012) \\
100 meters for on-street & Netherland & Chaniotakis and Pel (2015) \\
700 meters for off-street (shopping trips) & & \\
A range between 50 meters to more than 500 meters & Netherland & Van Der Waerden et al. (2017) \\
one, three, five minutes (close in CBD), seven, nine, 11 & Sydney, & Hensher and King (2001) \\
minutes (elsewhere in CBD) and 15, 20, 25 minutes & Australia & \\
(fringe of CBD) & & \\
\hline
\end{tabular}


We choose the maximum walking time based on the last trip leg of drivers who parked in a public off-street parking or on-street parking (i.e. walking time from parking to work) as reported in the NZHTS. Most of the drivers (59\%) walk up to five minutes from parking to work. Walking longer than five minutes up to 10 minutes is observed for $28 \%$ of drivers. Wellington City is different from the other cities studied in the literature (Table 5.2.). The city is smaller and partly hilly, and long walking times may not be reasonable for this case. Also, the city is relatively hilly and long distances may seem unrealistic. We collect data on parking features within five minutes and 10 minutes egress time.

Table 5.3 describes variables used in this chapter followed by further explanation of some variables in Sections 5.4.1 to 5.4.4.

Table 5.3. Variables used in Chapter 5

\begin{tabular}{|c|c|c|}
\hline Variable & Definition & Source \\
\hline Commute mode & $\begin{array}{l}\text { Commute mode of the head of household in a journey to } \\
\text { work (dummy for Drive, Carpool, PT, and AT) }\end{array}$ & NZHTS \\
\hline Parking choice & $\begin{array}{l}\text { Parking type where the driver parked (dummy for public off- } \\
\text { street parking, private off-street parking, on-street parking, } \\
\text { and "other" parking). }\end{array}$ & NZHTS \\
\hline Egress time off-street & $\begin{array}{l}\text { Weighted average of walking time from all public off-street } \\
\text { parking locations within a maximum walking time around } \\
\text { work, with respect to the probability of finding a public off- } \\
\text { street parking space (in minutes) (see section 5.4.1) }\end{array}$ & See section 5.4 .1 \\
\hline Egress time on-street & $\begin{array}{l}\text { Weighted average of walking time from all on-street parking } \\
\text { spaces within a maximum walking time around work, with } \\
\text { respect to the probability of finding an on-street parking } \\
\text { space (in minutes) (see section 5.4.1) }\end{array}$ & See section 5.4 .1 \\
\hline Cost off-street & $\begin{array}{l}\text { Weighted average of daily cost of all public off-street } \\
\text { parking locations within a maximum walking time around } \\
\text { work, with respect to the probability of finding a public off- } \\
\text { street parking space (unit = NZD10) }\end{array}$ & $\begin{array}{l}\text { Wilson Parking and } \\
\text { each parking } \\
\text { providers' website }\end{array}$ \\
\hline Cost on-street & $\begin{array}{l}\text { Weighted average of daily cost of all on-street parking spaces } \\
\text { within a maximum walking time around work, with respect } \\
\text { to the probability of finding an on-street parking space }\end{array}$ & $\begin{array}{l}\text { Wilson Parking and } \\
\text { each providers' } \\
\text { website }\end{array}$ \\
\hline
\end{tabular}


Table 5.3. continued

\begin{tabular}{|c|c|c|}
\hline Variable & Definition & Source \\
\hline Quantity off-street & $\begin{array}{l}\text { Total number of publicly available public off-street parking } \\
\text { spaces within a maximum walking time around work (unit = } \\
1000 \text { spaces) }\end{array}$ & $\begin{array}{l}\text { Wilson Parking } \\
\text { Google Satellite view } \\
\text { and a site validation }\end{array}$ \\
\hline Quantity on-street & $\begin{array}{l}\text { Total number of publicly available on-street parking spaces } \\
\text { within a maximum walking time around work (unit }=100 \\
\text { spaces) }\end{array}$ & $\begin{array}{l}\text { Wilson Parking } \\
\text { Google Satellite view } \\
\text { and a site validation }\end{array}$ \\
\hline D_Public off-street & $\begin{array}{l}\text { Access to a Public off-street parking location within a } \\
\text { maximum egress time (dummy) }\end{array}$ & See section 5.4.1 \\
\hline D_Private off-street & $\begin{array}{l}\text { Private off-street parking in the block the commuter works } \\
\text { (dummy) }\end{array}$ & $\begin{array}{l}\text { Google Satellite view } \\
\text { Google Street View }\end{array}$ \\
\hline Commute time & $\begin{array}{l}\text { Travel time in a journey from home to work for each mode in } \\
\text { hours (Drive time, PT time, AT time) }\end{array}$ & $\begin{array}{l}\text { Calculations in } \\
\text { ArcMap based on } \\
\text { Daglish et al. (2015) }\end{array}$ \\
\hline Income & 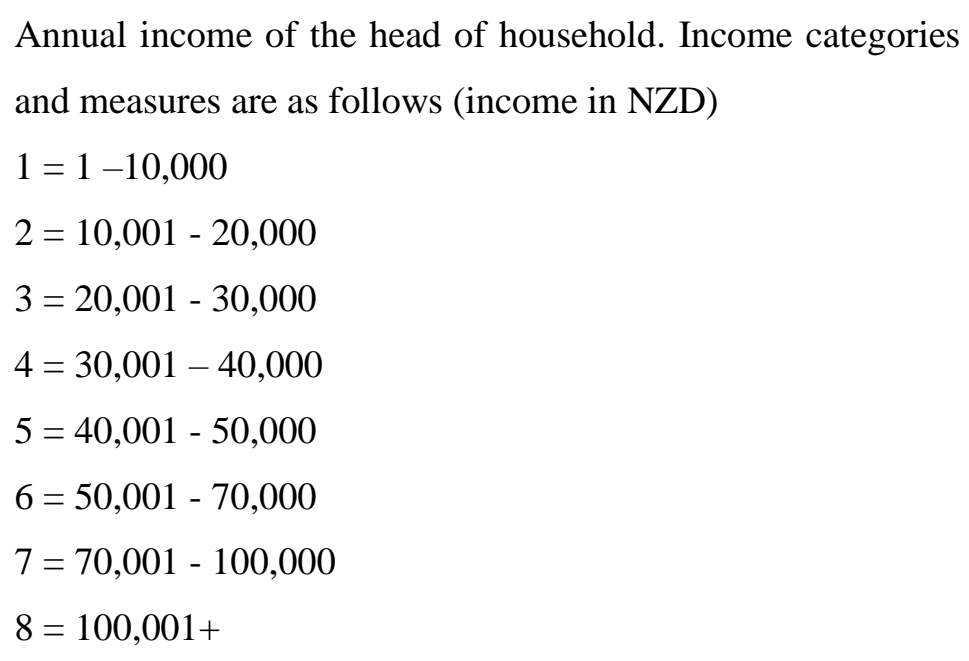 & NZHTS \\
\hline Work_CBD & Working in Wellington CBD (dummy) & NZHTS \\
\hline Car ownership & $\begin{array}{l}\text { Number of cars in household (dummy for no car, one car, two } \\
\text { cars and three or more cars) }\end{array}$ & NZHTS \\
\hline HH_Child & Household with children (dummy) & NZHTS \\
\hline D_Female & Household with female head (dummy) & NZHTS \\
\hline D_Full-time & Working full-time (dummy) & NZHTS \\
\hline Work_Free Parking & $\begin{array}{l}\text { Dummy for working in the free on-street parking zone } \\
\text { (dummy) }\end{array}$ & NZHTS \\
\hline D_early arrival & Arriving at work at 9 a.m. or earlier (dummy) & NZHTS \\
\hline
\end{tabular}




\subsubsection{Walking time from parking to work (Egress time)}

Public off-street parking buildings are based on addresses received from Wilson Parking, observed in Google Street View, and field observation. Vector lines for on-street parking are drawn along curbs in ESRI ArcMap 10.6 where a parking space without a time limit is observed through Google Satellite and Street View. For carparks aligned with the street curb, each line segment of 5.5 meters ( 5 meters for vehicle length and 0.5 meters for the distance between vehicles) is converted to a vector point. For angled parking, each line segment of 2.5 meters (two meters as vehicle width) is converted to a vector point. Workplaces are based on coordinates provided in the NZHTS dataset. Address points are provided by Land Information New Zealand (2020).

Pedestrian entrances of off-street parking, on-street parking points, and workplaces are placed on pedestrian routes in an adapted walking network in ESRI ArcMap 10.6.1 based on Daglish et al. (2015). Within the maximum walking time of each commuter, we calculate walking time from each parking point to work for both public off-street parking and on-street parking separately. In some cases, with multiple entrances for public off-street parking, we consider the closest entrance.

We posit that the probability of a driver parking in a particular parking space is inversely proportional to the number of drivers also considering parking in there. For example, suppose a driver is faced with the choice between two identically sized parking buildings. One is frequented by 200 other motorists, the other by only 100 . We assume that the driver parks in the quiet building two thirds of the time and in the busy building one third of the time.

We calculate the weighted average of the walking time from parking to work with respect to the probability of parking in a particular parking space. Our measure for the demand for parking location $\mathrm{j}\left(\right.$ Demand $\left._{j}\right)$ is calculated as the number of address points such that a commuter's five minutes or 10minutes walking time contains the particular parking space $\left(n_{j}\right)$. We then scale inverse demands to convert into probabilities of the motorist parking in each location. We calculate the weighted average of walking time with regard to the probability of finding a parking space for individual $i\left(\right.$ Egress $\left._{\text {time }}\right)$ as

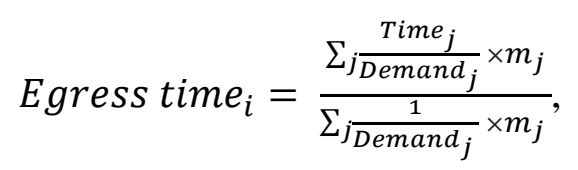

where Time $_{j}$ is the walking time from the parking $\mathrm{j}$ to the commuter $i$ 's work. In doing this, we scale each location by the number of parking spaces it provides $\left(m_{j}\right) . m_{j}$ is equal to one for 
on-street parking and $m_{j}>1$ for public off-street parking building or lot. This variable is calculated for public off-street parking and on-street parking separately as two explanatory variables.

\subsubsection{Cost of parking}

Cost of public off-street parking is provided by Wilson Parking and each provider's website. Cost is reported as hourly, daily, weekly, and monthly. We choose daily parking costs as commuters often park for all day. Coupon parking fees are retrieved from Wellington City Council (2019a). On-street parking outside the coupon parking zones is free of charge. Our measure for parking cost is the weighted average of daily parking cost with respect to the probability of parking in each space $\left(\operatorname{Cost}_{i}\right)$ :

$$
\text { Cost }_{i}=\frac{\sum_{j} \frac{\text { Parking Cost }_{j}}{\text { Demand }_{j}} *\left(m_{j}\right)}{\sum_{j} \frac{1}{\text { Demand }_{j}} *\left(m_{j}\right)},
$$

where Parking Cost Pis $_{j}$ the daily cost of parking location $j$. The parking cost measure is calculated for off-street and on-street parking separately.

\subsubsection{Quantity of parking}

Parking quantity is calculated as the total number of publicly available off-street or on-street parking spaces within the maximum walking time of a commuter. We do not consider parking spaces with a time limit less than seven hours.

\subsubsection{Existence of private off-street parking in the block}

Most relevant studies focus on public parking subject to public policies and where data is available (Bonsall and Palmer, 2004; Ottomanelli et al., 2011; Wang et al., 2015). However, private off-street parking, such as employer-provided parking, is common in many cities. Private parking usually costs less than the market price, is close to work, and less competitive. We consider private off-street parking as a parking alternative to account for this choice. We use Google Satellite View and Google Street View to observe private off-street parking within the blocks where commuters work. Any off-street parking not available for the public is recorded as private off-street parking.

\subsection{Summary statistics}

Table 5.4 shows summary statistics of variables in the model for heads of households. Driving is the most popular mode ( $52 \%$ drive and $31 \% \mathrm{PT}$ ). In calculating statistics for commute time 
of a mode, we consider all commuters and not only the users of that mode. This enables us to discuss the relationship between commute time with each mode and the preference for that mode.

Table 5.4. Commuters summary for Chapter 5

\begin{tabular}{|c|c|c|c|c|c|}
\hline Variable & Mean & S.D. & Minimum & Maximum & Number of observations \\
\hline Dummy for AT & 0.08 & 0.27 & 0 & 1 & 577 \\
\hline Dummy for driving & 0.52 & 0.50 & 0 & 1 & 577 \\
\hline Dummy for Carpool & 0.10 & 0.29 & 0 & 1 & 577 \\
\hline Dummy for PT & 0.31 & 0.46 & 0 & 1 & 577 \\
\hline AT time & 1.27 & 0.74 & 0.04 & 3.62 & 570 \\
\hline PT time & 0.73 & 0.36 & 0.04 & 2.75 & 577 \\
\hline Drive time & 0.22 & 0.18 & 0.00 & 1.87 & 577 \\
\hline Income & 6.00 & 1.85 & 0 & 8 & 577 \\
\hline Car ownership & 1.57 & 0.87 & 0 & 6 & 577 \\
\hline Work_CBD & 0.70 & 0.46 & 0 & 1 & 577 \\
\hline HH_Child & 0.37 & 0.48 & 0 & 1 & 577 \\
\hline D_Female & 0.48 & 0.50 & 0 & 1 & 577 \\
\hline Dummy for Public off-street parking & 0.08 & 0.27 & 0 & 1 & 577 \\
\hline Dummy for Private off-street parking & 0.35 & 0.48 & 0 & 1 & 577 \\
\hline Dummy for Public on-street parking & 0.06 & 0.23 & 0 & 1 & 577 \\
\hline Dummy for "other" parking & 0.03 & 0.18 & 0 & 1 & 577 \\
\hline D_Public off-street & 0.76 & 0.43 & 0 & 1 & 577 \\
\hline Egress time off-street & 2.74 & 0.89 & 0.10 & 4.90 & 440 \\
\hline Cost off-street & 1.89 & 0.48 & 0.4 & 2.92 & 440 \\
\hline Quantity off-street & 1.033 & 0.65 & 0.01 & 2.80 & 440 \\
\hline Egress time on-street & 3.72 & 0.75 & 1.21 & 5.00 & 398 \\
\hline Cost on-street & 5.81 & 3.92 & 0.00 & 8.50 & 398 \\
\hline Quantity on-street & 1.07 & 1.14 & 0.01 & 6.24 & 398 \\
\hline D_Public off-street & 0.79 & 0.41 & 0 & 1 & 577 \\
\hline Egress time off-street & 6.02 & 1.33 & 0.24 & 9.70 & 454 \\
\hline Cost off-street & 1.83 & 0.40 & 0.4 & 2.41 & 454 \\
\hline Quantity off-street & 3.88 & 2.04 & 0.000 & 6.90 & 457 \\
\hline Egress time on-street & 7.56 & 1.11 & 1.81 & 9.87 & 557 \\
\hline Cost on-street & 6.54 & 3.49 & 0.00 & 8.5 & 557 \\
\hline Quantity on-street & 3.89 & 3.66 & 0.01 & 18.92 & 557 \\
\hline
\end{tabular}


Table 5.4. continued

\begin{tabular}{|c|c|c|c|c|c|}
\hline Variable & Mean & S.D. & Minimum & Maximum & Number of observations \\
\hline D_Public off-street & 0.79 & 0.41 & 0 & 1 & 577 \\
\hline Egress time off-street & 6.02 & 1.33 & 0.24 & 9.70 & 454 \\
\hline Cost off-street & 1.83 & 0.40 & 0.4 & 2.41 & 454 \\
\hline Quantity off-street & 3.88 & 2.04 & 0.000 & 6.90 & 457 \\
\hline Egress time on-street & 7.56 & 1.11 & 1.81 & 9.87 & 557 \\
\hline Cost on-street & 6.54 & 3.49 & 0.00 & 8.5 & 557 \\
\hline Quantity on-street & 3.89 & 3.66 & 0.01 & 18.92 & 557 \\
\hline D_Priavte off-street & 0.79 & 0.41 & 0 & 1 & 577 \\
\hline D_Full-time & 0.88 & 0.33 & 0 & 1 & 577 \\
\hline Work_Free Parking & 0.25 & 0.43 & 0 & 1 & 577 \\
\hline
\end{tabular}

Half of the commuters (50.3\%) who live closer than the average driving time (12.9 minutes) to their work drive. This share increases to $55.9 \%$ for households who live farther from work.

Walking or cycling are the choices of many households where the trip is less than 20 minutes walking or cycling. Beyond the 20 minutes, $53.4 \%$ of commuters drive (Figure 5.3).

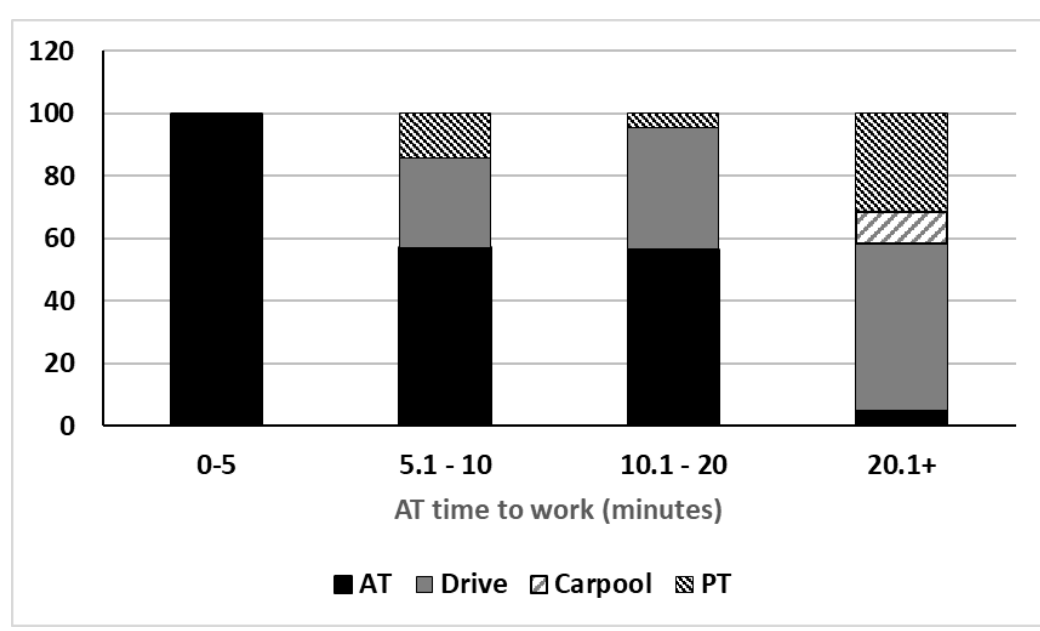

Figure 5.3. Share of mode users in each AT time to work category (\%) (Source: NZHTS)

Having a car might encourage driving to work. More than four out of five carless households (86.2\%) use AT or PT. Half of households with one car (49.6\%) drive or carpool. Households with two or more cars rarely choose AT or PT, instead $67.8 \%$ of them drive to work. Although having no car might be an incentive to drive less, only $5 \%$ of the sample are households without car. Many commuters (95\%) have at least one car and 54.6\% of them drive (Table 5.5). 
Table 5.5. Share of households' heads in car ownership categories (\%)

\begin{tabular}{lrrrrr}
\hline Car ownership & \multicolumn{1}{c}{ AT } & \multicolumn{1}{c}{ Drive } & Carpool & PT & Total \\
\hline 0 & 34.48 & 6.90 & 6.90 & 51.72 & 100 \\
1 & 10.07 & 41.73 & 7.91 & 40.29 & 100 \\
$2+$ & 2.59 & 67.78 & 11.48 & 18.15 & 100 \\
\hline \multicolumn{5}{c}{ (Source: NZHTS) }
\end{tabular}

An average household head earns NZD50,000 to NZD70,000 per year. There is no considerable difference between households below and above this average in terms of mode choice. For instance, $30.6 \%$ of commuters below the average income take PT. This share is $30.33 \%$ for households above the average. Driving is the choice of $51.4 \%$ of commuters below the average income and the choice of $53.5 \%$ of the households above the average. Most households drive regardless of their income. Seventy percent of commuters work in the Wellington CBD. As parking is expensive and competitive, less than half (40.6\%) of these commuters drive to the CBD. Full-time workers are more likely to consider the costs of traveling because they commute every day. The majority of full-time workers (51.1\%) drive to work. Having children makes a household more car-dependent. In our sample, driving is the choice of $63.7 \%$ of commuters with children. Male commuters are more likely to use AT than female commuters ( $10.7 \%$ of male commuters use AT, while $4.7 \%$ of female commuters walk or cycle). In contrast, $63 \%$ of women drive or carpool. This share is $38.1 \%$ among the male commuters.

Most public off-street parking buildings are in the Wellington CBD. More than three quarters (76\%) of commuters have access to a public off-street parking location within 5 minutes egress time. This share rises to $79 \%$ for the area of 10 minutes walking. Public off-street parking is chosen by $15.3 \%$ of drivers.

Within the 5 minutes egress time, public off-street parking is on average 2.7 minutes walking from work. Public off-street parking further away is less attractive. Public off-street parking is chosen by of $26.6 \%$ of drivers who work closer than 2.7 minutes walk from parking and $21.3 \%$ of drivers who work further away (Figure 4.4). Getting farther from public off-street parking makes private parking a more popular choice. If public off-street parking is farther than the average egress time, the share of private off-street parking users increases by $4.2 \%$ (Figure 5.4). 


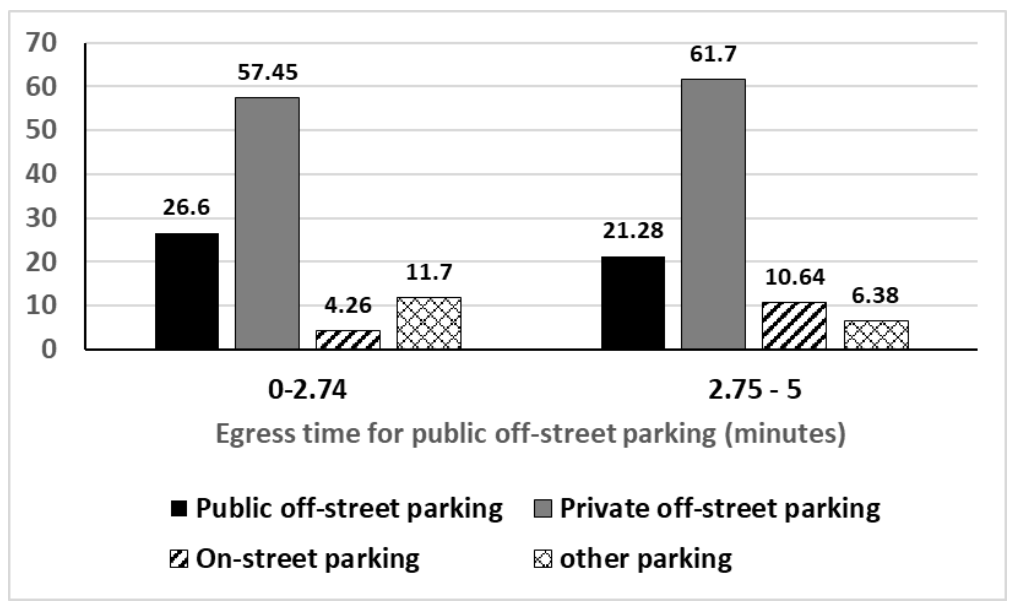

Figure 5.4. Share of drivers below and above average egress time for public off-street parking (\%) (Source: NZHTS)

On average, it costs NZD18.9 per day to park in a public off-street parking location within five minutes walking to work. An average commuter has access to 1033 public off-street parking spaces within five minutes walking of work. A high standard deviation indicates the uneven distribution of this parking type. Public off-street parking is the choice of $18.3 \%$ of drivers with 1033 or less public off-street parking spaces. Private off-street parking is less popular when more public off-street parking spaces are available (Table 5.6).

Table 5.6. Share of drivers in each public off-street parking quantity category (\%)

\begin{tabular}{llllll}
\hline $\begin{array}{l}\text { Number of off-street parking } \\
\text { spaces }\end{array}$ & $\begin{array}{l}\text { Public off-street } \\
\text { parking }\end{array}$ & $\begin{array}{l}\text { Private off-street } \\
\text { parking }\end{array}$ & $\begin{array}{l}\text { On-street } \\
\text { parking }\end{array}$ & Other & Total \\
\hline $9-1033$ & 18.33 & 63.33 & 10.83 & 7.50 & 100 \\
More than 1033 & 33.82 & 52.94 & 1.47 & 11.76 & 100 \\
\hline
\end{tabular}

(Source: NZHTS)

Workers enjoy free on-street or cheap coupon parking outside Wellington CBD which is less competitive. On-street parking is accessible by $69 \%$ of the commuters within five minutes of walking to work. Within 10 minutes of walking from work, $97 \%$ of the individuals have access to on-street parking. This type of parking is chosen by of $14 \%$ of drivers outside the CBD.

On average, on-street parking is 3.72 minutes from the commuters' work. When egress time for on-street parking is above the average, the share of drivers who choose on-street parking reduces and instead, the share of drivers who choose public off-street parking increase (Figure $5.5)$. 


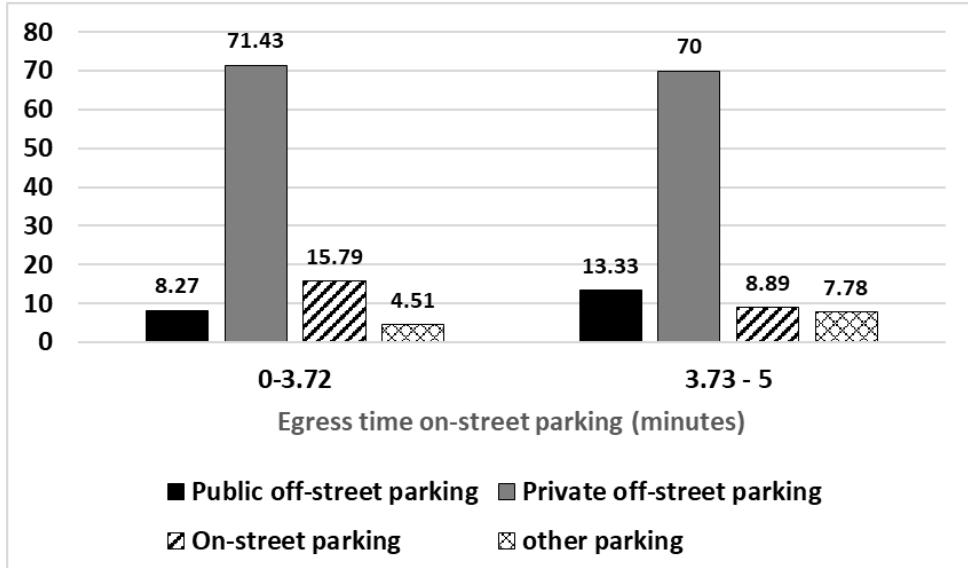

Figure 5.5. Share of drivers below and above average of egress time for on-street parking (\%) (Source: NZHTS)

In coupon parking areas (where parkers pay for coupon parking), only $5 \%$ of drivers park in on-street parking. This ratio is $69.7 \%$ for drivers who work outside the coupon parking areas and enjoy free on-street parking.

Private off-street parking is the most popular parking option. Seventy-nine percent of commuters have private parking in the block they work. This parking supply is probably a reason for the high share of driving and the popularity of this parking alternative. Most drivers (67.4\%) park in a private off-street parking. A high supply of private off-street parking is observed in the free of charge on-street parking zone. Many commuters who work in this area $(95.1 \%)$ have a private parking lot next to their work, and $76.7 \%$ of the drivers who work here park in a private off-street parking. A high supply of private off-street parking outside the CBD may reduce the efficiency of on-street parking policies because drivers are less likely to take into account on-street parking regulations.

\subsection{Results and discussion}

We calculate the $H M$ statistic as 48.3 for the sample and compare it with the chi-squared critical values. The significance level is $5 \%(\alpha=0.05)$. We compare the $H M$ statistic with the upper tail chi square critical values. The statistic is greater than the upper tail critical value at 19 degrees of freedom (30.1). The IIA assumption does not hold and we use the NL model.

Table 5.7 shows the NL model results within five minutes egress time. AT and PT are popular choices. In line with the literature, more cars in a household is a motivation to drive (He et al., 2017; Vij et al., 2017). The exponentiate of a coefficient of a variable shows the change in the odds ratio of the choice with regard to one unit change in the explanatory variable. Having one car reduces the preference of PT over driving by $51 \%(\exp (-0.71)=0.49)$ and the preference 
of AT over driving by $78 \%$ (exp $(-1.53)=0.22)$. Households with more cars are more likely to drive to work which, consequently, adds to the demand for parking and other car-related externalities in the main business areas.

Driving to the CBD is more expensive than other areas, mainly due to parking restrictions, competitiveness, and traffic congestion. Among the commuters who work in the CBD, PT is significantly preferred and is 8.6 times more probable than driving. High demand for PT indicates that improving PT facilities and services would benefit CBD workers. AT is also a popular choice, yet not significantly, because AT is only a viable choice for commuters who are in walking or biking distance to the CBD.

In line with the literature (Ko et al., 2019; Kim and Ulfarsson, 2008), households with children are more car-dependent. A household with children is 1.8 times more likely to choose driving over PT and 3.3 times more willing to drive than to walk or cycle to work. Carpooling is not significantly different from driving, because in some cases it is likely that another member of the household is driving the household head to work and children to school.

Female commuters are less likely to choose AT than their male counterparts. However, there is not a significant difference between male and female commuters in terms of mode choice.

Table 5.7. NL estimates for mode and parking choices (maximum egress time $=$ five minutes)

\begin{tabular}{llrll}
\hline Variables & Alternatives & Parameter estimate (t-test) \\
\hline Mode choice variables & & & & \\
Constants & PT & 2.70 & $(3.24)$ & $* * *$ \\
& AT & 4.81 & $(5.66)$ & $* * *$ \\
& Carpool & 0.28 & $(0.34)$ & \\
Commute time & & -1.99 & $(-5.18)$ & $* * *$ \\
Income & PT & -0.07 & $(-0.69)$ & \\
& AT & -0.07 & $(-0.63)$ & \\
& Carpool & -0.03 & $(-0.33)$ & \\
Car ownership & PT & -0.71 & $(-4.31)$ & $* * *$ \\
& AT & -1.53 & $(-7.05)$ & $* * *$ \\
Work_CBD & Carpool & -0.15 & $(-0.92)$ & \\
& PT & 2.15 & $(3.98)$ & $* * *$ \\
& AT & 0.74 & $(0.93)$ & \\
& Carpool & 1.27 & $(1.74)$ & $*$
\end{tabular}


Table 5.7. continued

\begin{tabular}{llccc}
\hline & Alternatives & \multicolumn{3}{c}{ Parameter estimate (t-test) } \\
\hline HH_Child & PT & -0.58 & $(-1.74)$ & $*$ \\
& AT & -1.19 & $(-2.02)$ & $* *$ \\
D_Female & Carpool & -0.49 & $(-0.69)$ & \\
& PT & 0.23 & $(0.62)$ & \\
& AT & -0.99 & $(-1.35)$ & \\
& Carpool & 0.15 & $(0.30)$ &
\end{tabular}

Parking choice variables

Constants

Egress time off-street

Cost off-street

Quantity off-street

Egress time on-street

Cost on-street

Quantity on-street

D_Private off-street

Income

D_Full-time

Work_Free Parking

D_early arrival

D_Public off-street

IV for nest AT

IV for nest PT

IV for nest Carpool

IV for nest Drive
Public off-street

On-street

Other

Public off-street

Public off-street

Public off-street

On-street

On-street

On-street

Private off-street

Public off-street

On-street

Other

Public off-street

On-street

Other

On-street

Public off-street

Public off-street
0.56

8.81

0.10

$-0.42$

$-0.25$

0.24

(0.77)

$-0.36$

$-0.97$

0.43

2.13

0.10

0.05

$-0.11 \quad(-0.98)$

$-0.49$

$-0.35$

0.29

$-7.55 \quad(-3.68)$

$-0.51 \quad(-0.92)$

1.84

1.00

1.00

1.00

0.92

$* * *$

Number of observations 577

${ }^{* * *}$ significant at $99 \%$ confidence interval. ${ }^{* *}$ significant at $95 \%$ confidence interval. ${ }^{*}$ significant at $90 \%$ confidence interval. 
In this study, commuters value travel time more than what has been reported in previous literature (Axhausen and Polak, 1991; Yan et al., 2019). Commuters prefer a fast mode to minimize their commute time. A mode one minute slower reduces the inclination of commuters for that mode by $3 \%$. If it takes 10 minutes to go to work on one mode, this mode is $20 \%$ more preferred than a mode with a 20 minutes time. Driving is the fastest mode in our sample and on average, driving is more than three times faster that PT (the second fastest mode). Developing a rapid public transport system for the GWR through allocating special street lanes for buses might reduce PT commute time and increase preference for PT. Connecting pedestrian walkways in the CBD would also make AT more efficient and attractive.

Within five minutes of egress time, walking time from public off-street parking to work is the most important public off-street parking feature for commuters. There is an inverse relationship between the egress time and the probability of choosing this parking alternative. The impact of the egress time is larger than reported in many parking studies (Antolín et al., 2018; Axhausen and Polak, 1991; Hilvert et al., 2012). Every additional minute of walking from parking to work reduces the attractiveness of public off-street parking over other parking alternatives by $34 \%$. Commuters value their egress time 1.68 times more than parking cost and 1.8 times more than parking quantity for choosing public off-street parking. Our result contrasts with studies that show parking cost is the more important determinant (Ibeas et al., 2014; Soto et al., 2018).

Egress time for on-street parking is an important determinant for choosing this parking. The results indicate that commuters value walking time from on-street parking to work slightly less than the walking time from a public off-street parking.

In line with the literature (Ibeas et al., 2014; Simićević, Vukanović, and Milosavljević, 2013b), we find a negative relationship between the cost of on-street parking and the probability of choosing this parking alternative. The impact of daily cost of on-street parking is 2.7 times more than the impact of walking time and 2.3 times larger than the impact of quantity of parking. This suggests prioritizing cost over location and quantity in on-street parking policy. This is in contrast with public off-street parking where the parking location is suggested as the top priority in policy making.

Outside the coupon parking zone, on-street parking in Wellington City, is less regulated and is usually available free of charge. We use the term "free parking zone" in this research. Parking options in these areas are on-street parking, private off-street parking and "other" parking. 
Private off-street parking at work for commuters who work in these areas is common. In our sample, $95 \%$ of commuters who work in these areas have access to a private off-street parking at work. High supply of private off-street parking next to work considerably discourages commuters from parking on-street which involves competing with others.

Private off-street parking is provided by employers or as some private rentable lots. The existence of private off-street parking in the block makes choosing this type of parking 8.41 times more probable than other parking types. Private off-street parking next to work helps drivers to save time in cruising for parking and walking time to work. In our sample, private off-street parking is the choice of $75 \%$ of drivers who work in the CBD and $96 \%$ of drivers who work outside. Contrary to public parking, which is limited through demand and could be regulated to have public benefits (e.g. revenue through parking costs could be used in improving AT and PT facilities), private off-street parking encourages driving to work without public benefits, which may undermine efforts on regulating parking and improving non-driving modes. It suggests introducing maximum staff parking requirements in administrative or commercial building consents based on on-street parking availability may be beneficial in reducing driving propensity.

Contrary to some studies (Hensher and King, 2001; Yan et al., 2019), a statistically significant relationship between income and parking choice does not exist. A primary explanation is that we consider private off-street parking which is usually next to work and costs below the market price. Moreover, as discussed earlier, income is not an important determinant for mode choice, and the cost of public off-street parking is not a determinant for parking choice. Therefore, commuters from all income ranges may drive and park in any parking alternative.

According to our results, full-time workers slightly prefer to park in a private off-street parking location. However, it does not show a significant difference. Coupon parking is popular and thus, competitive. Commuters who arrive at work after 9 a.m. are less likely to find a space in coupon parking and thus, less likely to park on-street. Instead, public off-street parking is more attractive.

Table 5.8 shows NL results when maximum egress time is 10 minutes. In this radius, commuters have more parking, and parking features for commuters working near each other are almost similar. 
Table 5.8. NL estimates for mode and parking choices (maximum egress time $=10$ minutes)

\begin{tabular}{|c|c|c|c|c|}
\hline \multirow{2}{*}{$\begin{array}{l}\text { Variables } \\
\text { Mode choice variables } \\
\text { Constants }\end{array}$} & \multirow{2}{*}{$\begin{array}{l}\text { Alternatives } \\
\text { PT }\end{array}$} & \multicolumn{3}{|c|}{ Parameter estimate (t-test) } \\
\hline & & 1.47 & $(1.84)$ & * \\
\hline & AT & 3.46 & $(3.70)$ & *** \\
\hline & Carpool & -1.38 & $(-1.54)$ & \\
\hline \multicolumn{2}{|l|}{ Commute time } & -2.81 & $(-7.57)$ & **** \\
\hline \multirow[t]{3}{*}{ Income } & PT & -0.07 & $(-1.11)$ & \\
\hline & AT & -0.09 & $(-0.87)$ & \\
\hline & Carpool & -0.03 & $(-0.32)$ & \\
\hline \multirow[t]{3}{*}{ Car ownership } & PT & -0.62 & $(-3.73)$ & *** \\
\hline & AT & -1.17 & $(-4.26)$ & $* * *$ \\
\hline & Carpool & -0.06 & $(-0.39)$ & \\
\hline \multirow[t]{3}{*}{ Work_CBD } & PT & 2.3 & $(6.57)$ & *** \\
\hline & AT & 1.03 & $(2.05)$ & $* *$ \\
\hline & Carpool & 1.37 & $(3.11)$ & $* * *$ \\
\hline \multirow[t]{3}{*}{ HH_Child } & PT & -0.55 & $(-2.30)$ & $* *$ \\
\hline & AT & -1.14 & $(-2.52)$ & $* *$ \\
\hline & Carpool & -0.47 & $(-1.45)$ & \\
\hline \multirow[t]{3}{*}{ D_Female } & $\mathrm{PT}$ & 0.17 & $(0.72)$ & \\
\hline & $\mathrm{AT}$ & -0.98 & $(-2.38)$ & $* *$ \\
\hline & Carpool & 0.15 & $(0.47)$ & \\
\hline \multicolumn{5}{|l|}{ Parking choice variables } \\
\hline \multirow[t]{3}{*}{ Constants } & Public off-street & 0.52 & $(0.63)$ & \\
\hline & On-street & 0.8 & $(0.78)$ & \\
\hline & Other & -0.06 & $(-0.08)$ & \\
\hline Egress time off-street & Public off-street & -0.11 & $(-1.07)$ & \\
\hline Cost off-street & Public off-street & 0.04 & $(0.10)$ & \\
\hline Quantity off-street & Public off-street & 0.12 & $(1.15)$ & \\
\hline Egress time on-street & On-street & -0.07 & $(-0.93)$ & \\
\hline Cost on-street & On-street & -0.08 & $(-0.63)$ & \\
\hline Quantity on-street & On-street & 0.06 & $(1.38)$ & \\
\hline D_Private off-street & Private off-street & 0.83 & $(1.71)$ & $*$ \\
\hline Work_Free Parking & On-street & -0.34 & $(-0.39)$ & \\
\hline D_early arrival & Public off-street & -0.18 & $(-0.57)$ & \\
\hline
\end{tabular}


Table 5.8. continued

\begin{tabular}{llcc}
\hline Variables & Alternatives & \multicolumn{2}{l}{ Parameter estimate (t-test) } \\
\hline Income & Public off-street & 0.03 & $(0.35)$ \\
& On-street & 0.00 & $(-0.06)$ \\
& Other & -0.05 & $(-0.53)$ \\
D_Full-time & Public off-street & -0.31 & $(-0.75)$ \\
& On-street & -0.14 & $(-0.40)$ \\
& Other & 0.14 & $(0.23)$ \\
D_Public off-street & Public off-street & 0.00 & $(0.00)$ \\
IV for nest AT & & 1.00 & $(1.00)$ \\
IV for nest PT & & 1.00 & $(1.00)$ \\
IV for nest Carpool & & 1.00 & $(1.00)$ \\
IV for nest Drive & & 0.40 & $(1.69)$ \\
Number of observations & & 577 & \\
\hline significant at 99\% confidence interval. ${ }^{* *}$ significant at 95\% confidence interval. & significant at 90\% \\
confidence interval. & & &
\end{tabular}

When maximum egress time is 10 minutes, commuters are not noticeably different in terms of parking features. For example, egress time for public off-street parking for most commuters $(56.3 \%)$ is between five to seven minutes. Therefore, there is small variation and the coefficients corresponding to parking features are considerably smaller than the associated coefficients estimated within five minutes walking radius.

Moreover, within a 10 minutes radius, calculated egress time for public off-street parking is greater than five minutes for $70 \%$ of commuters. For $95 \%$ of commuters, calculated egress time for on-street parking is greater than five minutes. According to our sample, only $28 \%$ of drivers are willing to walk between five to 10 minutes from parking to work. Therefore, calculated parking features at this radius seem less realistic and results within five minutes egress time are more reliable for policy making. As mentioned earlier, Wellington City is relatively small and often hilly. Therefore, long walking times may not be reasonable.

\subsection{Elasticities of mode and parking alternatives}

Elasticities are important as they show responses of commuters, in terms of mode choice or parking choice, to a change in parking feature. Table 5.9 presents elasticities. Direct elasticities are bolded. The elasticities are interpreted in each row. For example, a $1 \%$ increase in the walking time from public off-street parking to work results in decreasing the probability of 
using public off-street parking by $0.80 \%$ and increasing the probability of choosing private offstreet parking, on-street parking, other, AT, PT, and carpool by $0.08 \%, 0.06 \%, 0.10 \%, 0.05 \%$, $0.08 \%$ and, $0.10 \%$ respectively.

Table 5.9. Elasticities for maximum egress time $=$ five minutes

\begin{tabular}{|c|c|c|c|c|c|c|c|}
\hline \multirow[t]{2}{*}{ Variable changes } & \multicolumn{7}{|c|}{ Elasticity of the probability of choice } \\
\hline & AT & PT & Carpool & $\begin{array}{l}\text { Public off-street } \\
\text { parking }\end{array}$ & $\begin{array}{c}\text { Private off-street } \\
\text { parking }\end{array}$ & $\begin{array}{l}\text { On-street } \\
\text { parking }\end{array}$ & Other \\
\hline Egress time off-street & 0.05 & 0.08 & 0.10 & -0.80 & 0.08 & 0.06 & 0.10 \\
\hline Cost off-street & 0.02 & 0.04 & 0.05 & -0.36 & 0.03 & 0.03 & 0.05 \\
\hline Quantity off-street & -0.01 & -0.02 & -0.03 & 0.21 & -0.02 & -0.01 & -0.03 \\
\hline Egress time on-street & 0.05 & 0.03 & 0.04 & 0.05 & 0.08 & -0.76 & 0.08 \\
\hline Cost on-street & 0.07 & 0.10 & 0.13 & 0.16 & 0.15 & -1.72 & 0.15 \\
\hline Quantity on-street & -0.04 & -0.02 & -0.03 & -0.04 & -0.07 & 0.56 & -0.06 \\
\hline
\end{tabular}

A number of parking studies focus on parking price elasticities (Kobus et al., 2013; Kelly and Clinch, 2009; Lehner and Peer, 2019). For public off-street parking, we find that commuters are more sensitive to egress time than other parking features, indicating the high value placed on time by commuters. Egress time direct elasticities are higher than what is reported by Hensher and King (2001) and smaller than elasticities reported by Yan et al. (2019) for two campus parking. Commuters are less sensitive to the cost of public off-street parking. However, cost of on-street parking is a noticeable discouragement for this parking choice. The direct price elasticity for on-street parking is higher than the price elasticities in Hensher and King (2001) and in Yan et al. (2019) except for one campus parking, which indicates potential effectiveness of regulating on-street parking through cost mostly in coupon parking zones. A high supply of private off-street parking beyond the coupon parking area limits effectiveness of this policy.

Cross elasticities for parking alternatives are not considerably different than elasticities for nondriving modes. This is in contrast with Yan et al. (2019) because they study subsidized university parking, which is separately regulated from public parking in the city. In our research, in some cases, as a result of an increase in public off-street parking egress time or cost, the increase in the probability of shifting to non-driving modes is more than or equal to the probability change for other parking alternatives. For example, longer walk times from a 
public off-street parking location motivates commuters to carpool more than it encourages them to park in private off-street parking. The increase in the probability of shifting to PT is the same as the increase in using private off-street parking. Efforts to limit public off-street parking and improve carpooling and PT may be effective. For example, converting some public off-street parking buildings or lots into PT hubs or parking for carpoolers (e.g. setting minimum on number of passengers) in the CBD and developing a network of connected walkways where walkers enjoy micro-mobility modes (e.g. scooters, electric bikes, elevators) to speed up their walk to work.

Increasing public off-street parking costs and limiting the numbers of parking spaces encourage commuters to carpool or use PT. However, we did not find a statistically significant impact for cost and quantity of parking. Hence, we suggest regulating parking cost and quantity as the second priority after egress time. Regulating egress time for public off-street parking implies increasing egress time. For example, through converting some public off-street parking buildings to a PT hub or carpool parking.

A change in on-street parking features is a greater motivation to change parking rather than shifting to non-driving modes. Private off-street parking is a popular choice when on-street parking is farther from work. As discussed earlier, private off-street parking at work is common outside the CBD. Nonetheless, in the CBD where public off-street parking is an alternative, farther on-street parking results in similar probability change for choosing public off-street parking, AT, and carpooling. Limiting public off-street parking as suggested earlier and improving walkability and connectivity of walkways might result in more drivers shifting to AT or carpooling.

Commuters have the highest sensitivity to the cost of on-street parking. The cross elasticities for parking alternatives are higher than non-driving modes. This suggests that on-street parking pricing policies should be accompanied by limiting off-street parking and improving AT, PT and carpooling.

When fewer on-street parking spaces are available, private off-street parking is a popular alternative. However, public off-street parking and AT also have high elasticities. Allocating some on-street parking spaces to AT or PT facilities (e.g. cycling lanes) and introducing maximum staff parking requirements for businesses might contribute to the less car use goal. 


\subsection{Conclusion}

In this study, we model mode choice and parking choice simultaneously based on a NL model. We study 577 household heads who work in Wellington City. Commuters may choose to park in a public or private off-street parking location, on-street parking, and "other" parking types. They may park in any spaces of the chosen parking type around their work.

For our sample, at the mode choice level, we find that PT and AT are popular choices. However, their popularity decreases with higher car ownership and having children. Commuters prefer to travel on fast modes. Driving is the fastest mode in this study but is less popular for CBD workers due to the parking restrictions in this area. Developing a fast PT network and improving PT services would benefit commuters, particularly CBD workers.

Commuters value walking time from public off-street parking to work more than the parking cost. Regarding on-street parking, we find that commuters value the monetary costs of parking more than egress time and parking quantity. To achieve lower car use and to improve nondriving modes, we suggest prioritizing parking policies to consider location of public off-street parking and cost of on-street parking as the top priorities.

Most commuters have private off-street parking in the block they work. Consequently, drivers highly prefer this parking alternative. This high supply and preference for private off-street parking which is not subject to public parking policies undermines the efforts to regulate public parking and reduce car use. Private off-street parking is usually more difficult than public parking to regulate. It is under private ownership and restricting parking might be considered as impinging on private property rights and hence, controversial. Moreover, it often takes longer than on-street parking to see the impact of a new policy. New parking requirements are usually applied for future developments and renovations. However, applying policies aiming to limit private off-street parking is beneficial. In our study, private off-street parking is a major reason for car use and its externalities (e.g. traffic congestion and environmental pollution). Limiting private off-street parking by introducing maximum parking requirements on administrative or commercial buildings based on public parking availability would make this parking alternative less attractive.

The cross elasticities show little difference in terms of changes in probabilities of shifting to other parking alternatives and choosing non-driving modes. In some cases, it is more likely that drivers give up driving. This indicates potential for encouraging less car use through an 
integrated policy for restricting parking and improving non-driving modes. For example, converting some public off-street parking buildings to PT hubs or carpooling parking and developing a network of connected walkways where walkers enjoy micro-mobility modes (e.g. scooters, electric bikes, elevators) would result in more drivers shifting to non-driving modes. Regarding on-street parking, putting premiums on coupon parking in the morning peak hours, or limiting its availability through reducing parking duration or assigning some street spaces to AT-related activities (e.g. broadening footpaths or building bike lanes) would discourage parking on-street. 


\section{Chapter 6}

\section{Discussion}

This chapter centres around the contribution of our research to transportation economics, the transferability of our approach to future research, and policy implication of our findings. Our research is interdisciplinary. In the first part of this chapter, we view our research from an economic perspective and expand on how we make a contribution to transportation economics. In the next part, we explain some details of our approach that are important in the transferability of our approach and findings. The last part discusses some policy implications of our findings for managing parking and reducing car use.

\subsection{Contribution to transportation economics}

The thesis makes some contributions to the transport economics literature. The focus of transport economics is managing scarce transport resources. Parking is an important resource affecting urban transportation. In this research, we quantify parking and travel behavior to study the relationship between the two. Residential parking is a house feature and varies by residential location choice. We expect parking influences commute choice. However, commuters may choose residential location (and therefore, parking) based on their travel preferences. Residential Self-Selection (RSS) is defined as choosing a residential location to satisfy an individual's travel preferences (Cao, 2015; Ettema \& Nieuwenhuis, 2017; van Wee, 2009). For example, a person who prefers walking to work may choose to live in a suburb close to work. RSS is a major concern in studying the relationship between travel behaviour and residential location (Cao, Mokhtarian, \& Handy, 2009; Ettema \& Nieuwenhuis, 2017; Jarass $\&$ Scheiner, 2018; Lin et al., 2017; Zang et al., 2019). Estimation of the causal impact of the built environment on travel behaviour is difficult in the presence of RSS due to reverse causality (Kroesen, 2019; van de Coevering et al., 2018). 
Our contribution to the transportation economics literature is multifold. In Chapter 3, we address the RSS by considering residential location as a choice. The probability of choosing a place is accounted for. Hence, the estimated coefficient for home parking is the partial impact of home parking quantity on commuting choices. We manage the endogeneity in house prices based on a CF approach. This approach has some benefits over a 2SLS approach. It produces results that are statistically more consistent (Terza et al., 2008) and more robust to the underlying distributional assumptions of the model (Guevara \& Hess, 2019). We use an IV which is a good predictor for house prices. We use an average of median house prices for neighbouring MBs as an IV. MBs are small and it is likely that neighbouring MBs have similar house features. Households focus on a house price rather than neighbouring prices. It is unlikely that our IV correlates with the preference for a location.

In Chapter 4, we mitigate the reverse causality between home parking and car ownership using novel IVs with some advantages over IVs previously used in parking literature. Instead of using a proxy for parking supply (e.g. age of buildings), for each home parking type, we use the average supply of that parking type in the MB as an IV. We use the average number of garage spaces per household in the MB as an IV for the garage and the average number of driveway spaces per household in the MB as an IV for the driveway.

The second IVs that we introduce for garage and driveway are the property's ground floor area and land area respectively. These IVs are relevant to home parking. Garage and driveway are part of a property. In our building outline dataset (Land Information New Zealand, 2020a), a garage is part of a building outline, and hence, is included in the building floor area. A driveway is a part of the property's land where households may park. The number of driveway spaces depends on the land area available on the property. Intuitively, these two IVs seem more relevant to home parking than many other house features (e.g. number of bedrooms or sunlight).

These IVs pass both a test of relevance and the Sargan test. Therefore, in contrast with previous studies (Guo, 2013a; Ostermeijer et al., 2019a) we do not need to reduce our sample size through the exclusion of some households or breaking into subsamples.

Transferability of IVs for future studies is important. We may find a correlation between a neighbourhood feature (e.g. age of building) and home parking quantity in one city. However, we might not find a statistically significant correlation between these two variables in another 
city. For example, a new housing project may cover part of a relatively old neighbourhood. Similarly, houses built in the same decade may be located in different parts of the city and have different quantities of off-street and on-street parking. However, average garage or driveway supply in a small area around the household is more likely to correlate with the garage or driveway supply of the household. Hence, our IVs are more likely to be generally applicable than other IVs proposed in the literature.

In Chapter 5, we consider parking alternatives simultaneously with non-driving mode choice to account for the interaction between them (e.g. parking condition at work may influence mode choice). Instead of sampling parking locations, we include all parking types and locations in our case study (i.e. Wellington City) to give comprehensive and more realistic results. Parking demand is important for a public parking choice. Demand for public parking varies over a day or a week. Hence, estimation based on observation of number of drivers who parked in a parking location at a time may not be reliable for policy making. Our measure for parking demand is based on all address points within a maximum egress time of a public parking location. This measure accounts for all potential demand and is more appropriate for policy making. We also consider parking demand in calculating our measures for egress time and parking cost.

\subsection{Research limitations}

We recommend future researchers take into account the following details of our approach to ensure its transferability to their research.

We used data from NZHTS where households are surveyed on two consecutive days (or seven consecutive days for households surveyed between 2015 to 2017). Our findings for travel behavior are based on the survey days. Households may have different choice of commute mode or car ownership after the survey.

In some cases, home or work coordinates in the NZHTS were not accurate and did not place in a residential parcel or a business unit. There is no clue in the survey to identify the property or business unit these points represent.

Our data is based on a revealed preference dataset (NZHTS). Commuters' choices are reported as observed on the survey days. However, these observations may not necessarily reflect the 
commuters' real preferences. For example, a commuter might have driven to work in the survey days due to rainy weather, otherwise they often walk to work.

To ensure independent observations, we consider head of household. However, other household members may have different travel preferences.

Our sample size (1056 heads of households) is relatively small for the GWR with a population of 506,814 (in 2018). This is due to the number of surveys conducted in the NZHTS and exclusion of many commuters because they are not a head of household.

NZHTS sampling is not perfect. For example, some areas in the GWR are oversampled and some areas undersampled due to some reasons such as some organizations requiring a coverage of their area of interest.

The GWR has a land border in the North. People who work near this border are likely to consider living outside the GWR as a choice. To ensure all residential location choices are within the GWR, we exclude people who work within 10 kilometers of the border. However, some commuters who work farther than 10 kilometers from the border may consider living outside the GWR as an alternative location.

We use Google Satellite, Google Street View, and homes.co.nz for collecting data on the number of garages and driveway spaces. This approach has some limitations. Images taken at the time of survey may not be available, and some houses might be blocked in the images by vegetation or other obstacles.

We did not have data on home parking quantity of MBs outside Wellington City and used a dummy variable as an aggregate measure for home parking (D_City). This measure is usable when comparing Wellington City with the rest of the region. Nonetheless, if the focus is on another city, home parking quantity of MBs in that city should be collected.

Weather is a factor that may influence commute mode choice. For example, AT is probably less attractive on a rainy day. This requires collecting data on weather condition on the travel day for each commuter.

In identifying on-street parking spaces, we consider on-street parking for roads that are at least seven meters wide. In some narrower streets in residential areas, some drivers may park on-street. However, they cannot park all along the road as they make it impossible for 
vehicles to move in two directions. An ideal on-street parking dataset requires identifying all potential parking spaces on narrow streets without blocking the bidirectional traffic.

\subsection{Policy implications}

Using a private vehicle in daily commuting imposes substantial costs on society. A high number of drivers in a morning peak hour often leads to traffic congestion in bottlenecks. Commuters waste valuable time in traffic (Pierce \& Shoup, 2013; Qin et al., 2020). More drivers also indicate more fuel consumption and greenhouse gas emissions (Barata et al., 2011) that contribute to environmental pollution (Dasgupta et al., 2021; Lu et al., 2021).

Cars need to be parked somewhere. As a result of policies that focus on providing parking instead of more effective parking management (e.g. minimum parking requirements), parking is a huge use of land in cities (Chester et al., 2015; Davis et al., 2010; Manville \& Shoup, 2005; Shoup, 2005). In city centers, where land is precious, providing parking implies taking land from other activities, which may increase the cost of using non-driving modes (Jia \& Wachs, 1999; Manville, 2017; Shoup, 2005). In residential areas, minimum parking requirements impose an extra monetary cost on developers and therefore on households (Shoup, 1999). A high supply of parking then motivates more commuters to have cars and drive (Guo, 2013a, Guo, 2013b, Weinberger, 2012, Christiansen et al. 2017a, Christiansen et al. 2017b). Therefore, parking is a key factor responsible for car use and all the associated social costs.

However, parking policy is a relatively small part of transportation policies. Overlooking an effective parking policy would undermine traffic management efforts. In this research, we estimated the impact of parking in residential and work areas on car ownership (and use) to contribute to more effective parking planning. We find parking is a strong factor influencing the probability of driving to work. Providing off-street parking reduces the cost of driving and instead, imposes other costs such as development costs and higher house prices (Manville, 2013). A high supply of parking at work also imposes social costs. We find that private offstreet parking is a big motivation for driving to work. Private off-street parking encourages driving without generating public revenue to reimburse the congestion costs.

Restricting parking is commonly suggested as an instrument to discourage car ownership and use (Guo, 2013a, Guo, 2013b, Guo and Ren, 2013). Reducing minimum parking requirements or introducing maximum parking requirements are commonly used (Liu et al., 2017). We find an oversupply of residential off-street parking in the GWR. For example, $71.40 \%$ of households 
in our sample have at least one on-site parking space more than their number of cars. There is some evidence that developers provide less parking if minimum parking is not mandatory. For example, Manville (2013), in a study in the Los Angeles city centre, reported 40\% to $55 \%$ less off-street parking provision in the absence of mandatory minimum parking requirements. Guo and Ren (2013) find approximately 40\% less parking supply after introducing maximum parking requirements in London. According to our findings, less parking at home or at work considerably reduces the probability of driving. For example, a $10 \%$ reduction in home parking quantity is associated with $26 \%$ less probability of driving in Wellington City.

An effective parking policy for reducing car use requires regulating on-street parking along with off-street parking (Guo, 2013a, Guo \& Ren, 2013). This policy regulates off-street parking based on on-street parking condition and vice versa. For example, some households may live in suburbs with low population density and can easily find an on-street parking space near home. Others may live in neighbourhoods with high population density and a high demand for on-street parking. Maximum number of off-street parking spaces for the first group could be less than the second group. In Wellington City, the same minimum parking requirement has been applied to many suburbs regardless of their access to on-street parking.

Improving non-driving modes is also necessary to enhance the effectiveness of parking policies. Without sufficient public transport services, restricting parking would not make a substantial change in the share of drivers. For example, Hamre and Buehler (2014) argue that access to free parking at work for employees reduces their willingness to use public transport or active transport. Policies that restrict parking aim to increase the cost of driving. However, non-driving modes should be improved so that they are reasonably cheap, reliable, and convenient to be used as an alternative for private vehicles. According to our results, increasing egress time through converting some public off-street parking buildings or lots into PT hubs or parking for carpoolers (e.g. setting a minimum on the number of passengers) in the CBD would discourage driving. Moreover, walking could be made a more enjoyable experience through developing a network of connected walkways where walkers enjoy micro-mobility modes (e.g. scooters, electric bikes, elevators) to speed up their walk to work. 


\section{Chapter 7}

\section{Conclusion}

The main aim of this thesis is to explore the impact of parking on car ownership and commute mode choice. The first chapter explains the importance of research on home parking and work parking and provides an overview of thesis structure. Chapter 2 explains the key concepts used in this research and the underlying methodology.

Chapter 3 focuses on home parking quantity and answers the question of "How does home parking quantity affect households' car ownership and commute mode choice?". We consider residential location choice and mitigate the endogeneity between house price and residential location . We study a sample of commuters who could live and work anywhere in a region (GWR) with a diverse range of socioeconomic characteristics. The commuters also face a variety of built environment features, and parking conditions at home and work.

We find home parking is a factor that strongly motivates car ownership and the choice of driving to work. The influence of parking quantity is greater than that of income. A high supply of on-site parking is observed in residential areas in the GWR partly due to minimum parking requirements and low population density. This supply increases the utility of owning and using a car, while reducing housing affordability (Manville, 2013). This is while many households have access to on-street parking. According to our results, less off-street home parking supply in some MBs is a noticeable discouragement for owning cars and driving to work. However, according to Guo (2013a), Guo and Ren (2013), and Christiansen, Fearnley et al., 2017), access to on-street parking motivates more car use which leads to externalities such as traffic congestion and environmental pollution. We suggest viewing off-street and on-street parking holistically in residential areas to improve the effectiveness of parking policies. 
A higher proclivity for driving to work means more car trips and higher demand for parking in the city centre. This proclivity implies the influence of home parking on traffic congestion and parking in the city centre. We suggest considering home parking and work parking simultaneously in parking and transport planning. This approach might contribute to more effective parking policies to reduce car use.

Home parking is studied in more detail in Chapter 4. We study the impact of home parking type on car ownership at the property scale. We mitigate endogeneity between home parking type and car ownership by using novel IVs in a CF approach. We use two IVs for each parking type. The first IV is the average supply of each parking type (e.g. garage) per household in a small area around the household (MB). A MB (typically 30 to 60 dwellings) is smaller than most areas considered in the home parking literature (For example, Guo (2013a) uses census tract $(3,000$ to 4,000 people) or Ostermeijer et al. (2019) uses parking district (2000 properties)). An IV in MB scale is closer to single property scale, and it is more likely to predict parking quantity of the property. The second IV is the floor area of the ground floor, and land area of the property for garage and driveway respectively. We use a measure for on-street parking that considers both parking quantity and demand.

Our results show the positive and significant impact of number of garages, driveway spaces, and chance of finding on-street parking on car ownership. Off-street home parking is oversupplied in some areas of the GWR. Households may use an on-street parking space located in front of their garage or driveway entrance. It implies that minimum parking requirements contribute to a higher chance of on-street parking in addition to on-site parking, and according to the results of this study, motivates owning more vehicles. In line with our findings in Chapter 3, this indicates the importance of considering both on-street and off-street parking simultaneously in residential areas.

Based on our results, limiting garage and driveway quantity (e.g. through applying maximum parking requirements) would considerably reduce the probability of multiple car ownership. This policy would probably be more effective in central suburbs (i.e. Wellington CBD and coupon parking areas) where households enjoy more PT coverage and are close enough to work to use AT sometimes. However, this result is not straightforward. Parking requirements usually target areas designed for parking. In some cases, in the GWR, there are long roads or a large open space on the property that is not specifically designed for parking. If there is a restriction on garage supply, drivers would use these locations as parking. Home parking details (e.g. 
location of garage in the property, potential spaces for driveway) should be considered for more accurate and effective parking policies.

Living closer to work reduces the preference for car ownership. Nonetheless, some households in central suburbs in Wellington City, (where AT is a viable option and PT has better coverage), have on-site parking, or permits for resident on-street parking. A higher propensity for car ownership in these areas may result in slowing down traffic, longer cruising time for drivers, and other car-related externalities (e.g. greenhouse gas emissions).

Working in the CBD discourages owning cars. However, we find that owning a garage or having a chance for on-street parking reduces this impact. A high supply of garage and onstreet parking in residential areas may limit the effectiveness of parking and traffic policies in the CBD. These interactions highlight the importance of considering work parking and home parking holistically.

Chapter 5 studies various types of parking at work. We focus on the time costs of parking and answer the question "How does walking time from parking location to work impact parking type choice?". We consider driving and all non-driving modes in a joint model of parking choice and commute mode choice. Parking alternatives comprise public off-street parking, private off-street parking, and on-street parking. Our measure for the probability of finding a parking space captures potential demand from all individuals who work or live nearby. The probability of finding a parking space is embedded into our measures for walking time from parking and parking cost. Drivers may change their parking location for a parking type (e.g. public off-street parking) over a week or month due to availability and other parking conditions of the day. We consider parking type (and not the exact location) as a strong measure for parking alternatives to account for this possibility.

AT and PT are popular modal choices. However, high car ownership and having children increase the probability of driving. Reducing travel time by PT through developing a fast network of PT and express PT lanes would discourage driving to the CBD.

Walking time from public off-street parking to work is noticeably more important than the parking cost and quantity for attracting drivers. Commuters prefer to save time parking in a nearby parking location paying less attention to parking cost. For on-street parking, the monetary cost of parking is the most important factor. Most commuters with access to on-street 
parking work in less congested areas (around the CBD) and usually spend less time in traffic congestion. They look for cheap and nearby parking.

Commuters who have a private off-street parking location near their work are highly motivated to use that location. Private off-street parking is not subject to public parking policies. High supply of this parking type limits the effectiveness of public parking policies to reduce car use. Limiting private off-street parking supply (e.g. through introducing maximum parking requirements on businesses) might discourage commuters from using this parking type, and motivate them to consider using public parking or non-driving modes. Public parking is restricted through demand form other drivers and may have some benefits for the public through generating revenue.

No noticeable difference exists between the probability of choosing another parking type and shifting to non-driving modes if a parking feature changes. In some cases, not driving is more desirable than other parking alternatives. For example, if walking from a public off-street parking location to work takes longer, commuters are more likely to take the bus than park onstreet. This indicates potential effectiveness of an integrated policy to improve AT and PT and restrict parking. For example, developing a connected network of walkways with micromobility options (e.g. scooters, electric bikes, elevators) and converting some parking buildings to PT hubs or carpool parking might increase attractiveness of non-driving modes.

\section{Areas for future research}

Parking at home and at work are interconnected. In this thesis, we study each separately, while including some variables that explain parking conditions at the other end of the commute. For example, we include a dummy variable for commuters who work in the Wellington CBD in our home parking research. However, these variables are aggregated and do not explain the details of parking. For future research, we suggest modelling home and work parking simultaneously to account for their interaction.

Working from home has become more common recently due to COVID-19 lockdowns. This could lead to a considerable change in travel behavior. Commute mode and car ownership impact each other. It might seem intuitive that commuters make fewer car trips. However, it is not clear whether preference for car ownership is also changed. We suggest research to understand how car ownership and its relationship with parking is affected. 
There was a major change in bus lanes in Wellington City in July 2018. This may affect many commuters and their mode choice. We suggest doing similar research based on NZHTS travel data for a period of before and after July 2018. 


\section{References}

Abrantes, P. A. L., \& Wardman, M. R. (2011). Meta-analysis of UK values of travel time: An update. Transportation Research Part A: Policy and Practice, 45(1), 1-17. https://doi.org/10.1016/j.tra.2010.08.003

Acheampong, R. A. (2020). Spatial structure, intra-urban commuting patterns and travel mode choice: Analyses of relationships in the Kumasi Metropolis, Ghana. Cities, 96, 120. https://doi.org/10.1016/j.cities.2019.102432

Albalate, D., \& Gragera, A. (2020). The impact of curbside parking regulations on car ownership. Regional Science and Urban Economics, 81, 1-12. https://doi.org/10.1016/j.regsciurbeco.2020.103518

Amemiya, T. (1978). On a two-step estimation of a multivariate logit model. Journal of Econometrics, 8, 13-21. https://doi.org/https://doi.org/10.1016/0304-4076(78)90086-6

Amer, A., \& Chow, J. Y. J. (2017). A downtown on-street parking model with urban truck delivery behavior. Transportation Research Part A: Policy and Practice, 102, 51-67. https://doi.org/10.1016/j.tra.2016.08.013

Antolín, G., Ibeas, Á., Alonso, B., \& dell'Olio, L. (2018). Modelling parking behaviour considering users heterogeneities. Transport Policy, 67, 23-30. https://doi.org/10.1016/j.tranpol.2018.01.014

Antonakis, J., Bendahan, S., Jacquart, P., \& Lalive, R. (2010). On making causal claims: A review and recommendations. Leadership Quarterly, 21(6), 1086-1120. https://doi.org/10.1016/j.leaqua.2010.10.010

Ao, Y., Yang, D., Chen, C., \& Wang, Y. (2019). Exploring the effects of the rural built environment on household car ownership after controlling for preference and attitude: Evidence from Sichuan, China. Journal of Transport Geography, 74, 24-36. https://doi.org/10.1016/j.jtrangeo.2018.11.002

Arnott, R., \& Rowse, J. (1999). Modeling parking. Journal of Urban Economics, 45(1), 97 124. Retrieved from https://doi.org/10.1006/juec.1998.2084

Arnott, Richard, de Palma, A., \& Lindsey, R. (1991). A temporal and spatial equilibrium 
analysis of commuter parking. Journal of Public Economics, 45(3), 301-335. https://doi.org/10.1016/0047-2727(91)90030-6

Arnott, Richard, \& Inci, E. (2006). An integrated model of downtown parking and traffic congestion. Journal of Urban Economics, 60(3), 418-442. https://doi.org/10.1016/j.jue.2006.04.004

Arnott, Richard, Inci, E., \& Rowse, J. (2015). Downtown curbside parking capacity. Journal of Urban Economics, 86, 83-97. https://doi.org/10.1016/j.jue.2014.12.005

Arnott, Richard, \& Rowse, J. (2009). Downtown parking in auto city. Regional Science and Urban Economics, 39(1), 1-14. https://doi.org/10.1016/j.regsciurbeco.2008.08.001

Arnott, Richard, \& Williams, P. (2017). Cruising for parking around a circle. Transportation Research Part B: Methodological, 104, 357-375.

https://doi.org/10.1016/j.trb.2017.07.009

Australian Bureau of Statistics. (2017). More than two in three drive to work, Census reveals. Retrieved July 16, 2021, from https://www.abs.gov.au/ausstats/abs@.nsf/mediareleasesbyreleasedate/7DD5DC715B60 8612CA2581BF001F8404?OpenDocument

Autant-Bernard, C. (2006). Where do firms choose to locate their R\&D? A spatial conditional logit analysis on french data. European Planning Studies, 14(9), 1187-1208. https://doi.org/10.1080/09654310600933314

Awaworyi Churchill, S., \& Smyth, R. (2019). Transport poverty and subjective wellbeing. Transportation Research Part A: Policy and Practice, 124, 40-54. https://doi.org/10.1016/j.tra.2019.03.004

Axhausen, K. W., \& Polak, J. W. (1991). Choice of parking: Stated preference approach. Transportation, 18(1), 59-81. https://doi.org/10.1007/BF00150559

Bai, X., Zhai, W., Steiner, R. L., \& He, Z. (2020). Exploring extreme commuting and its relationship to land use and socioeconomics in the central Puget Sound. Transportation Research Part D: Transport and Environment, 88, 1-17. https://doi.org/10.1016/j.trd.2020.102574

Bajic, V. (1983). The Effects of a New Subway Line on Housing Prices in Metropolitan Toronto. Urban Studies, 20(2), 147-158. https://doi.org/10.1080/00420988320080291 
Barata, E., Cruz, L., \& Ferreira, J. P. (2011). Parking at the UC campus: Problems and solutions. Cities, 28(5), 406-413. https://doi.org/10.1016/j.cities.2011.04.001

Batley, R., \& Hess, S. (2016). Testing for regularity and stochastic transitivity using the structural parameter of nested logit. Transportation Research Part B: Methodological, 93, 355-376. https://doi.org/10.1016/j.trb.2016.07.018

Becker, H., Ciari, F., \& Axhausen, K. W. (2017). Modeling free-floating car-sharing use in Switzerland: A spatial regression and conditional logit approach. Transportation Research Part C: Emerging Technologies, 81, 286-299. https://doi.org/10.1016/j.trc.2017.06.008

Beige, S., \& Axhausen, K. W. (2017). The dynamics of commuting over the life course: Swiss experiences. Transportation Research Part A: Policy and Practice, 104, 179-194. https://doi.org/10.1016/j.tra.2017.01.015

Bhat, C. R., \& Guo, J. Y. (2007). A comprehensive analysis of built environment characteristics on household residential choice and auto ownership levels. Transportation Research Part B: Methodological, 41(5), 506-526. https://doi.org/10.1016/j.trb.2005.12.005

Bicalho, T., Silva, C., Cunha, I., Teixeira, J., \& Proença, A. (2019). Planners' attitudes towards the cycling potential of their cities - Creating awareness for attitude change. Travel Behaviour and Society, 17, 96-103. https://doi.org/10.1016/j.tbs.2019.08.002

Bonsall, P., \& Palmer, I. (2004). Modelling drivers' car parking behaviour using data from a travel choice simulator. Transportation Research Part C: Emerging Technologies, 12, 321-347. https://doi.org/10.1016/j.trc.2004.07.013

Börjesson, M., Isacsson, G., Andersson, M., \& Anderstig, C. (2019). Agglomeration, productivity and the role of transport system improvements. Economics of Transportation, 18, 27-39. https://doi.org/10.1016/j.ecotra.2018.12.002

Boschman, S., \& van Ham, M. (2015). Neighbourhood selection of non-Western ethnic minorities: testing the own-group effects hypothesis using a conditional logit model. Environment and Planning A, 47(5), 1155-1174. https://doi.org/10.1177/0308518X15592300

Bridgelall, R. (2014). Campus parking supply impacts on transportation mode choice. 
Transportation Planning and Technology, 37(8), 711-737.

https://doi.org/10.1080/03081060.2014.959354

Broyden, C. G. (1970). The convergence of a class of double-rank minimization algorithms 1. General considerations. IMA Journal of Applied Mathematics (Institute of Mathematics and Its Applications), 6(1), 76-90. https://doi.org/https://doi.org/10.1093/imamat/6.1.76

Cao, Xiaoshu, \& Yang, W. (2017). Examining the effects of the built environment and residential self-selection on commuting trips and the related $\mathrm{CO} 2$ emissions: An empirical study in Guangzhou, China. Transportation Research Part D: Transport and Environment, 52, 480-494. https://doi.org/10.1016/j.trd.2017.02.003

Cao, Xinyu. (2015). Heterogeneous effects of neighborhood type on commute mode choice: An exploration of residential dissonance in the Twin Cities. Journal of Transport Geography, 48, 188-196. https://doi.org/10.1016/j.jtrangeo.2015.09.010

Cao, Xinyu, Mokhtarian, P. L., \& Handy, S. L. (2009). Examining the impacts of residential self-selection on travel behaviour: A focus on empirical findings. Transport Reviews, 29(3), 359-395. https://doi.org/10.1080/01441640802539195

Cervero, R., \& Duncan, M. (2006). Which reduces vehicle travel more: Jobs-housing balance of retail-housing mixing? Journal of the American Planning Association, 72(4), 475490. https://doi.org/10.1080/01944360608976767

Chaniotakis, E., \& Pel, A. J. (2015a). Drivers' parking location choice under uncertain parking availability and search times: A stated preference experiment. Transportation Research Part A: Policy and Practice, 82, 228-239. https://doi.org/10.1016/j.tra.2015.10.004

Chaniotakis, E., \& Pel, A. J. (2015b). Drivers' parking location choice under uncertain parking availability and search times: A stated preference experiment. Transportation Research Part A: Policy and Practice, 82, 228-239. https://doi.org/10.1016/j.tra.2015.10.004

Chaniotakis, E., \& Pel, A. J. (2015c). Drivers' parking location choice under uncertain parking availability and search times: A stated preference experiment. Transportation Research Part A: Policy and Practice, 82, 228-239. https://doi.org/10.1016/j.tra.2015.10.004 
Cherkaoui, B., Beni-Hssane, A., El Fissaoui, M., \& Erritali, M. (2019). Road traffic congestion detection in VANET networks. Procedia Computer Science, 151, 11581163. https://doi.org/10.1016/j.procs.2019.04.165

Cheshire, P., \& Sheppard, S. (1995). On the Price of Land and the Value of Amenities. Economica, 62, 247-267. Retrieved from https://www.jstor.org/stable/2554906

Chester, M., Fraser, A., Matute, J., Flower, C., \& Pendyala, R. (2015). Parking Infrastructure: A constraint on or opportunity for urban redevelopment? a study of Los Angeles County parking supply and growth. Journal of the American Planning Association, 81(4), 268286. https://doi.org/10.1080/01944363.2015.1092879

Choné, P., \& Linnemer, L. (2012). A treatment effect method for merger analysis with an application to parking prices in Paris. Journal of Industrial Economics, 60(4), 631-656. https://doi.org/10.1111/joie.12003

Christiansen, P. (2014). A case study of parking charges at work places - effects on travel behaviour and acceptance. In Artikler fra Trafikdage på Aalborg Universitet (Proceedings from the Annual Transport Conference at Aalborg University) (pp. 1-13). https://doi.org/https://doi.org/10.5278/ojs.td.v1i1.5766

Christiansen, P., Engebretsen, Ø., Fearnley, N., \& Usterud Hanssen, J. (2017). Parking facilities and the built environment: Impacts on travel behaviour. Transportation Research Part A: Policy and Practice, 95, 198-206. https://doi.org/10.1016/j.tra.2016.10.025

Christiansen, P., Fearnley, N., Hanssen, J. U., \& Skollerud, K. (2017). Household parking facilities: Relationship to travel behaviour and car ownership. Transportation Research Procedia, 25, 4185-4195. https://doi.org/10.1016/j.trpro.2017.05.366

Coulson, N. E., \& Engle, R. F. (1987). Transportation costs and the rent gradient. Journal of Urban Economics, 21(3), 287-297. https://doi.org/10.1016/0094-1190(87)90003-9

Daglish, T., de Roiste, M., Sağlam, Y., \& Law, R. (2015). Commuting and Residential Decisions in the Greater Wellington Region. (Working Paper), 1-26. Retrieved from http://researcharchive.vuw.ac.nz/handle/10063/4184

Dargay, J., \& Gately, D. (1999). Income's effect on car and vehicle ownership, worldwide: 1960-2015. Transportation Research Part A:Policy and Practice, 33(2), 101-138. 
https://doi.org/https://doi.org/10.1016/S0965-8564(98)00026-3

Dargay, J., \& Hanly, M. (2007). Volatility of car ownership, commuting mode and time in the UK. Transportation Research Part A: Policy and Practice, 41(10), 934-948. https://doi.org/10.1016/j.tra.2007.05.003

Dargay, J. M. (2001). The effect of income on car ownership: Evidence of asymmetry. Transportation Research Part A: Policy and Practice, 35(9), 807-821. https://doi.org/10.1016/S0965-8564(00)00018-5

Dasgupta, S., Lall, S., \& Wheeler, D. (2021). Spatiotemporal analysis of traffic congestion, air pollution, and exposure vulnerability in Tanzania. Science of the Total Environment, 778. https://doi.org/10.1016/j.scitotenv.2021.147114

Davis, A. Y., Pijanowski, B. C., Robinson, K., \& Engel, B. (2010). The environmental and economic costs of sprawling parking lots in the United States. Land Use Policy, 27(2), 255-261. https://doi.org/10.1016/j.landusepol.2009.03.002

De Nijs, R. (2012). The price discrimination effect of a large merger of parking garages. Economics Letters, 117(3), 928-931. https://doi.org/10.1016/j.econlet.2012.07.018 de Palma, A., Motamedi, K., Picard, N., \& Waddell, P. (2005). A model of residential location choice with endogenous housing prices and traffic for the Paris region. European Transport \Trasporti Europei, (31), 67-82.

Dell'Orco, M., Ottomanelli, M., Sassanelli, D. (2003). Modelling uncertainty in parking choice behaviour. 82nd Annual Meeting of the Transportation Research Board, 1-20.

Ding, C., Liu, C., Zhang, Y., Yang, J., \& Wang, Y. (2017). Investigating the impacts of built environment on vehicle miles traveled and energy consumption: Differences between commuting and non-commuting trips. Cities, 68(May), 25-36. https://doi.org/10.1016/j.cities.2017.05.005

Ding, C., Wang, Y., Tang, T., Mishra, S., \& Liu, C. (2018). Joint analysis of the spatial impacts of built environment on car ownership and travel mode choice. Transportation Research Part D: Transport and Environment, 60, 28-40. https://doi.org/10.1016/j.trd.2016.08.004

Dorsey, B. (2005). Mass transit trends and the role of unlimited access in transportation demand management. Journal of Transport Geography. 
https://doi.org/10.1016/j.jtrangeo.2004.07.004

Ettema, D., \& Nieuwenhuis, R. (2017). Residential self-selection and travel behaviour: What are the effects of attitudes, reasons for location choice and the built environment? Journal of Transport Geography, 59, 146-155. https://doi.org/10.1016/j.jtrangeo.2017.01.009

Euchi, J., \& Kallel, A. (2021). Internalization of external congestion and CO2emissions costs related to road transport: The case of Tunisia. Renewable and Sustainable Energy Reviews, 142. https://doi.org/10.1016/j.rser.2021.110858

Feng, J. (2017). The influence of built environment on travel behavior of the elderly in urban China. Transportation Research Part D: Transport and Environment, 52, 619-633. https://doi.org/10.1016/j.trd.2016.11.003

Fernández-Antolín, A., Guevara-Cue, A., de Lapparent, M., \& Bierlaire, M. (2016). Correcting for endogeneity due to omitted attitudes: Empirical assessment of a modified MIS method using RP mode choice data. Journal of Choice Modelling, 20, 1-15. https://doi.org/10.1016/j.jocm.2016.09.001

Fishman, E. (2016). Bikeshare: A Review of Recent Literature. Transport Reviews, 36(1), 92-113. https://doi.org/10.1080/01441647.2015.1033036

Fletcher, R. (1970). A new approach to variable metric algorithms. The Computer Journal, 13(3), 317-322.

Forinash, C. V., \& Koppelman, F. S. (1993). Application and Interpretation of Nested Logit Models of Intercity Mode Choice. Transportation Research Record, 1413, 98-106. Retrieved from https://trid.trb.org/view/385097

Fosgerau, M., \& Kim, J. (2019). Commuting and land use in a city with bottlenecks: Theory and evidence. Regional Science and Urban Economics, 77, 182-204. https://doi.org/10.1016/j.regsciurbeco.2019.04.004

Franco, S. F. (2017). Downtown parking supply, work-trip mode choice and urban spatial structure. Transportation Research Part B: Methodological, 101, 107-122. https://doi.org/10.1016/j.trb.2017.03.012

Friedman, J. (1981). A Conditional Logit Model of the Role of Local Public Services in Residential Choice. Urban Studies, 18(3), 347-358. 
https://doi.org/10.1080/00420988120080641

Froeb, L., Tschantz, S., \& Crooke, P. (2003). Bertrand competition with capacity constraints: Mergers among parking lots. Journal of Econometrics, 113(1), 49-67. https://doi.org/10.1016/S0304-4076(02)00166-5

Fulman, N., Benenson, I., \& Ben Elia, E. (2020). Modeling parking search behavior in the city center: A game-based approach. Transportation Research Part C: Emerging Technologies, 120, 1-24. https://doi.org/10.1016/j.trc.2020.102800

Gabbe, C. J., Pierce, G., \& Clowers, G. (2020). Parking policy: The effects of residential minimum parking requirements in Seattle. Land Use Policy, 91, 1-8. https://doi.org/10.1016/j.landusepol.2019.104053

Gallo, M., D’Acierno, L., \& Montella, B. (2011). A multilayer model to simulate cruising for parking in urban areas. Transport Policy, 18(5), 735-744. https://doi.org/10.1016/j.tranpol.2011.01.009

Gillen, D. W. (1977). Estimation and specification of the effects of parking costs on urban transport mode choice. Journal of Urban Economics, 4(2), 186-199. https://doi.org/10.1016/0094-1190(77)90022-5

Goldfarb, D. (1970). A family of variable-metric methods derived by variational means. Mathematics of Computation, 24(109), 23. https://doi.org/10.2307/2004873

Golias, J., Yannis, G., \& Harvatis, M. (2002). Off-street parking choice sensitivity. Transportation Planning and Technology, 25(4), 333-348. https://doi.org/10.1080/0308106022000019620

Gonzalez-Urango, H., Pira, M. Le, Inturri, G., Ignaccolo, M., \& García-Melón, M. (2020). Designing walkable streets in congested touristic cities: The case of Cartagena de Indias, Colombia. Transportation Research Procedia, 45(2019), 309-316. https://doi.org/10.1016/j.trpro.2020.03.021

Greene, W. H. (2003). Econometric Analysis. Prentice Hall (Fifth). New Jersey. https://doi.org/10.1017/CBO9781107415324.004

Groote, J. De, Ommeren, J. Van, \& Koster, H. R. A. (2016). Car ownership and residential parking subsidies: Evidence from Amsterdam. Economics of Transportation, 6, 25-37. https://doi.org/10.1016/j.ecotra.2016.07.001 
Guerra, E. (2015). The geography of car ownership in Mexico City: A joint model of households' residential location and car ownership decisions. Journal of Transport Geography, 43, 171-180. https://doi.org/10.1016/j.jtrangeo.2015.01.014

Guerra, E., \& Daziano, R. A. (2020). Electric vehicles and residential parking in an urban environment: Results from a stated preference experiment. Transportation Research Part D: Transport and Environment, 79, 1-10. https://doi.org/10.1016/j.trd.2020.102222

Guevara, C. Angelo. (2015). Critical assessment of five methods to correct for endogeneity in discrete-choice models. Transportation Research Part A, 82, 240-254. https://doi.org/https://doi.org/10.1016/j.tra.2015.10.005

Guevara, C.Angelo, \& Hess, S. (2019). A control-function approach to correct for endogeneity in discrete choice models estimated on SP-off-RP data and contrasts with an earlier FIML approach by Train \& Wilson. Transportation Research Part B: Methodological, 123, 224-239. https://doi.org/10.1016/j.trb.2019.03.022

Guevara, Cristian Angelo, \& Ben-Akiva, M. (2006). Endogeneity in residential location choice models. Transportation Research Record, (1977), 60-66. https://doi.org/10.3141/1977-10

Guevara, Cristian Angelo, \& Thomas, A. (2007). Multiple classification analysis in trip production models. Transport Policy, 14(6), 514-522. https://doi.org/10.1016/j.tranpol.2007.08.001

Gujarati, D. N. (2004). Basic Econometrics. McGraw-Hill/Irwin (Fourth). New York: McGraw-Hill/Irwin. https://doi.org/10.2307/2230043

Guo, Z, \& McDonnell, S. (2013). Curb parking pricing for local residents: An exploration in New York City based on willingness to pay. Transport Policy, 30, 186-198. https://doi.org/10.1016/j.tranpol.2013.09.006

Guo, Zhan. (2013a). Does residential parking supply affect household car ownership? The case of New York City. Journal of Transport Geography, 26, 18-28. https://doi.org/10.1016/j.jtrangeo.2012.08.006

Guo, Zhan. (2013b). Home parking convenience, household car usage, and implications to residential parking policies. Transport Policy, 29, 97-106. https://doi.org/10.1016/j.tranpol.2013.04.005 
Guo, Zhan. (2013c). Residential street parking and car ownership. Journal of the American Planning Association, 79(1), 32-48. https://doi.org/10.1080/01944363.2013.790100

Guo, Zhan, \& Ren, S. (2013). From Minimum to Maximum: Impact of the London Parking Reform on Residential Parking Supply from 2004 to 2010? Urban Studies, 50(6), 1183 1200. https://doi.org/10.1177/0042098012460735

Ha, T. V., Asada, T., \& Arimura, M. (2019). Determination of the influence factors on household vehicle ownership patterns in Phnom Penh using statistical and machine learning methods. Journal of Transport Geography, 78, 70-86. https://doi.org/10.1016/j.jtrangeo.2019.05.015

Haining, R. P. (2001). Spatial Autocorrelation. In P. B. Smelser, N.J.; Baltes (Ed.), International Encyclopedia of the Social \& Behavioral Sciences (First, pp. 1476314768). Oxford: Pergamon.

Hamre, A., \& Buehler, R. (2014). Commuter Mode Choice and Free Car Parking, Public Transportation Benefits, Showers/Lockers, and Bike Parking at Work: Evidence from the Washington, DC Region. Journal of Public Transportation, 17(2), 67-91. https://doi.org/10.5038/2375-0901.17.2.4

Hanck, C., Arnold, M., Gerber, A., Schmelzer, M. (2019). Introduction to Econometrics with $R$. Essen, Germany: University of Duisburg-Essen. Retrieved from https://www.econometrics-with-r.org/12-3-civ.html

Hausman, J. and McFadden, D. (1984). Specification Tests for the Multinomial Logit Model. Econometrica, 52(5), 1219-1240. https://doi.org/10.2307/1910997

Hausman, J. A. (1978). Specification tests in econometrics. Econometrica, 46(6), 1251-1271. https://doi.org/https://doi.org/10.2307/1913827

He, M., \& Zhao, S. (2017). Determinants of long-duration commuting and long-duration commuters' perceptions and attitudes toward commuting time: Evidence from Kunming, China. IATSS Research, 41(1), 22-29. https://doi.org/10.1016/j.iatssr.2016.08.001

He, S. Y., \& Thøgersen, J. (2017). The impact of attitudes and perceptions on travel mode choice and car ownership in a Chinese megacity: The case of Guangzhou. Research in Transportation Economics, 62, 57-67. https://doi.org/10.1016/j.retrec.2017.03.004

Heckman, J. J. (1978). Dummy Endogenous Variables in a Simultaneous Equation System. 
Econometrica, 46(4), 931-959. https://doi.org/10.2307/1909757

Henneberry, J. (1998). Transport investment and house prices. Journal of Property Valuation and Investment, 16(2), 144-158. https://doi.org/10.1108/14635789810212913

Hensher, David A., Rose, John M., Greene, W. H. (2013). Applied Choice Analysis. Cambridge University Press (Vol. 53). Cambridge. https://doi.org/10.1017/CBO9781107415324.004

Hensher, D. A., \& King, J. (2001). Parking demand and responsiveness to supply, pricing and location in the Sydney central business district. Transportation Research Part A: Policy and Practice, 35(3), 177-196. https://doi.org/10.1016/S0965-8564(99)00054-3

Hilvert, O., Toledo, T., \& Bekhor, S. (2012). Framework and model for parking decisions. Transportation Research Record, (2319), 30-38. https://doi.org/10.3141/2319-04

Hoffman, Saul D.; Duncan, G. J. (1988). Multinomial and conditional logit discrete-choice models in demography. Demographics, 25(3), 415-427.

https://doi.org/https://doi.org/10.2307/2061541

Hu, L., \& Schneider, R. J. (2017). Different ways to get to the same workplace: How does workplace location relate to commuting by different income groups? Transport Policy, 59, 106-115. https://doi.org/10.1016/j.tranpol.2017.07.009

Hunt, J. D. (1988). Parking location choice: insights and representations based on observed behaviour and the hierarchical logit modelling formulation. 58th Annual Meeting of the Institute of Transportation Engineers (ITE), Vancouver, Canada.

Hunt, J. D., \& Teply, S. (1993). A nested logit model of parking location choice. Transportation Research Part B, 27(4), 253-265. https://doi.org/10.1016/01912615(93)90035-9

Ibeas, A., Dell'Olio, L., Bordagaray, M., \& Ortúzar, J. de D. (2014). Modelling parking choices considering user heterogeneity. Transportation Research Part A: Policy and Practice, 70, 41-49. https://doi.org/10.1016/j.tra.2014.10.001

Jarass, J., \& Scheiner, J. (2018). Residential self-selection and travel mode use in a new inner-city development neighbourhood in Berlin. Journal of Transport Geography, 70, 68-77. https://doi.org/10.1016/j.jtrangeo.2018.05.018 
Jia, W., \& Wachs, M. (1999). Parking requirements and housing affordability: case study of San Francisco. Transportation Research Record, (1685), 156-160.

https://doi.org/10.3141/1685-20

Jiang, Y., Gu, P., Chen, Y., He, D., \& Mao, Q. (2017a). Influence of land use and street characteristics on car ownership and use: Evidence from Jinan, China. Transportation Research Part D: Transport and Environment, 52, 518-534. https://doi.org/10.1016/j.trd.2016.08.030

Jiang, Y., Gu, P., Chen, Y., He, D., \& Mao, Q. (2017b). Influence of land use and street characteristics on car ownership and use: Evidence from Jinan, China. Transportation Research Part D: Transport and Environment, 52, 518-534. https://doi.org/10.1016/j.trd.2016.08.030

Jourquin, B., \& Beuthe, M. (2019). Cost, transit time and speed elasticity calculations for the European continental freight transport. Transport Policy, 83, 1-12. https://doi.org/10.1016/j.tranpol.2019.08.009

Kelly, J. A., \& Clinch, J. P. (2009). Temporal variance of revealed preference on-street parking price elasticity. Transport Policy, 16(4), 193-199. https://doi.org/10.1016/j.tranpol.2009.06.001

Khodaii, A., Aflaki, E., \& Moradkhani, A. (2010). Modeling the effect of parking fare on personal car use. Scientia Iranica, 17(3 A), 209-216.

Kim, S., \& Ulfarsson, G. F. (2008). Curbing automobile use for sustainable transportation: analysis of mode choice on short home-based trips. Transportation, 35(6), 723-737.

Ko, J., Lee, S., \& Byun, M. (2019). Exploring factors associated with commute mode choice: An application of city-level general social survey data. Transport Policy, 75, 36-46. https://doi.org/10.1016/j.tranpol.2018.12.007

Kobus, M. B. W., Gutiérrez-i-Puigarnau, E., Rietveld, P., \& Van Ommeren, J. N. (2013). The on-street parking premium and car drivers' choice between street and garage parking. Regional Science and Urban Economics, 43(2), 395-403. https://doi.org/10.1016/j.regsciurbeco.2012.10.001

Kroesen, M. (2019). Residential self-selection and the reverse causation hypothesis: Assessing the endogeneity of stated reasons for residential choice. Travel Behaviour and 
Society, 16, 108-117. https://doi.org/10.1016/j.tbs.2019.05.002

Land Information New Zealand. (2016). NZ Street Address. Retrieved from

https://data.linz.govt.nz/layer/53353-nz-street-address/

Land Information New Zealand. (2017). Wellington LiDAR 1m DEM (2013-2014).

Retrieved from https://data.linz.govt.nz/layer/53621-wellington-lidar-1m-dem-20132014/

Land Information New Zealand. (2020a). NZ Building Outlines. Retrieved from https://data.linz.govt.nz/layer/101290-nz-building-outlines/

Land Information New Zealand. (2020b). NZ Parcels. Retrieved from https://data.linz.govt.nz/layer/51571-nz-parcels/

Land Transport Safety Authority. (2000). Travel survey report 1997/1998. Wellington, New Zealand: Land Transport Safety Authority. Retrieved from https://www.transport.govt.nz//assets/Uploads/Report/1998-travel-survey-results.pdf

Lee, C. (2020). Impacts of two-scale urban form and their combined effects on commute modes in U.S. metropolitan areas. Journal of Transport Geography, 88, 1-13. https://doi.org/10.1016/j.jtrangeo.2020.102821

Lee, S. (2017). Correlation and Spatial Autocorrelation. In X. Shekhar, Shashi; Xiong, Hui; Zhou (Ed.), Encyclopedia of GIS. Boston, MA: Springer International Publishing. https://doi.org/https://doi.org/10.1007/978-3-319-17885-1_1524

Lehner, S., \& Peer, S. (2019). The price elasticity of parking: A meta-analysis. Transportation Research Part A: Policy and Practice, 121(October 2018), 177-191. https://doi.org/10.1016/j.tra.2019.01.014

Lei, C., \& Ouyang, Y. (2017). Dynamic pricing and reservation for intelligent urban parking management. Transportation Research Part C: Emerging Technologies, 77, 226-244. https://doi.org/10.1016/j.trc.2017.01.016

Li, F., \& Guo, Z. (2014). Do parking standards matter? Evaluating the London parking reform with a matched-pair approach. Transportation Research Part A: Policy and Practice, 67, 352-365. https://doi.org/10.1016/j.tra.2014.08.001

Lin, H., \& Wang, I. Y. (2015). Competition and Price Discrimination: Evidence from the 
Parking Garage Industry. Journal of Industrial Economics, 63(3), 522-548. https://doi.org/10.1111/joie.12080

Lin, T., Wang, D., \& Guan, X. (2017). The built environment, travel attitude, and travel behavior: Residential self-selection or residential determination? Journal of Transport Geography, 65, 111-122. https://doi.org/10.1016/j.jtrangeo.2017.10.004

Liu, Q., Wang, J., Chen, P., \& Xiao, Z. (2017). How does parking interplay with the built environment and affect automobile commuting in high-density cities? A case study in China. Urban Studies, 54(14), 3299-3317. https://doi.org/10.1177/0042098016667040

Louviere, J. J., Hensher, D. A., Swait, J. D., \& Adamowicz, W. (2000). Stated Choice Methods: Anlaysis and Applications. Cambrdge University Press. Cambrdge. https://doi.org/10.1017/cbo9780511753831.006

Louviere, J., Train, K., Ben-Akiva, M., Bhat, C., Brownstone, D., Cameron, T. A., ... Waldman, D. (2005). Recent progress on endogeneity in choice modeling. Marketing Letters, 16(3-4), 255-265. https://doi.org/10.1007/s11002-005-5890-4

Lu, J., Li, B., Li, H., \& Al-Barakani, A. (2021). Expansion of city scale, traffic modes, traffic congestion, and air pollution. Cities, 108. https://doi.org/10.1016/j.cities.2020.102974

Ma, R., \& Zhang, H. M. (2017). The morning commute problem with ridesharing and dynamic parking charges. Transportation Research Part B: Methodological, 106, 345 374. https://doi.org/10.1016/j.trb.2017.07.002

Ma, X., Longley, I., Gao, J., \& Salmond, J. (2020). Assessing schoolchildren's exposure to air pollution during the daily commute - A systematic review. Science of the Total Environment, 737, 1-13. https://doi.org/10.1016/j.scitotenv.2020.140389

Manville, M. (2013). Parking requirements and housing development. Journal of the American Planning Association, 79(1), 49-66. https://doi.org/10.1080/01944363.2013.785346

Manville, M. (2017). Travel and the Built Environment: Time for Change. Journal of the American Planning Association, 83(1), 29-32. https://doi.org/10.1080/01944363.2016.1249508

Manville, M., \& Shoup, D. (2005). Parking, People, and Cities. Journal of Urban Planning and Development, 131(4), 233-245. https://doi.org/10.1061/(ASCE)0733- 
9488(2005)131:4(233)

Martens, K., Benenson, I., \& Levy, N. (2010). The dilemma of on-street parking policy: exploring cruising for parking using an agent-based model. In B. Jiang \& X. Yao (Eds.), Geospatial Analysis and Modelling of Urban Structure and Dynamics (2nd ed., pp. 121138). Dordrecht, the Netherlands: Springer.

Matas, A., \& Raymond, J. Ll. (2008). Changes in the structure of car ownership in Spain. Transportation Research Part A: Policy and Practice, 42(1), 187-202. https://doi.org/10.1016/j.tra.2007.08.005

Melo, P. C., \& de Abreu e Silva, J. (2017). Home telework and household commuting patterns in Great Britain. Transportation Research Part A: Policy and Practice, 103, 124. https://doi.org/10.1016/j.tra.2017.05.011

Meng, F., Du, Y., Chong Li, Y., \& Wong, S. C. (2018). Modeling heterogeneous parking choice behavior on university campuses. Transportation Planning and Technology, 41(2), 154-169. https://doi.org/10.1080/03081060.2018.1407518

Milne, A., Rendall, S., \& Abley, S. (2011). National travel profiles part B : trips , trends and travel prediction December 2011.

Moreno-monroy, A. I., \& Posada, H. M. (2017). The effect of commuting costs and transport subsidies on informality rates. Journal of Development Economics, 130(October), 99112. https://doi.org/10.1016/J.JDEVECO.2017.09.004

Mulalic, I., Pilegaard, N., \& Rouwendal, J. (2016). Does Improving Public Transport Decrease Car Ownership? Evidence from the Copenhagen Metropolitan Area. SSRN Electronic Journal. https://doi.org/10.2139/ssrn.2710547

Mulalic, I., \& Rouwendal, J. (2020). Does improving public transport decrease car ownership? Evidence from a residential sorting model for the Copenhagen metropolitan area. Regional Science and Urban Economics, 83, 1-19. https://doi.org/10.1016/j.regsciurbeco.2020.103543

My Thanh, T. T., \& Friedrich, H. (2017). Legalizing the illegal parking, a solution for parking scarcity in developing countries. Transportation Research Procedia, 25, 49504965. https://doi.org/10.1016/j.trpro.2017.05.374

Næss, P. (2005). Residential location affects travel behavior - but How and Why 
(Copenhagen). Progress in Planning, 63, 167-257.

Næss, P. (2011). 'New urbanism' or metropolitan-level centralization? Journal of Transport and Land Use, 4(1), 25-44. https://doi.org/10.5198/jtlu.v4i1.170

Næss, P. (2012). Urban form and travel behavior: Experience from a Nordic context. Journal of Transport and Land Use, 5(2), 21-45. https://doi.org/10.5198/jtlu.v5i2.314

New Zealand government. (2020). National Policy Statement on Urban Development 2020.

Retrieved from https://www.hud.govt.nz/urban-development/national-policy-statementon-urban-development-nps-ud/

New Zealand Health Survey. (2016). Sample Design from 2015/16. Retrieved from https://www.moh.govt.nz/notebook/nbbooks.nsf/0/C472299B46A3ECA6CC258090007 9B5D0/\$file/sample-design-2015-16-nzhs-dec16.pdf

New Zealand Ministry of Transport. (2020). New Zealand Household Travel Survey.

Retrieved from https://www.transport.govt.nz/area-of-interest/public-transport/newzealand-household-travel-survey/

New Zealand Ministry Of Transport. (2018). New Zealand Household Travel Survey methodology report 2015-2017. Wellington. Retrieved from https://www.transport.govt.nz/assets/Uploads/Research/NZHTS-Methodology-Reportv1-12June2018.pdf

Niedzielski, M. A., Hu, Y., \& Stępniak, M. (2020). Temporal dynamics of the impact of land use on modal disparity in commuting efficiency. Computers, Environment and Urban Systems, 83, 1-11. https://doi.org/10.1016/j.compenvurbsys.2020.101523

Nolan, A. (2010). A dynamic analysis of household car ownership. Transportation Research Part A: Policy and Practice, 44(6), 446-455. https://doi.org/10.1016/j.tra.2010.03.018

Nourinejad, M., \& Roorda, M. J. (2017). Impact of hourly parking pricing on travel demand. Transportation Research Part A: Policy and Practice, 98, 28-45. https://doi.org/10.1016/j.tra.2017.01.023

Nunes de Oliveira, B., Minatto, G., Galdino da Costa, B. G., Veber Lopes, M. V., \& Samara da Silva, K. (2020). Association between psychosocial factors and active commuting to school in Brazilian adolescents. Journal of Transport and Health, 19, 1-8. https://doi.org/10.1016/j.jth.2020.100964 
O'Fallon, C., Sullivan, C., \& Hensher, D. A. (2004). Constraints affecting mode choices by morning car commuters. Transport Policy, 11(1), 17-29. https://doi.org/10.1016/S0967070X(03)00015-5

Ostermeijer, F., Koster, H. R., \& van Ommeren, J. (2019). Residential parking costs and car ownership: Implications for parking policy and automated vehicles. Regional Science and Urban Economics, 77(January), 276-288. https://doi.org/10.1016/j.regsciurbeco.2019.05.005

Ottomanelli, M., Dell'Orco, M., \& Sassanelli, D. (2011). Modelling parking choice behaviour using possibility theory. Transportation Planning and Technology, 34(7), 647-667. https://doi.org/10.1080/03081060.2011.602846

Ou, S., Lin, Z., He, X., \& Przesmitzki, S. (2018). Estimation of vehicle home parking availability in China and quantification of its potential impacts on plug-in electric vehicle ownership cost. Transport Policy, 68, 107-117. https://doi.org/10.1016/j.tranpol.2018.04.014

Pandhe, A., \& March, A. (2012a). Parking availability influences on travel mode: Melbourne CBD offices. Australian Planner, 49(2), 161-171. https://doi.org/10.1080/07293682.2011.616177

Pandhe, A., \& March, A. (2012b). Parking availability influences on travel mode: Melbourne CBD offices. Australian Planner, 49(2), 161-171. https://doi.org/10.1080/07293682.2011.616177

Parady, G. T. (2015). Introduction to Discrete Choice Models. In The 14 th Behavior Modeling Summer School. The University of Tokyo.

Petrin, A., \& Train, K. (2010). A control function approach to endogeneity in consumer choice models. Journal of Marketing Research, 47(1), 3-13. https://doi.org/10.1509/jmkr.47.1.3

Pierce, G., \& Shoup, D. (2013). Getting the prices right. Journal of the American Planning Association, 79(1), 67-81. https://doi.org/10.1080/01944363.2013.787307

Pierce, G., Willson, H., \& Shoup, D. (2015). Optimizing the use of public garages: Pricing parking by demand. Transport Policy, 44, 89-95. https://doi.org/10.1016/j.tranpol.2015.07.003 
Potoglou, D., \& Kanaroglou, P. S. (2008). Modelling car ownership in urban areas: a case study of Hamilton, Canada. Journal of Transport Geography, 16(1), 42-54. https://doi.org/10.1016/j.jtrangeo.2007.01.006

Qin, H., Yang, X., Wu, Y. J., Guan, H., Wang, P., \& Shahinpoor, N. (2020). Analysis of parking cruising behaviour and parking location choice. Transportation Planning and Technology, 43(7), 717-734. https://doi.org/10.1080/03081060.2020.1805545

Ritter, N., \& Vance, C. (2013a). Do fewer people mean fewer cars? Population decline and car ownership in Germany. Transportation Research Part A: Policy and Practice, 50, 74-85. https://doi.org/10.1016/j.tra.2013.01.035

Ritter, N., \& Vance, C. (2013b). Do fewer people mean fewer cars? Population decline and car ownership in Germany. Transportation Research Part A: Policy and Practice, 50, 74-85. https://doi.org/10.1016/j.tra.2013.01.035

Rüger, H., Pfaff, S., Weishaar, H., \& Wiernik, B. M. (2017). Does perceived stress mediate the relationship between commuting and health-related quality of life? Transportation Research Part F: Traffic Psychology and Behaviour, 50, 100-108. https://doi.org/10.1016/j.trf.2017.07.005

Ruisong, Y., Meiping, Y., \& Xiaoguang, Y. (2009). Study on driver's parking location choice behavior considering drivers' information acquisition. 2009 2nd International Conference on Intelligent Computing Technology and Automation, ICICTA 2009, 3, 764-770. https://doi.org/10.1109/ICICTA.2009.650

Ryan, J. M., \& Han, G. (1999). Vehicle-ownership model using family structure and accessibility application to Honolulu, Hawaii. Transportation Research Record, (1676), 1-10. https://doi.org/10.3141/1676-01

Ryoo, S. K., \& Lee, C. W. (2004). Genetic algorithm and simultaneous parameter estimation of the nested logit model. KSCE Journal of Civil Engineering, 8(1), 129-133. https://doi.org/10.1007/bf02829088

Salon, D. (2009). Neighborhoods, cars, and commuting in New York City: A discrete choice approach. Transportation Research Part A: Policy and Practice. https://doi.org/10.1016/j.tra.2008.10.002

Sattler, M. C., Färber, T., Traußnig, K., Köberl, G., Paier, C., Dietz, P., \& van Poppel, M. N. 
M. (2020). Cross-sectional association between active commuting and perceived commuting stress in Austrian adults: Results from the HOTway study. Mental Health and Physical Activity, 19. https://doi.org/10.1016/j.mhpa.2020.100356

Scorrano, M., Danielis, R., \& Giansoldati, M. (2020). Dissecting the total cost of ownership of fully electric cars in Italy: The impact of annual distance travelled, home charging and urban driving. Research in Transportation Economics, 80(January). https://doi.org/10.1016/j.retrec.2019.100799

Seya, H., Nakamichi, K., \& Yamagata, Y. (2016). The residential parking rent price elasticity of car ownership in Japan. Transportation Research Part A: Policy and Practice, 85, 123-134. https://doi.org/10.1016/j.tra.2016.01.005

Shaheen, S., Guzman, S., \& Zhang, H. (2010). Bikesharing in Europe, the Americas, and Asia. Transportation Research Record, (2143), 159-167. https://doi.org/10.3141/214320

Shanno, D. F. (1970). Conditioning of Quasi-Newton Methods for Function Minimization. Mathematics of Computation, 24(11), 647-656. https://doi.org/https://doi.org/10.2307/2004840

Shen, T., Hong, Y., Thompson, M. M., Liu, J., Huo, X., \& Wu, L. (2020). How does parking availability interplay with the land use and affect traffic congestion in urban areas? The case study of Xi'an, China. Sustainable Cities and Society, 57. https://doi.org/10.1016/j.scs.2020.102126

Shoup, D. C. (1999). The trouble with minimum parking requirements. Transportation Research Part A: Policy and Practice, 33(7-8), 549-574. https://doi.org/10.1016/S0965-8564(99)00007-5

Shoup, D. C. (2005). The high cost of free parking. Chicago: American Planning Association.

Shoup, D. C. (2006). Cruising for parking. Transport Policy, 13(6), 479-486. https://doi.org/10.1016/j.tranpol.2006.05.005

Simićević, J., Vukanović, S., \& Milosavljević, N. (2013). The effect of parking charges and time limit to car usage and parking behaviour. Transport Policy, 30, 125-131. https://doi.org/10.1016/j.tranpol.2013.09.007

Small, K. A. (2012). Valuation of travel time. Economics of Transportation, 1(1-2), 2-14. 
https://doi.org/10.1016/j.ecotra.2012.09.002

So, H. M., Tse, R. Y. C., \& Ganesan, S. (1997). Estimating the influence of transport on house prices: evidence from Hong Kong. Journal of Property Valuation and Investment, 15(1), 40-47. https://doi.org/10.1108/14635789710163793

Soltani, A. (2017). Social and urban form determinants of vehicle ownership; evidence from a developing country. Transportation Research Part A: Policy and Practice, 96, 90100. https://doi.org/10.1016/j.tra.2016.12.010

Soto, J. J., Márquez, L., \& Macea, L. F. (2018). Accounting for attitudes on parking choice: An integrated choice and latent variable approach. Transportation Research Part A: Policy and Practice, 111, 65-77. https://doi.org/10.1016/j.tra.2018.03.003

Statistics Canada. (2016). Commuters using sustainable transportation in census metropolitan areas. Retrieved July 16, 2021, from https://www12.statcan.gc.ca/censusrecensement/2016/as-sa/98-200-x/2016029/98-200-x2016029-eng.cfm

Statistics New Zealand. (2013a). 2013 Census meshblock dataset. Retrieved from http://archive.stats.govt.nz/Census/2013-census/data-tables/meshblock-dataset.aspx

Statistics New Zealand. (2013b). Geographic definitions. Retrieved from http://infoshare.stats.govt.nz/Census/2013-census/info-about-2013-census-data/2013census-definitions-forms/definitions/geographic.aspx\#gsc.tab=0

Statistics New Zealand. (2016). Statistical standard for meshblock. Wellington. Retrieved from https://www.stats.govt.nz/assets/Uploads/Retirement-of-archive-website-projectfiles/Methods/Statistical-standard-for-meshblock/stats-stnd-meshblock.pdf

Statistics New Zealand. (2017). Statistical Standard for Meshblock - Definition. Retrieved from http://archive.stats.govt.nz/methods/classifications-and-standards/classificationrelated-stats-standards/meshblock/definition.aspx

Statistics New Zealand. (2020). 2018 Census population and dwelling counts. Retrieved from https://www.stats.govt.nz/information-releases/2018-census-population-and-dwellingcounts

Su, Q., \& Zhou, L. (2012). Parking management, financial subsidies to alternatives to drive alone and commute mode choices in Seattle. Regional Science and Urban Economics, 42(1-2), 88-97. https://doi.org/10.1016/j.regsciurbeco.2011.07.002 
Sun, C., Zhang, W., Fang, X., Gao, X., \& Xu, M. (2019). Urban public transport and air quality: Empirical study of China cities. Energy Policy, 135, 1-9. https://doi.org/10.1016/j.enpol.2019.110998

Taylor, E. J. (2018). Who's been parking on my street? The politics and uneven use of residential parking space. Land Use Policy, (November), 103706. https://doi.org/10.1016/j.landusepol.2018.11.011

Taylor, E. J. (2020). Parking policy: The politics and uneven use of residential parking space in Melbourne. Land Use Policy, 91, 1-11. https://doi.org/10.1016/j.landusepol.2018.11.011

Terza, J. V., Basu, A., \& Rathouz, P. J. (2008). Two-stage residual inclusion estimation: Addressing endogeneity in health econometric modeling. Journal of Health Economics, 27(3), 531-543. https://doi.org/10.1016/j.jhealeco.2007.09.009

Thompson, R. G., \& Richardson, A. J. (1998). A parking search model. Transportation Research Part A: Policy and Practice, 32(3), 159-170. https://doi.org/10.1016/S09658564(97)00005-0

Train, K. E. (2009). Discrete Choice Methods with Simulation. Cambridge University Press. https://doi.org/10.1108/EUM0000000006709

University of Otago - National School of Surveying. (2017). 16 Wellington 15m DEM. Retrieved from https://koordinates.com/layer/3743-16-wellington-15m-dem-nzsosdemv10/

van de Coevering, P., Maat, K., \& van Wee, B. (2018). Residential self-selection, reverse causality and residential dissonance. A latent class transition model of interactions between the built environment, travel attitudes and travel behavior. Transportation Research Part A: Policy and Practice, 118(October), 466-479. https://doi.org/10.1016/j.tra.2018.08.035

Van Der Waerden, P., De Bruin, M., \& Da Silva, A. N. R. (2017). Car drivers' knowledge and preferences regarding additional services at parking facilities. Transportation Research Procedia, 25, 4053-4061. https://doi.org/10.1016/j.trpro.2017.05.321

Van Ommeren, J., de Groote, J., \& Mingardo, G. (2014). Residential parking permits and parking supply. Regional Science and Urban Economics, 45(1), 33-44. 
https://doi.org/10.1016/j.regsciurbeco.2013.11.003

van Ommeren, J., McIvor, M., Mulalic, I., \& Inci, E. (2021). A novel methodology to estimate cruising for parking and related external costs. Transportation Research Part B: Methodological, 145, 247-269. https://doi.org/10.1016/j.trb.2020.12.005

van Wee, B. (2009). Self-selection: A key to a better understanding of location choices, travel behaviour and transport externalities? Transport Reviews, 29(3), 279-292. https://doi.org/10.1080/01441640902752961

Verhoef, E., Nijkamp, P., \& Rietveld, P. (1995). The economics of regulatory parking policies: The (IM)possibilities of parking policies in traffic regulation. Transportation Research Part A, 29(2), 141-156. https://doi.org/10.1016/0965-8564(94)E0014-Z

Vij, A., Gorripaty, S., \& Walker, J. L. (2017). From trend spotting to trend's plaining: Understanding modal preference shifts in the San Francisco Bay Area. Transportation Research Part A: Policy and Practice, 95, 238-258. https://doi.org/10.1016/j.tra.2016.11.014

Vijayaraman, P., \& Jesu Jayarin, P. (2021). Design of embedded data analyzer based mitigation model for traffic congestion and its challenges. Microprocessors and Microsystems, 81. https://doi.org/10.1016/j.micpro.2020.103633

Wang, B., Shao, C., Li, J., Zhao, D., \& Meng, M. (2015). Investigating the interaction between the parking choice and holiday travel behavior. Advances in Mechanical Engineering, 7(6), 1-11. https://doi.org/10.1177/1687814015589499

Wang, J., Zhang, X., \& Zhang, H. M. (2018). Parking permits management and optimal parking supply considering traffic emission cost. Transportation Research Part D: Transport and Environment, 60, 92-103. https://doi.org/10.1016/j.trd.2016.02.005

Wangsness, P. B., Proost, S., \& Rødseth, K. L. (2020). Vehicle choices and urban transport externalities. Are Norwegian policy makers getting it right? Transportation Research Part D: Transport and Environment, 86. https://doi.org/10.1016/j.trd.2020.102384

Waraich, R., \& Axhausen, K. (2012). Agent-based parking choice model. Transportation Research Record, 2319, 39-46. https://doi.org/10.3141/2319-05

Weinberger, R., Seaman, M., \& Johnson, C. (2008). Suburbanizing the city: how New York City parking requirements lead to more driving. Transportation Alternatives. 
Weinberger, Rachel. (2012). Death by a thousand curb-cuts: Evidence on the effect of minimum parking requirements on the choice to drive. Transport Policy, 20, 93-102. https://doi.org/10.1016/j.tranpol.2011.08.002

Weinberger, Rachel, Seaman, M., \& Johnson, C. (2009). Residential off-street parking impacts on car ownership, vehicle miles traveled, and related carbon emissions: New York city case study. Transportation Research Record, (2118), 24-30. https://doi.org/10.3141/2118-04

Wellington City Council. (2019a). Coupon parking zones and fees. Retrieved from https://wellington.govt.nz/services/parking-and-roads/parking/coupon-parking/couponparking-zones-and-fees

Wellington City Council. (2019b). Pay by Space parking locations and fees. Retrieved from https://wellington.govt.nz/services/parking-and-roads/parking/central-city-streetparking/parking-hours-fees

Wellington City Council. (2020a). Applying for a coupon parking exemption permit.

Retrieved from https://wellington.govt.nz/parking-roads-and-transport/parking/residentparking/apply-for-a-coupon-parking-exemption-permit

Wellington City Council. (2020b). Applying for a resident parking permit. Retrieved from https://wellington.govt.nz/parking-roads-and-transport/parking/resident-parking/applyfor-a-resident-parking-permit

Wellington Regional Council. (2013). Wellington region map. Retrieved from https://www.gw.govt.nz/Wellington-region-map/

Whelan, G. (2007). Modelling car ownership in Great Britain. Transportation Research Part A: Policy and Practice, 41(3), 205-219. https://doi.org/10.1016/j.tra.2006.09.013

Wong, K. I. (2013). An Analysis of Car and Motorcycle Ownership in Macao. International Journal of Sustainable Transportation, 7(3), 204-225. https://doi.org/10.1080/15568318.2013.710057

Wooldridge, J. M. (2013). Introductory econometrics : a modern approach (fifth). Mason, Ohio : South-Western Cengage Learning.

Wu, G., Yamamoto, T., Kitamura, R. (1999). Vehicle ownership model that incorporates the causal structure underlying attitudes toward vehicle ownership. Transportation Research 
Record, 1676(1), 61-67. https://doi.org/https://doi.org/10.3141/1676-08

Xiao, C., Yang, Y., \& Chi, G. (2020). Does the mental health of migrant workers suffer from long commute time? Evidence from China. Journal of Transport and Health, 19, 1-13. https://doi.org/10.1016/j.jth.2020.100932

Yagi, M., \& Managi, S. (2016). Demographic determinants of car ownership in Japan. Transport Policy, 50, 37-53. https://doi.org/10.1016/j.tranpol.2016.05.011

Yan, X., Levine, J., \& Marans, R. (2019). The effectiveness of parking policies to reduce parking demand pressure and car use. Transport Policy, 73, 41-50. https://doi.org/10.1016/j.tranpol.2018.10.009

Yang, Z., Jia, P., Liu, W., \& Yin, H. (2017). Car ownership and urban development in Chinese cities: A panel data analysis. Journal of Transport Geography, 58, 127-134. https://doi.org/10.1016/j.jtrangeo.2016.11.015

Yiu, C. Y., \& Wong, S. K. (2005). The effects of expected transport improvements on housing prices. Urban Studies, 42(1), 113-125. https://doi.org/10.1080/0042098042000309720

Zakharenko, R. (2016). The time dimension of parking economics. Transportation Research Part B: Methodological, 91, 211-228. https://doi.org/10.1016/j.trb.2016.04.008

Zang, P., Lu, Y., Ma, J., Xie, B., Wang, R., \& Liu, Y. (2019). Disentangling residential selfselection from impacts of built environment characteristics on travel behaviors for older adults. Social Science and Medicine, 238. https://doi.org/10.1016/j.socscimed.2019.112515

Zheng, Y., Moody, J., Wang, S., \& Zhao, J. (2021). Measuring policy leakage of Beijing's car ownership restriction. Transportation Research Part A: Policy and Practice, 148, 223-236. https://doi.org/10.1016/j.tra.2021.03.008

Zhou, H., He, S., Cai, Y., Wang, M., \& Su, S. (2019). Social inequalities in neighborhood visual walkability: Using street view imagery and deep learning technologies to facilitate healthy city planning. Sustainable Cities and Society, 50, 1-15. https://doi.org/10.1016/j.scs.2019.101605

Zhu, P., Ho, S. N., Jiang, Y., \& Tan, X. (2020). Built environment, commuting behaviour and job accessibility in a rail-based dense urban context. Transportation Research Part D: 
Transport and Environment, 87, 1-18. https://doi.org/10.1016/j.trd.2020.102438 